\title{
HUMAN PHARMACEUTICALS IN ONTARIO'S ENVIRONMENT: A REVIEW OF MANAGEMENT OPPORTUNITIES
}

\author{
by \\ Emily (Hanna) Cooper \\ Bachelor of Science, Chemical Engineering, Queen's University, 2007 \\ A thesis \\ presented to Ryerson University \\ in partial fulfillment of the \\ requirements for the degree of \\ Master of Applied Science \\ in the Program of \\ Environmental Applied Science and Management
}

Toronto, Ontario, Canada, 2016

(C)Emily (Hanna) Cooper 2016 


\section{Author's Declaration}

I hereby declare that I am the sole author of this thesis. This is a true copy of the thesis, including any required final revisions, as accepted by my examiners.

I authorize Ryerson University to lend this thesis to other institutions or individuals for the purpose of scholarly research.

I further authorize Ryerson University to reproduce this thesis by photocopying or by other means, in total or in part, at the request of other institutions or individuals for the purpose of scholarly research. I understand that my thesis may be made electronically available to the public. 


\title{
HUMAN PHARMACEUTICALS IN ONTARIO'S ENVIRONMENT: A REVIEW OF MANAGEMENT OPPORTUNITIES
}

\author{
Emily (Hanna) Cooper \\ Master of Applied Science, 2016 \\ Environmental Applied Science and Management \\ Ryerson University
}

\begin{abstract}
Pharmaceuticals have been detected in water throughout the developed world. Some, while at low concentrations, can negatively affect freshwater wildlife. This thesis explores the level of risk that pharmaceuticals pose to Ontario's environment, and possible challenges and opportunities for government action to address this issue. In addition to a literature review, this work replicates an earlier similar study by collecting information directly from seven purposefully selected Ontario experts. Results make it clear that pharmaceuticals pose some risk, but a consensus cannot be reached on the level of risk. With limited financial resources, it is difficult to prioritize pharmaceutical removal over other environmental problems without a clear understanding of the harm that pharmaceuticals pose. Nevertheless, there are opportunities for government action. Ontario could follow what British Columbia has done; it developed a Water Quality Guideline for pharmaceuticals that must be considered by government when making decisions that could affect water quality.
\end{abstract}




\section{Acknowledgements}

I would like to thank my supervisor, Dr. Christopher Gore, for his expert assistance and guidance over the course of my studies. I would also like to thank my friends, family, and colleagues, for their support and encouragement. 


\section{Table of Contents}

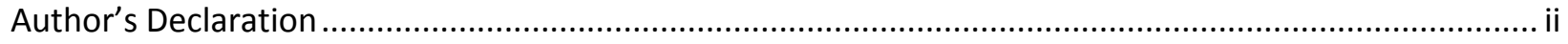

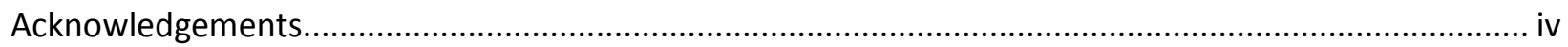

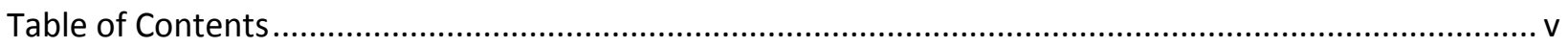

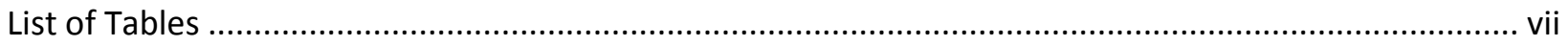

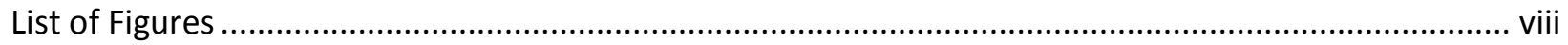

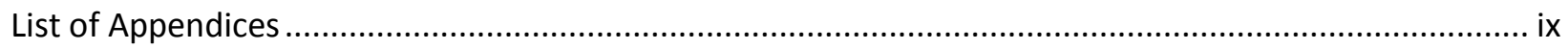

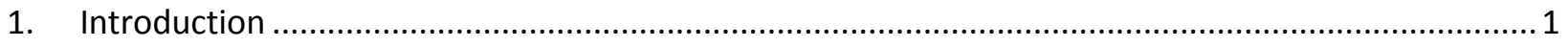

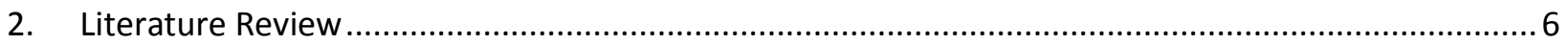

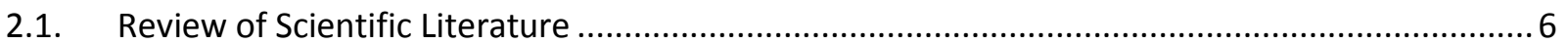

2.1.1. Sources and Behaviour of PhACs in Wastewater Streams and the Environment ............... 8

2.1.2. Water Treatment Plants - Technology Overview...........................................................13

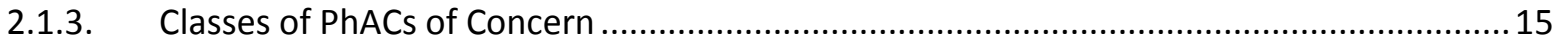

2.1.4. Occurrence of PhACs in Water Systems ................................................................... 18

2.1.5. Municipal Wastewater Effluent …............................................................................. 18

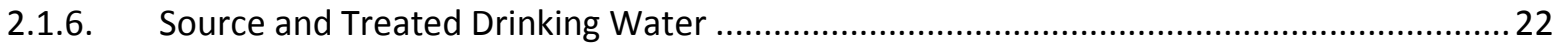

2.1.7. Hospital and Long-Term Care Home Effluent ..............................................................26

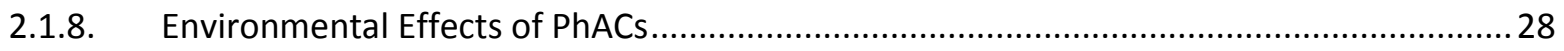

2.1.9. Information Gaps Documented During the Literature Review ........................................30

2.2. A Review of Risk Management Principles Related to PhACs in the Environment .....................32

2.3. Review of Relevant Legislation and Policies in Ontario and Other Selected Jurisdictions .........37

2.3.1. Policies from Other Selected Jurisdictions ....................................................................... 40

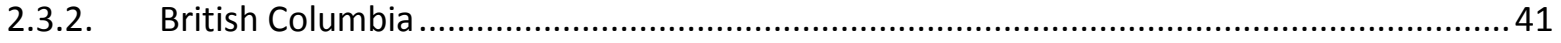

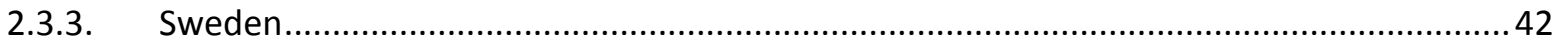

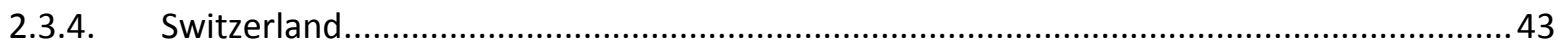

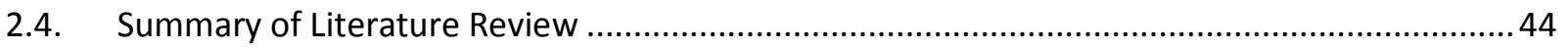

3. Evaluation Framework and Data Collection............................................................................... 46

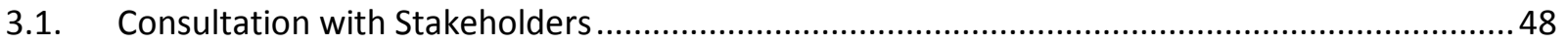

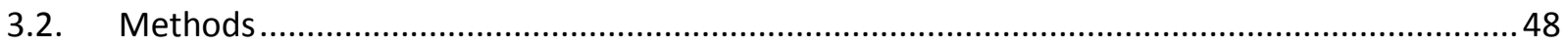

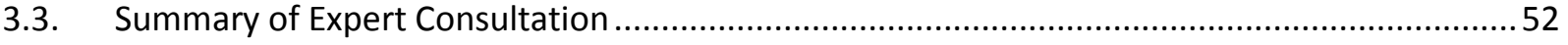

4. Findings Collected During Expert Consultation .......................................................................5 
4.1. Risk PhACs pose to the Aquatic Ecosystem and/or Human Health ......................................54

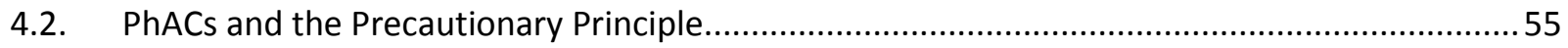

4.3. Familiarity with Wastewater Treatment Plants in Ontario........................................................57

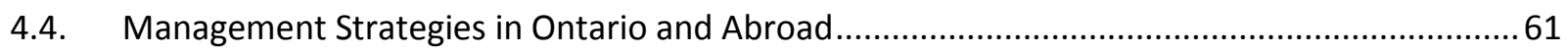

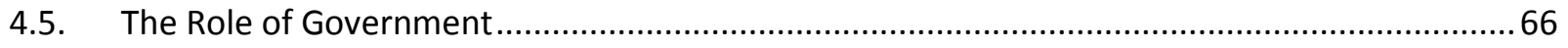

4.6. Removing PhACs from Wastewater Streams - Opportunities and Barriers.............................71

4.7. Comparing These Findings to Doerr-MacEwen and Haight's Results from 2006 .....................74

4.8. Summary of Significant Findings Collected During this Consultation.....................................76

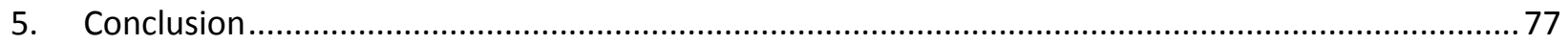

5.1. Summary of Significant Findings Collected During this Study ............................................ 81

5.2. Future Considerations for Researchers and/or Decision-Makers............................................ 83

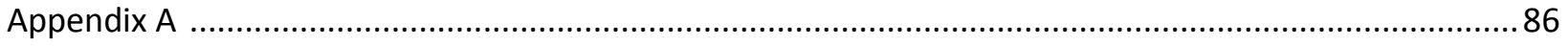

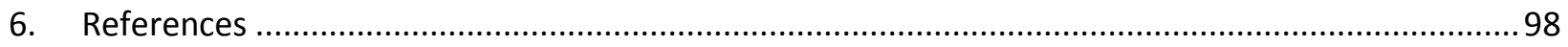




\section{List of Tables}

Table 1: Wastewater Treatment Plant Removal Rates for Select PhACs.............................................. 11

Table 2: Summary of Conceptual-Level Cost Curve Regression Equations ............................................. 15

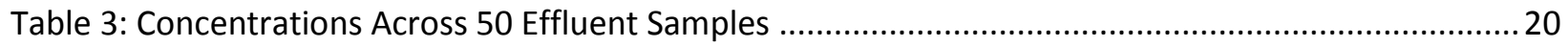

Table 4: An Overview of Detected Compounds in Untreated Source and Finished Drinking Water in

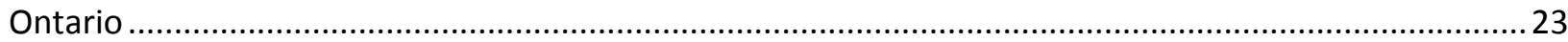

Table 5: Frequency of Detection and Overall Concentration Data for the Most Common Untreated

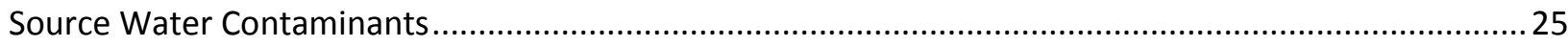

Table 6: Frequency of Detection and Overall Concentration Data for the Most Common Untreated

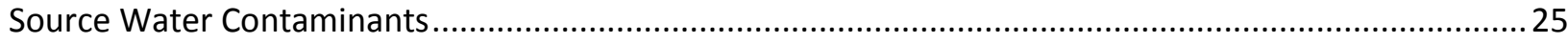

Table 7: Loading of Select PhACs From Two Hospital and Two Long-Term Care Facilities (\% Averaged

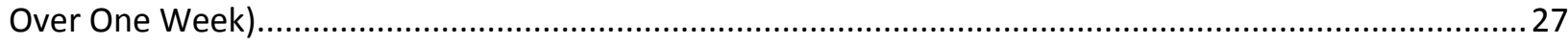

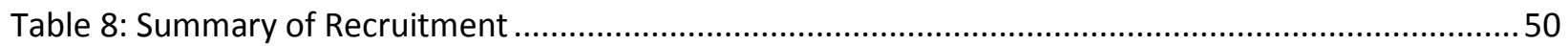

Table 9: View of the Precautionary Principle as it Relates to PhACs in the Environment (Responses to

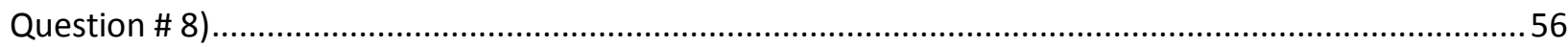

Table 10: Knowledge of Ontario's WWTP and their Ability to Reduce/Eliminate PhACs (Responses to

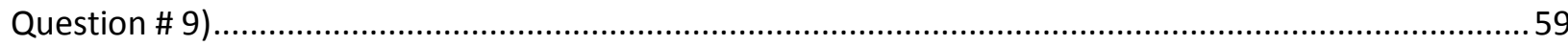

Table 11: Expert \# 13's Response to Question \# 10 - Ontario's Management Strategies for PhACs before

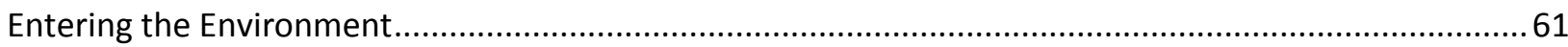

Table 12: Experts' Responses When Asked if Ontario Needs Further Actions / Programs / Legislation in Ontario Related to PhACs and the Environment (Question 10 b) ......................................................65 Table 13: Experts' Responses When Asked if Federal, Provincial, or Municipal Governments Should Take Additional Action to Reduce the Release of PhACs to the Environment (Question 14)..... 68 


\section{List of Figures}

Figure 1: An Illustration of Analytical Methods Applied to Detect PhACs in Water and Wastewater ......... 8

Figure 2: Sources and Fate of PhACs in the Environment................................................................. 10

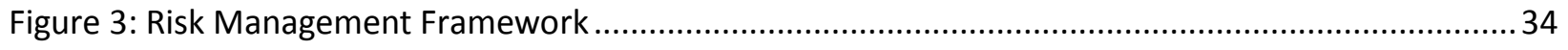

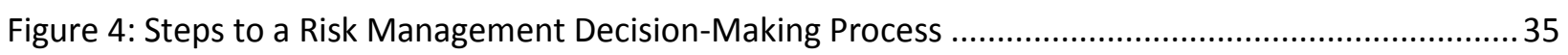




\section{List of Appendices}

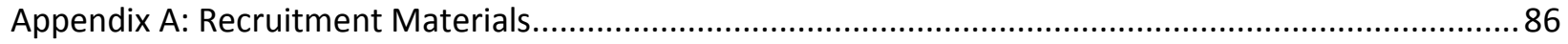

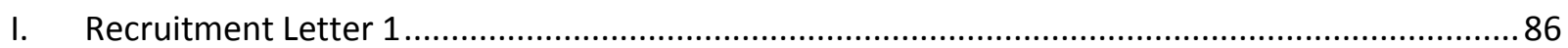

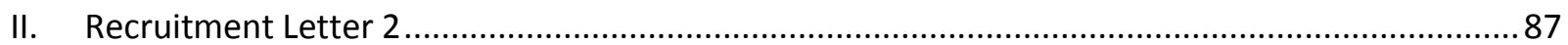

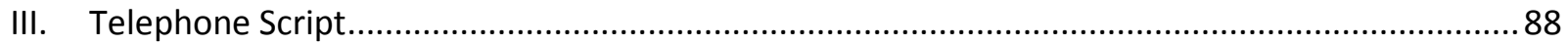

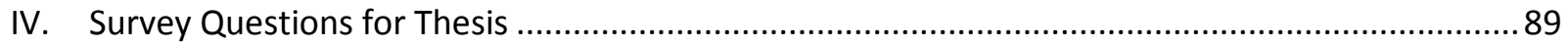

V. Interview Guide for Follow-up Discussions..................................................................... 97 


\section{Introduction}

There have been reports of pharmaceutically active compounds (PhACs) in the natural environment since the 1970s (Jones et al., 2005). Since then, analytical tools have improved and PhACs have been repeatedly detected at low concentrations throughout the water cycle (WHO, 2012). Trace amounts of PhACs have been measured in various ground waters (Eckel et al., 1993; Holm et al., 1995; Fent et al., 2006; Fram and Belitz, 2011; Kostich et al., 2014), surface waters (Terns, 1998; Cahill et al., 2004; Fent et al., 2006; Verlicchi et al., 2014), and drinking waters (Heberer, 2002; Benotti et al., 2009; Postigo and Richardson, 2014). As human populations have increased, there has also been a notable increase in the amount and diversity of PhACs used (Arnold et al., 2013).

Human PhACs can enter the water cycle through a variety of different pathways, although municipal wastewater is believed to be one of the primary sources of human pharmaceuticals (or their metabolites) entering the environment (Ternes et al., 2004). This is because human bodies only process a certain amount of each prescription drug and they may excrete as much as 50 percent of these compounds in an unchanged state (Ternes, 1998). Sanitary sewers in Canada collect discharge from the toilets and drains of households, commercial establishments, institutions (including hospitals), and factories; many of these streams are connected with municipal wastewater collection and treatment systems (Environment Canada, 2001). Even though wastewater carrying human excrement generally undergoes various treatment processes through municipal systems, their removal rates can range significantly because conventional wastewater treatment plants are not designed to eliminate these compounds (Gauthier et al., 2010). Conventional systems are instead designed to accelerate the time required for water to purify itself, and many of these systems use natural biological processes to remove conventional organic material (U.S. EPA, 2004). There are also thousands of different active chemical ingredients approved for use in pharmaceuticals, and removal efficiencies vary based on the plant design, operation, and the compounds present (Zwiener, 2007). 
PhACs are intended to influence biological processes at low concentrations. Aquatic organisms are therefore important receptors for these contaminants because they are continually exposed throughout their lifetime (Fent et al., 2006). For example,

a 7-year, whole-lake experiment at the Experimental Lakes Area (ELA) in north-western Ontario... showed that chronic exposure of fathead minnow (Pimephales promelas) to low concentrations $\left(5-6 \mathrm{ng} \bullet \mathrm{L}^{-1}\right)$ of the potent $17 \alpha$-ethynylestradiol led to feminization of males ... and, ultimately, a near extinction of this species from the lake....observations demonstrate that the concentrations of estrogens and their mimics observed in freshwaters can impact the sustainability of wild fish populations. (Kidd et al., 2007, p. 8897)

Municipal wastewater effluent has been shown to have an effect on field-deployed freshwater mussels (Gillis et al., 2014). In the UK, the feminization of male fish in rivers was associated with steroid estrogens from domestic sewage (Gross-Sorokin et al., 2005). Literature further indicates that even relatively short-lived PhACs in the environment may act like persistent pollutants because they are continuously released into the environment (Daughton and Ternes, 1999). It is, however, difficult to generalize how these contaminants behave in the environment because published articles typically focus on only a handful of PhACs at a time, and inconsistent analytical methods and reporting formats are used across different studies, which limits the ability to combine studies and extrapolate results (Kostich et al., 2014).

Since PhACs can pose harm to some aquatic organisms, and they can act like persistent pollutants unless they are otherwise managed, the concept of the precautionary principle is important to consider and/or use in the analysis of PhACs. The precautionary principle states: "where there are threats of serious or irreversible damage, lack of full scientific certainty shall not be used as a reason for postponing cost-effective measures to prevent environmental degradation" (United Nations General Assembly, 1992). This principle is reaffirmed in the Canadian Environmental Protection Act, 1999. The connection of PhAC management to the precautionary principle was also made in 2006 by two Ontario researchers, Doerr-MacEwen and Haight, who published a report to "evaluate the scope of the issue 
[pharmaceuticals in the environment] and possible management strategies from the perspectives of expert stakeholders, drawn from government, academia, and the pharmaceutical and consulting industries" (p. 853). Their interviewees generally acknowledged PhACs are a concern, and several suggestions for governments interested in managing the environmental risks of PhACs were put forward. Almost one decade later, Ontario has implemented two of the suggested management strategies (O. Reg. 298/12, Ontario's pharmaceutical return program; and all of Ontario's primary wastewater treatment plants have been upgraded to secondary wastewater treatment technologies), while more scientific research on this issue has been published. No follow-up study has been performed to see if stakeholders still believe that more management action could be taken.

The purpose of this study is to evaluate the scope and sufficiency of current Ontario regulations, policies, and programs related to pharmaceutical products in municipal wastewater treatment plants. This thesis examines whether a purposefully selected group of experts believe PhACs are a concern, and if additional action should be taken in Ontario to manage this risk. Experts were identified based on their: current occupations; contributions to published, peer-reviewed scientific papers; attendance at relevant conferences and workshops; contribution to industry magazines; and referrals. Consulting with a purposefully selected group of experts replicates an earlier study published on a similar topic by DoerrMacEwen and Haight in 2006, based on a 2007 PhD thesis by Doerr-MacEwen.

This current thesis asks: what is the perceived risk of pharmaceuticals to Ontario's aquatic environment, and what are the challenges and opportunities for government action to address this issue? Data for this thesis is derived from questionnaires and interviews with policymakers, academics, and industry experts.

The thesis also has several sub-objectives. Hence, in addition to the central question, the thesis considers: 
1) how potential point sources for PhACs are addressing pharmaceuticals in wastewater streams (e.g., hospitals, municipalities).

2) how governments currently understand and perceive the risk associated with pharmaceuticals;

3) whether existing legislation follows from that perceived risk;

4) in light of answers to 1 and 2, what actions have been taken or have been proposed to address pharmaceuticals and why; and

5) potential options available to the government, considering what other jurisdictions have done, and the cost and overall effectiveness of removing pharmaceutical products from streams.

This thesis reviews published literature on cost estimates for different water treatment technologies and mitigation options that can be used to reduce the total release of these contaminants into municipal wastewater treatment plants and, ultimately, the environment. The research also looks at possible action that can be taken at the federal level in Canada. Recently, the federal government introduced national effluent water quality standards from municipal treatment, yet this regulation does not include any standard for testing or removing pharmaceutical compounds.

The literature indicates that some risk is posed by PhACs to the environment, but the exact nature of this risk is yet to be fully understood. Experts consulted for this study believe more information is needed before significant changes can be considered. There are potentially low-cost techniques that can be taken to collect more information and address some immediate environmental concerns. Ontario's Drinking Water Surveillance Program regularly monitors provincial water streams for a variety of contaminants. Results are published regularly through the government's Open Data platform. One year, for a special government report, this program was used to measure the amount of certain PhACs from across Ontario's water streams. This author therefore believes that expanding the program to always include PhACs would benefit scientists, researchers, and policy-makers, especially because the data collected under this program is made available to the public on a regular basis. This author also believes that the MOECC should consider setting a guidance level for certain pharmaceuticals, perhaps in its Provincial Water Quality Objectives, as has been done in British 
Columbia. The province of British Columbia developed a Water Quality Guideline in 2009 for PhACs that must be considered by British Columbia's Ministry of the Environment when making any decision that could affect water quality. The guideline currently sets an ideal limit for only one PhAC, and is written as follows: "For the protection of freshwater aquatic life, it is recommended that the 30 -day average concentration of $17 \alpha$-ethinylestradiol (EE2) in water, based on 5 weekly samples, should not exceed 0.5 ng L-1 with no single value to exceed 0.75 ng L-1 (no more than $50 \%$ above the guideline value)." (Nagpal \& Meays, 2009, p.17).

This thesis is organized as follows. Chapter 2 provides an extensive literature review covering academic papers published between 1972 and 2015 from peer-reviewed journals, as well as government websites and policy papers. Chapter 3 outlines the method used to consult with expert stakeholders (including academic, government, and industry professionals). Chapter 4 then reviews and analyzes the results of this consultation with expert stakeholders. Chapter 5 concludes this thesis, and summarizes policy strategies for the management of PhACs in the environment. 


\section{Literature Review}

The basic problem under investigation in this thesis is the increasing presence of PhACs in the environment, the risk these contaminants pose, and the question of whether or not Ontario's policies address this risk. Information for this study was initially collected via a comprehensive literature review that focused on both scientific data and risk management principles. Relevant public policy in Ontario was also studied.

Several important points and discoveries were made during this literature review, which are discussed within relevant subsections of this chapter. To summarize, pharmaceuticals were first detected in the environment in the 1970s (Richardson and Bowron, 1985; Jones et al., 2005). Municipal wastewater is likely the primary sources of human pharmaceuticals or their metabolites entering the environment (Ternes, et al., 2004). Once PhACs enter the environment, the compounds are generally not volatile, hence they are more likely to travel as either a solid or liquid (Fent et al., 2006). Both conventional wastewater treatment plants and advanced wastewater treatment processes can be used to reduce the amount of PhACs entering the environment, but there is no silver bullet technology that can remove all possible contaminants (Luo et al., 2014), and regulations dictate what level of wastewater treatment is required. While advanced treatment technologies can assist with removing PhACs, they come with their own drawbacks, specifically higher costs and the potential generation of harmful by-products (Bedner and MacCrehan, 2006).

\subsection{Review of Scientific Literature}

Over the last century, major scientific progress by the pharmaceutical industry has had a positive impact on the quality and wellbeing of both human and animal life. Given that the Earth is a closed system, materials used in one area can cycle through and move to a different area of our ecosystem. Early reports of human pharmaceuticals in the environment were first published in the 1970s (Richardson and Bowron, 1985; Jones et al., 2005). Analyses at the time involved extracting large 
water amounts and using Gas Chromatography or Gas Chromatography/Mass Spectrometry (GC/MS) (Snyder et al., 2010). These techniques were limited in sensitivity to the higher part per billion range, which hindered researchers' abilities to detect PhACs at lower concentrations (i.e., in treated effluent or drinking water). Although the technology was limited, some policy makers in the 1970 s knew that water treatment processes were unable to remove certain pharmaceutical products, like the female birth control pill, from wastewater streams (Westman, 1972).

In the decade following, the first observed occurrence of feminized fish was documented (Routledge et al., 1998) and additional measurements and analyses of PhACs in the environment were performed (Richardson \& Bowron, 1985). Technology continued to advance in the 1990s, giving researchers access to more sensitive measurement technology, specifically Liquid ChromatographyMass Spectrometry (LC-MS) (Snyder et al., 2010). This allowed researchers to detect PhACs they had never detected before and at very low concentrations. Figure 1, adapted from the World Health Organization's report on pharmaceuticals in the environment, shows how certain technologies are more suitable for measuring certain PhACs. 
GC-MS or GC-MS?

without dorivatization

Aspirin

Codeine

Cyclaphouphanide

Galowolide

Pentaxylyline

Tonalide

Tilicloan
GC-MS or GC-MS

after derivatixation

Aspirin

Ecofibiat

Eolylinddibeot

Flubipidon

Kefoprolon

Nadcld

Tolonomic add

\section{Carbamazupine}

Diasopam

ibuprotion

Parocitame

Ptsenazone

Bezolbrote

Clolibrulo

Didolono:

Fencilbrate

Fencorder

Gomibrozil

Indemethocine

koptoenido

Metenamic acid
Melopedid

Noproien

fropeonold

Propypherazone

Povitiromycin

Salbetand

Salfamethonazde

\begin{tabular}{|c|c|}
\hline 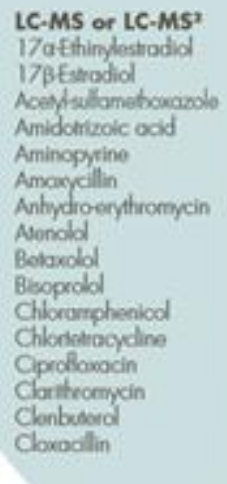 & 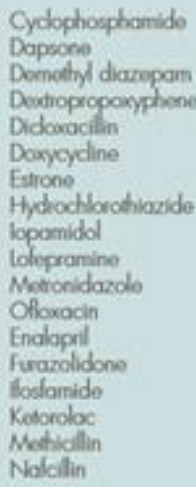 \\
\hline
\end{tabular}

Eythoemycin

Futcesomide

bonkeprol

lincoenycin

Mrtholieogle

Norfloxocin

Oleandomycin

Simnoswalin

Solold.

Omeprazolo

Oxocillin

Oxyentocyclins

Ponicilln G

Poniclin V

Pindold

Pircoscom

Ronilidine

Ronidarclo
Spiramycin

Sulocelamide

Stllodiarine

Sutadienothoxine

Stelodimidine

Sitloguonidin

Stelomethazine

Silfopyidine

Sidopalovine

Salfotiagino

Sutathiazine

Tomociton

Torbutaline

Totracyctine

Timicosin

Trimetroprim

Tyloein

Viginianycin

\section{Figure 1: An Illustration of Analytical Methods Applied to Detect PhACs in Water and Wastewater}

Source: World Health Organization, 2012.

\subsubsection{Sources and Behaviour of PhACs in Wastewater Streams and the Environment}

There are several different ways that PhACs can enter our environment, as shown in Figure 2.

Each pathway is in some way linked to human activity and this is why some hydrologists have used

PhACs as tracers for determining if humans have had an impact on water (Moller et al., 2002).

Municipal wastewater is believed to be one of the primary sources of human pharmaceuticals

(or their metabolites) entering the environment (Ternes, et al., 2004). This is because human bodies

only metabolize a certain amount of each prescription drug and they may excrete as much as 50 percent 
of these compounds in an unchanged state (Ternes, 1998). ${ }^{1}$ Some people may also improperly dispose of PhACs by flushing them down the toilet - a practice that is still recommended by the US Food and Drug Administration for certain medicines that are harmful or fatal in small doses (e.g., morphine, Percocet) (US FDA, 2015).

The loading of PhACs into the environment after human consumption is complicated to predict. It depends on the input streams, the technology at the wastewater treatment plant, and the operating parameters for the wastewater treatment facility (Ternes, 1998; Tauxe-Wuersch et al,. 2005; Zwiener, 2007). Removal rates range greatly because conventional wastewater treatment plants are not designed to eliminate pharmaceuticals (Gauthier et al., 2010). It is therefore useful to examine the general behavior of PhACs as they travel through the environment and during the different stages of wastewater treatment processes.

\footnotetext{
${ }^{1}$ Of note, PhACs that have been metabolized into inactive conjugates through glucuoronidation can potentially be re-released into the environment after passing through sewers or wastewater treatment plants, because these inactive conjugates may be cleaved by bacteria and turned back into the active parent PhACs (Baronti et al. 2000, Suarez et al., 2008).
} 


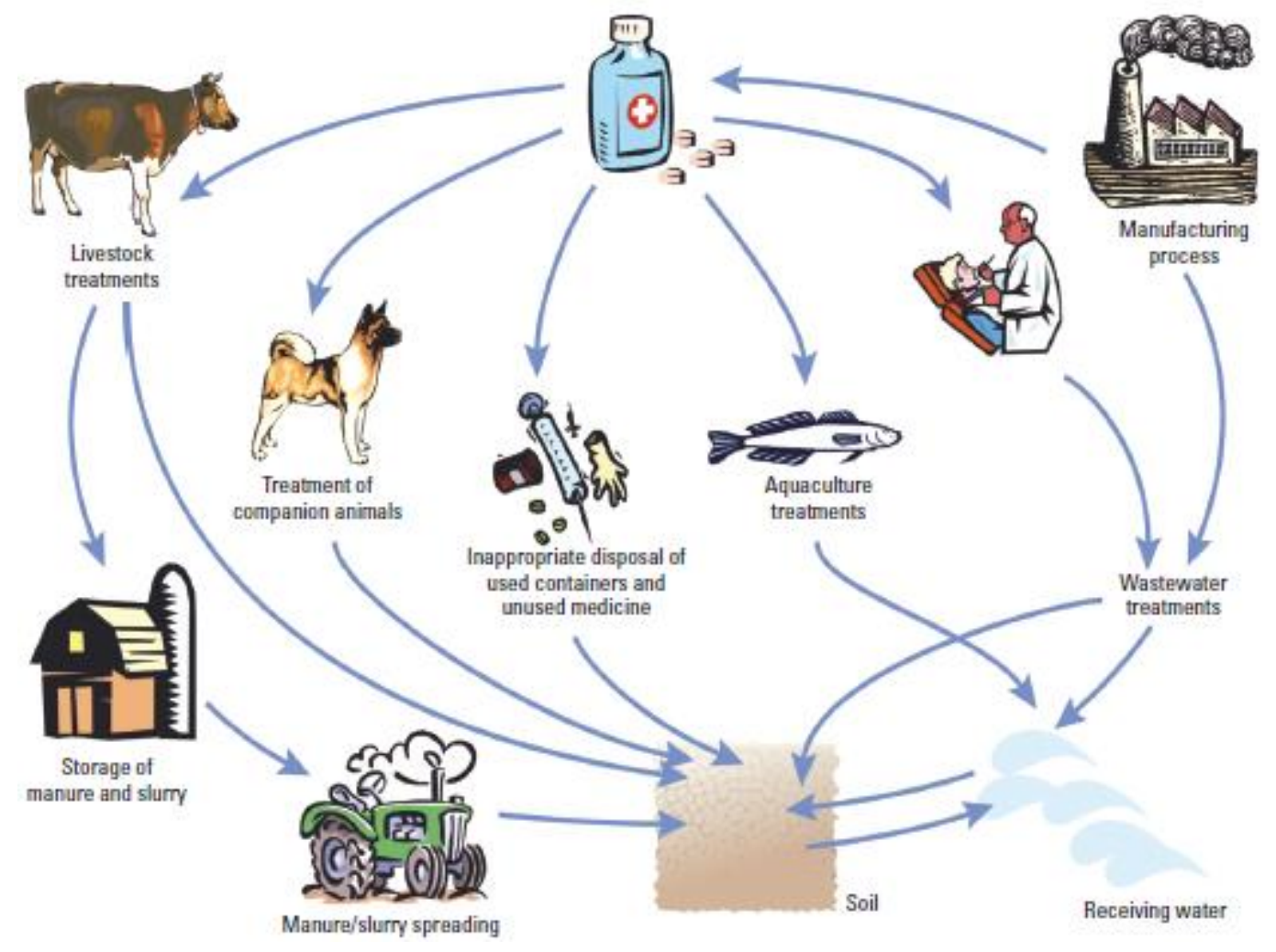

Figure 2: Sources and Fate of PhACs in the Environment

Source: Boxall et al., 2012

PhACs are not usually volatile, hence they are more likely to travel through the environment as either a solid or liquid (Fent et al., 2006). Trace amounts of PhACs have been measured in various ground waters, surface waters, and drinking waters (Eckel et al., 1993; Fent et al., 2006; Benotti et al., 2009; Kostich et al., 2014). Given the large number of PhACs and their unique physical properties throughout these different water systems, the precise behaviour and fate of these compounds in the environment is not entirely known (Fent et al., 2006; Mrozik and Stefanska, 2014).

Most studies report removal of parent PhACs by measuring the difference in concentration between the influent and effluent streams from municipal wastewater treatment plants (Suarez et al., 2008). While this limits detailed knowledge of overall removal processes because it is often not known 
if a PhAC was mineralized or structurally altered, it is still a useful proxy to measure and compare overall removal rates for different compounds across different treatment plants. ${ }^{2}$

Table 1 provides a comparison of removal rates across different wastewater treatment plants, as compiled by Luo et al. (2014). There is clearly a large range in removal rates for certain PhACs (e.g., clofibric acid, which ranges from 0 -94\%). There are several reasons for this large range, one of which is how the different wastewater treatment plants are operated (Tauxe-Wuersch et al,. 2005; Luo et al., 2014). Certain conditions within conventional plant designs can have a positive effect on removal rates for PhACs that are biologically degraded, such as longer solids retention times (Clara et al., 2005), longer hydraulic retention times (Tauxe-Wuersch et al,. 2005), and different operating temperatures (Ternes, 1998). There are also advanced technologies, such as ozonation, UV-radiation, activated carbon, and membrane filtration, which can potentially improve the overall removal rate of PhACs from wastewater treatment plant, but these come at an additional cost (Carballa et al., 2007; Luo et al., 2014).

Table 1: Wastewater Treatment Plant Removal Rates for Select PhACs

\begin{tabular}{|c|c|c|c|c|c|}
\hline Categories & $\begin{array}{l}\text { Selected } \\
\text { compounds }\end{array}$ & Sampling sites & $\begin{array}{l}\text { Influent } \\
(\mu \mathrm{g} / \mathrm{L})\end{array}$ & $\begin{array}{l}\text { Effluent } \\
(\mu \mathrm{g} / \mathrm{L})\end{array}$ & Removal (\%) ${ }^{\mathrm{a}}$ \\
\hline \multicolumn{6}{|l|}{ Pharmaceutical } \\
\hline \multirow{6}{*}{$\begin{array}{l}\text { Analgesic and } \\
\text { anti- } \\
\text { inflammatory }\end{array}$} & Acetaminophen & Korea, Spain, WB ${ }^{\mathrm{c}}$ & $\begin{array}{l}1.57- \\
56.9\end{array}$ & $N D^{\underline{d}}-0.03$ & $98.7-100$ \\
\hline & Diclofenac & $\begin{array}{l}\text { EU-wide, Greece, Korea, Sweden, } \\
\text { Switzerland, UK, WB }\end{array}$ & $\begin{array}{l}<0.001 \\
-94.2\end{array}$ & $\begin{array}{l}<0.001- \\
0.69\end{array}$ & $<0-81.4$ \\
\hline & Ibuprofen & $\begin{array}{l}\text { China, EU-wide, Greece, Korea, } \\
\text { Sweden, UK, US, WB }\end{array}$ & $\begin{array}{l}<0.004 \\
-603\end{array}$ & ND-55 & $72-100$ \\
\hline & Ketoprofen & China, EU-wide, Korea, Spain, UK, WB & $\begin{array}{l}<0.004 \\
-8.56\end{array}$ & $\begin{array}{l}<0.003- \\
3.92\end{array}$ & $10.8-100$ \\
\hline & Mefenamic acid & EU-wide, Korea, Spain, UK & $\begin{array}{l}<0.017 \\
-1.27\end{array}$ & $\begin{array}{l}<0.005- \\
0.39\end{array}$ & $<0-70.2$ \\
\hline & Naproxen & Greece, Korea, Spain, Sweden, UK, & $<0.002$ & $<0.002-$ & $43.3-98.6$ \\
\hline
\end{tabular}

\footnotetext{
${ }^{2}$ A mass balance calculation across the different unites within a wastewater treatment plant helps determine how the PhAC is transformed, but this information is not readily available from published literature (Carballa et al., 2007).
} 


\begin{tabular}{|c|c|c|c|c|c|}
\hline Categories & $\begin{array}{l}\text { Selected } \\
\text { compounds }\end{array}$ & Sampling sites & $\begin{array}{l}\text { Influent } \\
(\mu \mathrm{g} / \mathrm{L})\end{array}$ & $\begin{array}{l}\text { Effluent } \\
(\mu \mathrm{g} / \mathrm{L})\end{array}$ & Removal (\%) \\
\hline & & WB & -52.9 & 5.09 & \\
\hline & Salicylic acid & Greece, Spain, UK & $\begin{array}{l}0.58- \\
63.7\end{array}$ & ND-0.50 & $89.6-100$ \\
\hline Anticonvulsant & Carbamazepine & $\begin{array}{l}\text { China, EU-wide, Greece, Korea, Spain, } \\
\text { UK, WB }\end{array}$ & $\begin{array}{l}<0.04- \\
3.78\end{array}$ & $\begin{array}{l}<0.005- \\
4.60\end{array}$ & $<0-62.3$ \\
\hline \multirow{3}{*}{ Lipid regulator } & Bezafibrate & EU-wide, Spain, Korea, UK, WB & $\begin{array}{l}0.05- \\
1.39\end{array}$ & $0.03-0.67$ & $9.10-70.5$ \\
\hline & Clofibric acid & $\begin{array}{l}\text { China, EU-wide, Greece, Korea, Spain, } \\
\text { Sweden, UK, WB }\end{array}$ & $0-0.74$ & ND-0.33 & $<0-93.6$ \\
\hline & Gemfibrozil & EU-wide, Greece, Korea, Spain, WB & $\begin{array}{l}0.10- \\
17.1\end{array}$ & $\begin{array}{l}<0.0025- \\
5.24\end{array}$ & $<0-92.3$ \\
\hline \multirow{3}{*}{ Antibiotic } & Erythromycin & China, Spain, UK, WB & $\begin{array}{l}0.14- \\
10.0\end{array}$ & $0.02-2.84$ & $<0-82.5$ \\
\hline & Sulfamethoxazole & $\begin{array}{l}\text { EU-wide, France, Korea, Spain, } \\
\text { Sweden, Switzerland, UK, WB }\end{array}$ & $\begin{array}{l}<0.003 \\
-0.98\end{array}$ & $\begin{array}{l}<0.003- \\
1.15\end{array}$ & $4-88.9$ \\
\hline & Trimethoprim & China, EU-wide, Korea, Spain, UK & $\begin{array}{l}0.06- \\
6.80\end{array}$ & $<0.01-3.05$ & $<0-81.6$ \\
\hline \multirow{2}{*}{$\beta$-Blocker } & Atenolol & Korea, Spain, Switzerland, UK,WB & $\begin{array}{l}0.1- \\
33.1\end{array}$ & $0.13-7.60$ & $<0-85.1$ \\
\hline & Metoprolol & China, Korea, Spain, Switzerland, UK & $\begin{array}{l}0.002- \\
1.52\end{array}$ & $0.003-0.25$ & $3-56.4$ \\
\hline \multicolumn{6}{|l|}{ Steroid hormone } \\
\hline & Estrone & $\begin{array}{l}\text { China, France, Germany, Italy, Korea, } \\
\text { Sweden, US }\end{array}$ & $\begin{array}{l}0.01- \\
0.17\end{array}$ & $\begin{array}{l}<0.001- \\
0.08\end{array}$ & $74.8-90.6$ \\
\hline & Estradiol & $\begin{array}{l}\text { China, France, Germany, Italy, Korea, } \\
\text { Sweden, US }\end{array}$ & $\begin{array}{l}0.002- \\
0.05\end{array}$ & $\begin{array}{l}<0.001- \\
0.007\end{array}$ & $92.6-100$ \\
\hline & $\begin{array}{l}17 \alpha- \\
\text { Ethynylestradiol }\end{array}$ & $\begin{array}{l}\text { China, France, Germany, Italy, } \\
\text { Sweden, US }\end{array}$ & $\begin{array}{l}0.001- \\
0.003\end{array}$ & $\begin{array}{l}<0.001- \\
0.002\end{array}$ & $43.8-100$ \\
\hline & Estriol & China, Korea & $\begin{array}{l}0.125- \\
0.80\end{array}$ & ND & 100 \\
\hline
\end{tabular}

- When the removal efficiency was not presented in a study, it was calculated using the following equation, removal efficiency $(\%)=\left(C_{i n f}-C_{e f f}\right) / C_{i f f} \times 100$ ( $C_{\text {inf }}$ is the influent concentration of a compound and $C_{\text {eff }}$ is the effluent concentration of a compound).

'WB: Western Balkan Region (including Bosnia and Herzegovina, Croatia and Serbia).

${ }^{\circ} \mathrm{ND}$ : not detected.'

Source: Lou et al., 2014.

It is therefore important to understand the general behavior of PhACs in conventional wastewater treatment plants and during advanced wastewater treatment processes because both can be used to reduce the amount of PhACs entering the environment. 


\subsubsection{Water Treatment Plants - Technology Overview}

In general, wastewater treatment plants use either a primary or a primary and secondary treatment process. In Ontario, the wastewater effluent guidelines (Guideline F-5, Levels of Treatment for Municipal and Private Sewage Treatment Words Discharging to Surface Waters) require at least secondary wastewater treatment for processing normal municipal and private sewage that is discharged to surface water. Secondary wastewater plants produce better quality effluent than their primary counterparts (Lou et al., 2014). They expose wastewater to a wide variety of different treatment processes and biological processes, including dispersion, dilution, partition, biodegradation, and abiotic transformation.

Biodegradation and sorption are the main removal mechanisms for PhACs during secondary treatment (Carballa et al., 2007, Lou et al., 2014). Sorption refers to absorption and or adsorption; absorption is when molecules enter a bulk phase that can be solid, liquid or gas; adsorption is when molecules physically adhere onto the surface of another molecule because of electrostatic interactions (Suarez et al., 2008). Biodegradation can take place anaerobically or aerobically (Fent el al., 2006). Longer hydraulic retention times and longer solids retention times have been shown to have a positive effect on the degradation rate during this process (Clara et al., 2005, Kim et al., 2005, Estrada-Arriaga \& Mijaylova, 2011). If an accurate partition coefficient is known $\left(K_{d}\right)$, it can help predict how a PhAC is distributed between the solid and liquid phases. Anticipating this distribution is important because PhACs can potentially re-enter groundwater or surface water if the solid phase is moved back into the environment (e.g., when sludge is used as an agricultural fertilizer) (Topp et al., 2008). In Ontario, roughly 120,000 dry tonnes per year of sewage sludge is applied as an agricultural fertilizer (Sabourin et al., 2012). Dr. Lynda McCarthy of Ryerson University has performed work in this area, studying the effects of land application of municipal biosolids on nitrogen-fixing bacteria. Her team has shown that 
the application of biosolids in Ontario can introduce elevated levels of metals, PhACs, personal care products, and viable bacteria (Holt et al., 2010).

Other specialized technologies can be used to remove some PhACs, but advanced treatment technologies are not required under Ontario's Guideline F-5. Advanced technologies include: oxidation via ozonation or chlorination, which can remove PhACs from water effluents (Esplugas et al. 2007, Acero et al., 2010); membrane filtration and reverse osmosis that physically separates the PhAC from the liquid phase (Bellona et al, 2008, Suarez et al. 2008, Snyder et al. 2007); UV-radiation, which can cause photolysis of PhACs (Carlson et al., 2015); and activated carbon can remove some PhACs from water via sorption (Suarez et al. 2008, Snyder et al. 2007). These technologies do not come without their own drawbacks, such as high cost and the generation of harmful by-products (Bedner and MacCrehan, 2006). Dr. Mehrab Mehrvar from Ryerson University and his team have performed extensive work examining how to select wastewater treatment technologies based on the waste stream, environmental regulations, and cost (Mohajerani et al. 2009). This type of work can optimize which treatment process is chosen for a specific site.

Table 2 provides equations behind theoretical cost curves for advanced wastewater treatment plants, based on 2011 US dollars and published by Plumlee et al. in 2014. According to their research, ozone treatment is the lowest cost tertiary treatment process, followed by Biological Activated Carbon or UV/H2O2. Finally, membrane treatment is the highest cost unit process. 
Table 2: Summary of Conceptual-Level Cost Curve Regression Equations

\begin{tabular}{|c|c|c|}
\hline & Capital Cost ${ }^{\mathrm{a}}$ & Annual O\&M Cost \\
\hline Process & $(\$ M / M G D)$ & $(\$ M / M G D)$ \\
\hline Ozone & $2.26 \times(\text { Plant Capacity, in MGD })^{-0.54}$ & $0.0068 \times(\text { Plant Capacity, in MGD })^{-0.051}$ \\
\hline Ozone $/ \mathrm{H}_{2} \mathrm{O}_{2}$ & $2.26 \times(\text { Plant Capacity, in MGD })^{-0.54}$ & $0.016 \times(\text { Plant Capacity, in MGD })^{-0.020}$ \\
\hline $\mathrm{UV} / \mathrm{H}_{2} \mathrm{O}_{2}$ & $0.474 \times(\text { Plant Capacity, in MGD })^{-0.056}$ & $0.038 \times(\text { Plant Capacity, in MGD })^{-0.052}$ \\
\hline MF or UF & $3.57 \times(\text { Plant Capacity, in MGD })^{-0.22}$ & $0.30 \times(\text { Plant Capacity, in MGD })^{-0.22}$ \\
\hline NF or RO & $7.14 \times(\text { Plant Capacity, in MGD })^{-0.22}$ & $0.44 \times{\text { (Plant Capacity, in MGD })^{-0.13}}^{-13}$ \\
\hline \multicolumn{3}{|r|}{ 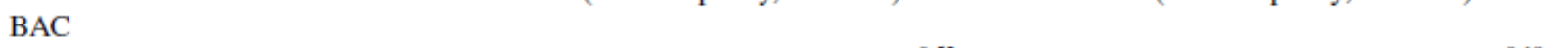 } \\
\hline $10 \mathrm{~min}$ EBCT, $1-10 \mathrm{MGD}$ & $2.92 \times(\text { Plant Capacity, in MGD })^{-0.52}$ & $0.074 \times(\text { Plant Capacity, in MGD })^{-0.19}$ \\
\hline $20 \mathrm{~min}$ EBCT, $1-10 \mathrm{MGD}$ & $3.03 \times(\text { Plant Capacity, in MGD })^{-0.48}$ & $0.085 \times(\text { Plant Capacity, in MGD })^{-0.16}$ \\
\hline $10 \mathrm{~min}$ EBCT, $10-80 \mathrm{MGD}$ & $1.43 \times{\text { (Plant Capacity, in MGD })^{-0.17}}^{-17}$ & 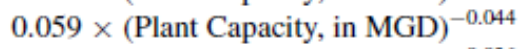 \\
\hline $20 \mathrm{~min}$ EBCT, $10-80 \mathrm{MGD}$ & $1.52 \times(\text { Plant Capacity, in MGD })^{-0.15}$ & $0.070 \times(\text { Plant Capacity, in MGD })^{-0.036}$ \\
\hline
\end{tabular}

Notes: "Capital costs include contractor OH\&P and contingency.

Note: \$M/MGD, or million US dollars per million gallons per day of treated flow. Above equations are valid for design flowrates ranging from 1 -500 MGD.

Source: Plumlee et al. 2014

Each advanced wastewater treatment technology comes at an additional cost over current wastewater treatment plants, and will also increase the energy consumption of treatment plant. In addition to cost, the desired/required effluent quality strongly influences whether or not a wastewater treatment technology is used in a facility. Therefore, without requiring advanced wastewater treatment processes in Ontario's municipal plants, it is very unlikely that any of these would be adopted in Ontario.

\subsubsection{Classes of PhACs of Concern}

The following discussion highlights PhACs that have been identified as a concern for the environment. Some PhACs are used in large amounts, others can influence biological systems at very low concentrations, and some persist throughout the environment; yet all are designed to influence biological processes. 
Analgesics and anti-inflammatory medications are ubiquitous surface water contaminants and are frequently detected in sewage systems. Common PhACs include acetaminophen, ibuprofen, diclofenac, and naproxen (Fent et al., 2006). Of particular concern, diclofenac is known to have caused kidney failure and widespread death in vultures, G. africanus and G. fulvus, endemic to South Asia (Green et al., 2007). While high rates of acetaminophen removal in treatment plants have been observed, the oxidation of acetaminophen in advanced wastewater treatment plants produces toxic byproducts (Bedner and MacCrehan, 2006).

The anticonvulsant carbamazepine is the most frequently detected PhAC neuroactive compound (Ternes, 1998). It has been detected in sewage treatment plant effluents across Canada (Metcalfe et al., 2003). As shown in Table 1, it has a relatively low removal rate in wastewater treatment plants. Carbamazepine is considered a highly persistent compound in nature, and, when Mediterranean mussels were exposed to concentrations of carbamazepine typically found in the environment, there were observed modifications to their biochemical pathways (Calisto and Esteves, 2012; Martin-Diaz et al., 2009). In a 2014 study by the US EPA that examined effluent for trace PhACs from 50 large wastewater treatment plants, carbamazepine was found in over $90 \%$ of the samples (Kostich et al., 2014).

Lipid regulators are commonly studied PhACs and considered ubiquitous contaminants of concern (Fent et al., 2006). Clofibric acid is a persistent contaminant and was one of the first prescription drugs ever detected in sewage effluent; it remains one of the most frequently reported PhACs in published studies (Spellman, 2014). In 1996, the first "direct link between sewage effluents, contaminated surface water, and contamination of ground and even drinking water with residues of pharmaceuticals" (Goldstein, 2014, p. 14) was made by measuring concentrations of clofibric acid. This 
PhAC has been shown to affect the common carp fish (Cyprinus carpio) by influencing levels of mRNA for several genes involved with detoxification/biotransformation systems (Corcoran et al., 2015).

There is a significant amount of literature on antibiotics in the environment (Spellman, 2014). Antibiotics have the potential to accumulate in the environment and contribute to antibiotic resistance if gene transfer to pathogenic bacteria occurs. Kim and Aga (2007) note "antibiotic resistance genes against ampicillin, streptomycin, and tetracycline are known to be transferable to other bacteria" ( $p$. 566). Indeed, the widespread use of antibiotics is possibly one cause of accelerated antibiotic resistance among bacteria (Spellman, 2014). In addition, trace levels of the antibiotic sulfamethoxazole can negatively affect the population of native denitrifying bacteria in soil (Underwood et al., 2011). Denitrifying bacteria are important for overall soil health and the natural assimilation process of nitrate pollution.

Beta-blockers are another class of important PhACs because they are one of the most widely used PhACs to treat cardiovascular disease and are frequently detected in the environment (Maszkowski et al., 2014a). In a 2014 study by the US EPA that examined effluent for trace PhACs from 50 large wastewater treatment plants, metoprolol and atenolol were found in over $90 \%$ of the samples (Kostich et al., 2014). In fact, propranolol, bisoprolol and metoprolol have all been measured throughout surface waters and groundwaters (Fent et al., 2006). Propranolol and metoprolol can harm certain types of algae, and have the potential to be harmful to some aquatic organisms (Maszkowski et al., 2014b). However, based on their typical environmental concentrations, this class of contaminants are currently thought to pose a minor risk to the environment.

There are many studies citing synthetic hormones in different water systems around the world (Fent et al., 2006). These hormones have the potential to influence endocrine systems at relatively low concentrations. Two frequently cited hormones from the literature are $17 \alpha$-ethinyl estradiol (EE2) and 
mestranol, both are from the female contraceptive pill. Some reported concentrations of EE2 and mestranol have ranged as high as nanograms per litre (or parts per trillion) for treated wastewater.

This section reviewed several classes of PhACs, which are all designed to cause a desired therapeutic effect in the individual receiving medical treatment. However, human bodies only metabolize a certain amount of each prescription, and may release as much as 50 percent of these compounds in an unchanged state (Ternes, 1998), and some people may improperly dispose of PhACs. The result is that these compounds can enter water systems and have the opportunity to exert a physical effect on non-target organisms.

\subsubsection{Occurrence of PhACs in Water Systems}

There are very few studies on the human health risk from PhACs present in Canada's waterways (Khan and Nicell, 2015). Most available literature on the significance of PhACs in the environment focuses on data collected from either the U.S. or Europe, which cannot be easily extrapolated to Ontario because prescription rates can vary. For example, in Canada the per capita consumption for meprobamate is $1.5 \mathrm{ng} /$ capita $\bullet$ day, yet in the US it is almost $12,000 \mathrm{ng} /$ capita $\bullet$ day. Nevertheless, review articles from other jurisdictions are helpful to gauge the occurrence of PhACs in our waterways.

The following section discusses recent articles or government reports that identified occurrences of PhACs in different water systems, specifically within: municipal wastewater effluent, source and treated drinking water, and hospital effluent. Data from Canada and Ontario are discussed when available and appropriate.

\subsubsection{Municipal Wastewater Effluent}

In 2014, a comprehensive American research paper was published that measured concentrations of $56 \mathrm{PhACs}$ present in the effluent of fifty large wastewater treatment plants from 
across the US (Kostich et al., 2014). The authors selected plants to take samples from by identifying the fifty largest plants that discharged to surface water and served a population that had at least $75 \%$ of their flow originating from municipal sources (not from industrial or storm water sources). In total, the fifty wastewater treatment plants selected served over 46 million people and represented about $17 \%$ of the total load from all US wastewater treatment plants. All samples were collected and analyzed in similar ways, which provides a large and comparable dataset. The results from this study are summarized in

Table 3. Notably, every water sample contained the diuretic hydrochlorothiazide. Over $90 \%$ of the samples contained beta-blockers (metoprolol and atenolol) and the anticonvulsant carbamazepine. Among the compounds present, Kostich's team detected carbamazepine, gemfibozil, and ibuprofen, which have all been detected in Ontario (see section 2.1.6).

Kostich et al. also took these measured concentrations, as shown in Table 3, and compared them against minimum daily therapeutic dose rate to estimate the potential risk of these PhACs to humans. They also measured the free plasma concentrations after therapeutic dosing (Cmax-free, which represents the concentration that a PhAC can potentially cause an effect in non-human organisms). Potential risk of these PhACs to humans was found to be low. "Lisinopril ... showed the highest ratio of concentration $(3300 \mathrm{ng} / \mathrm{L}$ ) to DdMin [minimum daily therapeutic dose rate] (2.5 $\mathrm{mg} /$ day). Assuming someone was drinking two liters per day of water at this concentration, that person would consume slightly less than one minimum daily dose of lisinopril per year" (p. 357). However, four of the studied PhACs (sertraline, propanolol, desmethyl-sertraline, and valsartan) had "maximum concentrations above one tenth of the Cmax-free... suggesting the effluent concentrations of these analytes are close to plasma concentrations which are known to cause readily measurable responses in 
patients and lab animals... further emphasizing the potential for physiological effects" (p.357). The authors note a more detailed study of potential ecological impacts from these PhACs is required.

Table 3: Concentrations Across 50 Effluent Samples

\begin{tabular}{|c|c|c|c|c|c|c|c|c|}
\hline$\frac{\stackrel{ \pm}{\frac{\pi}{\pi}}}{\frac{\pi}{\pi}}$ & ల్ & 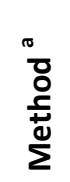 & $\begin{array}{l}\overrightarrow{0} \\
\vec{a} \\
\vec{x} \\
\vec{x}\end{array}$ & 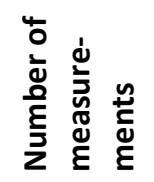 & 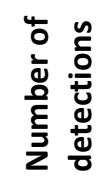 & 岧 & 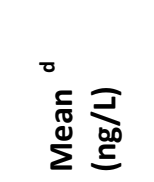 & 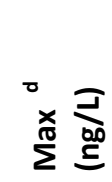 \\
\hline $\begin{array}{l}\text { 10-Hydroxy- } \\
\text { ampitriptyline }\end{array}$ & $64520-05-4$ & 1 & 5 & 50 & 6 & 5029 & $<R L$ & $<\mathrm{RL}$ \\
\hline Acetaminophen & $103-90-2$ & 1 & 5 & 50 & 7 & 306955 & $79(300)$ & $\begin{array}{l}1500 \\
(4500)\end{array}$ \\
\hline Albuterol & $18559-94-9$ & 1 & 9.7 & 50 & 27 & 471 & 14 & 35 \\
\hline Alprazolam & 28981-97-7 & 1 & 9.1 & 50 & 15 & 103 & 10 & 31 \\
\hline Amitriptyline & $549-18-8$ & 1 & 5 & 50 & 20 & 5029 & 11 & 110 \\
\hline Amlodipine & $111470-99-6$ & 1 & 5 & 50 & 11 & 94 & 6.9 & 18 \\
\hline Amphetamine & $51-63-8$ & 1 & 1.6 & 50 & 5 & 387 & 3.5 & 40 \\
\hline Atenolol & 29122-68-7 & 1 & 6 & 50 & 48 & 4137 & 940 & 3000 \\
\hline Atorvastatin & $134523-00-5$ & 1 & 38 & 48 & 4 & 2906 & $<\mathrm{RL}$ & $<\mathrm{RL}$ \\
\hline Benztropine & $86-13-5$ & 1 & 10 & 50 & 0 & 33 & ND & ND \\
\hline Carbamazepine & $298-46-4$ & 1 & 4.4 & 50 & 48 & 5607 & $97(140)$ & $\begin{array}{l}240 \\
(460)\end{array}$ \\
\hline Ciprofloxacin & $85721-33-1$ & 2 & 10 & 49 & 30 & NA & $67(72)$ & $\begin{array}{l}260 \\
(320)\end{array}$ \\
\hline Clonidine & $4205-91-8$ & 1 & 35 & 50 & 0 & 43 & ND & ND \\
\hline $\begin{array}{l}\text { Desmethyl- } \\
\text { sertraline }\end{array}$ & 79902-63-9 & 1 & 9.4 & 50 & 9 & 615 & $9.9(10)$ & 24 \\
\hline Diltiazem & $33286-22-5$ & 1 & 2.8 & 49 & 41 & 3343 & 85 & 340 \\
\hline $\begin{array}{l}\text { Diltiazem- } \\
\text { desmethyl }\end{array}$ & $130606-60-9$ & 1 & 1.6 & 50 & 34 & 3343 & 24 & 100 \\
\hline Enalapril & $76095-16-4$ & 1 & 1 & 50 & 9 & 369 & 4.6 & 38 \\
\hline Enalapril & $76095-16-4$ & 2 & 11 & 49 & 13 & 369 & 13 & 32 \\
\hline Enalaprilat & $76420-72-9$ & 2 & 9 & 49 & 5 & 369 & $14(18)$ & 150 \\
\hline Florfenicol & $73231-34-2$ & 2 & 60 & 49 & 0 & NA & ND & ND \\
\hline Fluocinonide & $356-12-7$ & 1 & 10 & 50 & 0 & 12 & ND & ND \\
\hline Fluoxetine & 59333-67-4 & 1 & 2.8 & 48 & 18 & NA & 8.7 & 31 \\
\hline Fluticasone & $57-83-0$ & 1 & 19 & 50 & 0 & 4.2 & ND & ND \\
\hline Furosemide & $54-31-9$ & 1 & 38 & 50 & 45 & 7283 & $280(350)$ & $\begin{array}{l}810 \\
(2100)\end{array}$ \\
\hline Gemfibrozil & $25812-30-0$ & 1 & 10 & 50 & 38 & NA & $420(480)$ & 2300 \\
\hline Hydrochloro- & $58-93-5$ & 1 & 10 & 50 & 50 & 13947 & 1100 & 2800 \\
\hline
\end{tabular}




\begin{tabular}{|c|c|c|c|c|c|c|c|c|}
\hline$\frac{\stackrel{ \pm}{\frac{\pi}{\pi}}}{\frac{5}{4}}$ & ֻั & 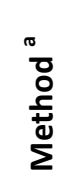 & $\begin{array}{l}\underset{0}{\vec{a}} \\
\vec{a} \\
\vec{a}\end{array}$ & 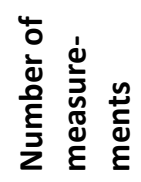 & 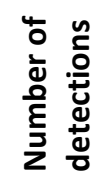 & u & 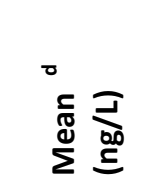 & 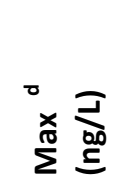 \\
\hline thiazide & & & & & & & (1200) & \\
\hline Hydrocodone & $143-71-5$ & 1 & 3.8 & 50 & 22 & 2561 & $22(24)$ & $\begin{array}{l}92 \\
(100)\end{array}$ \\
\hline Hydrocortisone & $50-23-7$ & 1 & 25 & 50 & 0 & 2368 & ND & ND \\
\hline Ibuprofen & $15687-27-1$ & 1 & 12 & 50 & 23 & 20257 & $460(690)$ & $\begin{array}{l}4200 \\
(4600)\end{array}$ \\
\hline Lincomycin & 859-18-7 & 2 & 8 & 49 & 0 & NA & ND & ND \\
\hline Lisinopril & $83915-83-7$ & 2 & 45 & 49 & 23 & 814 & $180(1700)$ & $\begin{array}{l}3300 \\
(13000)\end{array}$ \\
\hline $\begin{array}{l}\text { Melengestrol } \\
\text { acetate }\end{array}$ & 2919-66-6 & 2 & 9 & 49 & 0 & NA & ND & ND \\
\hline $\begin{array}{l}\text { Methyl- } \\
\text { prednisolone }\end{array}$ & $83-43-2$ & 1 & 25 & 50 & 0 & 250 & ND & ND \\
\hline Metoprolol & $56392-17-7$ & 1 & 14 & 50 & 49 & 1451 & $410(450)$ & $\begin{array}{l}660 \\
(1200)\end{array}$ \\
\hline Norethindrone & $68-22-4$ & 1 & 6.9 & 50 & 0 & 111 & ND & ND \\
\hline Norfluoxetine & 83891-03-6 & 1 & 7.2 & 46 & 8 & NA & 7.7 & 15 \\
\hline Norverapamil & $67814-42-4$ & 1 & 4.4 & 48 & 25 & 5328 & 5.8 & 20 \\
\hline Ofloxacin & 82419-36-1 & 2 & 10 & 49 & 44 & NA & 160 & 660 \\
\hline Oxycodone & $124-90-3$ & 1 & 2.5 & 50 & 30 & NA & 53 & 310 \\
\hline Paroxetine & 110429-35-1 & 1 & 5 & 50 & 0 & NA & ND & ND \\
\hline Prednisolone & $50-24-8$ & 1 & 11 & 50 & 0 & 1420 & ND & ND \\
\hline Prednisone & 1953-03-02 & 1 & 30 & 50 & 0 & 2194 & ND & ND \\
\hline Progesterone & $80474-14-2$ & 1 & 188 & 50 & 2 & NA & $<\mathrm{RL}$ & $<\mathrm{RL}$ \\
\hline Progesterone & $80474-14-2$ & 2 & 9 & 49 & 0 & NA & ND & ND \\
\hline Promethazine & $58-33-3$ & 1 & 5 & 50 & 0 & 1668 & ND & ND \\
\hline Propoxyphene & $1639-60-7$ & 1 & 16 & 48 & 12 & 8300 & 17 & $34(46)$ \\
\hline Propranolol & $318-98-9$ & 1 & 4.4 & 50 & 44 & 991 & 33 & 260 \\
\hline Ranitidine & 66357-59-3 & 1 & 11 & 50 & 19 & NA & 120 & 1400 \\
\hline Sertraline & 79559-97-0 & 1 & 5 & 50 & 32 & 615 & 21 & 71 \\
\hline Simvastatin & 79902-63-9 & 1 & 41 & 50 & 12 & 548 & $<\mathrm{RL}$ & $<\mathrm{RL}$ \\
\hline Sulfadimethoxine & $122-11-2$ & 2 & 1 & 49 & 0 & NA & ND & ND \\
\hline Sulfamethazine & $57-68-1$ & 2 & 10 & 49 & 1 & NA & 12 & 87 \\
\hline Sulfamethoxazole & $723-46-4$ & 1 & 1.6 & 50 & 40 & NA & 910 & 2900 \\
\hline Sulfamethoxazole & $723-46-6$ & 2 & 1 & 49 & 44 & NA & 330 & 1000 \\
\hline Testosterone & 58-55-9 & 1 & 3.5 & 50 & 0 & NA & ND & ND \\
\hline Testosterone & $58-55-9$ & 2 & 1 & 49 & 0 & NA & ND & ND \\
\hline Theophylline & $58-55-9$ & 1 & 88 & 50 & 4 & 5696 & $<R L(88)$ & $\begin{array}{l}R \mathrm{RL} \\
(100)\end{array}$ \\
\hline
\end{tabular}




\begin{tabular}{|c|c|c|c|c|c|c|c|c|}
\hline 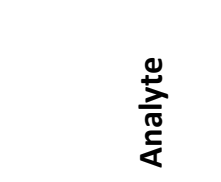 & 厄̋ & 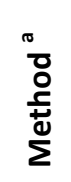 & 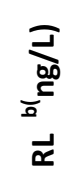 & 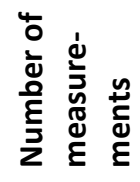 & 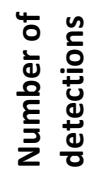 & 㟧 & 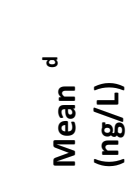 & 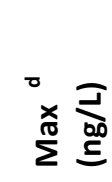 \\
\hline Triamterene & $396-01-0$ & 1 & 1.3 & 50 & 35 & 4504 & 37 & 170 \\
\hline Trimethoprim & $738-70-5$ & 1 & 2.5 & 43 & 37 & NA & 170 & 370 \\
\hline Trimethoprim & $738-70-5$ & 2 & 1 & 49 & 40 & NA & 90 & 210 \\
\hline Valsartan & $396-01-0$ & 1 & 11 & 41 & 40 & 2628 & $\begin{array}{l}1600 \\
(1700)\end{array}$ & $\begin{array}{l}5300 \\
(8200)\end{array}$ \\
\hline Verapamil & 137862-53-4 & 1 & 2.5 & 49 & 39 & 5328 & 26 & 97 \\
\hline Warfarin & $81-81-2$ & 1 & 11 & 50 & 0 & 28 & ND & ND \\
\hline
\end{tabular}

${ }^{\text {a }}$ Method employed.

${ }^{\mathrm{b}}$ Reporting limit, defined as $3 \mathrm{X}$ the EPA MDL (method detection limit) or the lowest calibration point, whichever is greater.

${ }^{c}$ Predicted national average concentration from Kostich and Lazorchak (2008).

${ }^{d}$ Numbers in parentheses include estimated concentrations from samples that failed quantification criteria.

Source: Kostich et al., 2014

In 2012, a study of the occurrence of steroidal estrogens in south-eastern Ontario wastewater treatment plants (Ottawa and Cornwall) was undertaken by Atkinson et al. at the University of Ottawa. Measurements of estrone, $17 \beta$-estradiol, $17 \alpha$-ethinylestradiol (EE2) were performed. The studied wastewater treatment plants had estrone present in both inlet and outlet streams, $17 \beta$-estradiol was also detected in inlet and outlet streams, although at much lower concentrations than estrone.

Conversely, $17 \alpha$-ethinylestradiol was only detected in two samples, which the authors suggest may be "because it is not released at such an elevated and constant rate from a population, compared to the other estrogens." (p. 122). However, due to its physical properties, EE2 may experience high rates of sorption to sewage sludge (discussed in 2.1.2), which was not investigated as part of this study. The authors note that the presence of EE2 in sludge is a concern because sludge can be used as a fertilizer and EE2 in the sludge is not a well studied issue.

\subsubsection{Source and Treated Drinking Water}


In 2010, the Ontario Ministry of the Environment (MOE, which is now the Ministry of the Environment and Climate Change) published a study on the occurrence of pharmaceuticals and other emerging contaminants in different water locations throughout the province (Ontario MOE, 2010). MOE's study objective was two-fold: 1 ) to determine the levels and occurrence of select PhACs and contaminants in untreated source and finished drinking water in Ontario; and 2) to determine if Ontario's existing treatment processes effectively lower the levels of PhACs and other emerging contaminants. Ontario's MOE, with the help of municipalities through Ontario's Drinking Water Surveillance Program, analyzed seventeen municipal drinking water systems for forty-six compounds of interest (twenty-five antibiotics, nine hormones, eleven PhACs, and bisphenol A). Twenty-three of the forty-six compounds analyzed were detected in source water, and twenty-two were detected in finished drinking water at low concentrations. A summary of the compounds detected in untreated source and finished drinking water are summarized below in Table 4, Table 5, and Table 6. Many of these compounds were also detected in the 2014 US EPA's study of wastewater effluent (as shown above in

Table 3). For the tables from MOE's study, it is clear that antibiotics are frequently detected in both untreated source and finished drinking water in Ontario. The hormone equilin, which is used for hormone replacement therapy, was also detected in finished drinking water.

Table 4: An Overview of Detected Compounds in Untreated Source and Finished Drinking Water in Ontario

\begin{tabular}{|l|l|l|l|l|l|}
\hline \multirow{2}{*}{ Compound } & \multirow{2}{*}{ Group } & Sample Type & $\begin{array}{l}\text { Number of } \\
\text { Detections }\end{array}$ & $\begin{array}{l}\text { Percent } \\
\text { Detection (\%) }\end{array}$ & $\begin{array}{l}\text { Number of } \\
\text { Sites (n=17) }\end{array}$ \\
\hline \multicolumn{2}{|l|}{ Compounds Detected in Untreated Source Water and Finished Drinking Water } \\
\hline \multirow{2}{*}{ Carbamazepine } & \multirow{2}{*}{ PhAC } & Untreated & 63 & 50 & 10 \\
\cline { 3 - 7 } & \multirow{2}{*}{ Gemfibrozil } & Finished & 31 & 25 & 8 \\
\hline \multirow{2}{*}{ Bisphenol A } & Untreated & 41 & 33 & 7 \\
\cline { 3 - 7 } & \multirow{2}{*}{ Ibuprofen } & Finished & 18 & 15 & 6 \\
\hline & \multirow{2}{*}{ Contaminant } & Untreated & 27 & 22 & 11 \\
\cline { 3 - 7 } & Finished & 15 & 12 & 11 \\
\hline
\end{tabular}




\begin{tabular}{|c|c|c|c|c|c|}
\hline \multirow{2}{*}{ Lyncomycin } & \multirow{2}{*}{ Antibiotic } & Untreated & 24 & 19 & 6 \\
\hline & & Finished & 3 & 2 & 3 \\
\hline \multirow{2}{*}{ Sulfamethoxazole } & \multirow{2}{*}{ Antibiotic } & Untreated & 23 & 18 & 8 \\
\hline & & Finished & 1 & 1 & 1 \\
\hline \multirow{2}{*}{ Acetaminophen } & \multirow{2}{*}{ PhAC } & Untreated & 14 & 11 & 8 \\
\hline & & Finished & 1 & 1 & 1 \\
\hline \multirow{2}{*}{ Benzafibrate } & \multirow{2}{*}{$\mathrm{PhAC}$} & Untreated & 13 & 10 & 2 \\
\hline & & Finished & 2 & 2 & 1 \\
\hline \multirow{2}{*}{ Trimethoprim } & \multirow{2}{*}{ Antibiotic } & Untreated & 13 & 10 & 3 \\
\hline & & Finished & 1 & 1 & 1 \\
\hline \multirow{2}{*}{ Erythromycin* } & \multirow{2}{*}{ Antibiotic } & Untreated & 12 & 10 & 4 \\
\hline & & Finished & 4 & 3 & 4 \\
\hline \multirow{2}{*}{ Ketoprofen } & \multirow{2}{*}{ PhAC } & Untreated & 11 & 9 & 3 \\
\hline & & Finished & 1 & 1 & 1 \\
\hline \multirow{2}{*}{ Tylosin } & \multirow{2}{*}{ Antibiotic } & Untreated & 5 & 4 & 5 \\
\hline & & Finished & 8 & 6 & 4 \\
\hline \multirow{2}{*}{ Monensin Sodium* } & \multirow{2}{*}{ Antibiotic } & Untreated & 14 & 11 & 7 \\
\hline & & Finished & 9 & 7 & 4 \\
\hline \multirow{2}{*}{ Enrofloxacin } & \multirow{2}{*}{ Antibiotic } & Untreated & 3 & 2 & 3 \\
\hline & & Finished & 4 & 3 & 4 \\
\hline \multirow{2}{*}{ Roxithromycin } & \multirow{2}{*}{ Antibiotic } & Untreated & 3 & 2 & 3 \\
\hline & & Finished & 3 & 2 & 3 \\
\hline \multirow{2}{*}{ Tetracycline } & \multirow{2}{*}{ Antibiotic } & Untreated & 3 & 2 & 3 \\
\hline & & Finished & 5 & 4 & 5 \\
\hline \multirow{2}{*}{ Norfloxacin } & \multirow{2}{*}{ Antibiotic } & Untreated & 2 & 2 & 2 \\
\hline & & Finished & 1 & 1 & 1 \\
\hline \multirow{2}{*}{ Meclocyclin } & Antihinti & Untreated & 1 & 1 & 1 \\
\hline & 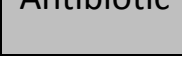 & Finished & 1 & 1 & 1 \\
\hline Compounds Only Det & cted in Unt & Source Wa & & & \\
\hline Naproxen & PhAC & Untreated & 26 & 21 & 5 \\
\hline Sulfamethazine & Antibiotic & Untreated & 12 & 10 & 4 \\
\hline Norethisterone & Antibiotic & Untreated & 1 & 1 & 1 \\
\hline Oxytetracycline & Antibiotic & Untreated & 1 & 1 & 1 \\
\hline Sulfathiozole & Antibiotic & Untreated & 1 & 1 & 1 \\
\hline Compounds Only Dete & cted in Finis & Drinking Wa & & & \\
\hline Sulfachloropyridazine & Antibiotic & Finished & 2 & 2 & 2 \\
\hline Clofibric acid & PhAC & Finished & 1 & 1 & 1 \\
\hline Diclofenac & PhAC & Finished & 1 & 1 & 1 \\
\hline
\end{tabular}




\begin{tabular}{|l|l|l|l|l|l|}
\hline Equilin & Hormone & Finished & 1 & 1 & 1 \\
\hline
\end{tabular}

* chemical analysis did not meet QA/QC standards for recovery.

Source: Ontario MOE, 2010

Table 5: Frequency of Detection and Overall Concentration Data for the Most Common Untreated Source Water Contaminants

\begin{tabular}{|l|c|c|c|c|c|c|}
\hline Compound & $\begin{array}{c}\text { Number of } \\
\text { Detections }\end{array}$ & $\begin{array}{c}\text { Detection } \\
\text { Percentage } \\
(\%)\end{array}$ & $\begin{array}{c}\text { Detection } \\
\text { Limit } \\
\text { (ng/L) }\end{array}$ & $\begin{array}{c}\text { Median } \\
\text { (ng/L) }\end{array}$ & $\begin{array}{c}95^{\text {th }} \\
\text { Percentile } \\
\text { (ng/L) }\end{array}$ & $\begin{array}{c}\text { Maximum } \\
\text { (ng/L) }\end{array}$ \\
\hline Carbamazepine & 63 & 50 & 1 & 3 & 152 & 749 \\
\hline Gemfibrozil & 41 & 33 & 1 & 0.7 & 6 & 9 \\
\hline $\begin{array}{l}\text { Bisphenol A } \\
\text { (BPA) }\end{array}$ & 27 & 22 & 2 & 2.1 & 44 & 87 \\
\hline Ibuprofen & 26 & 21 & 0.5 & 0.98 & 24 & 79 \\
\hline Naproxen & 26 & 21 & 2 & 1.0 & 58 & 199 \\
\hline Lincomycin & 24 & 19 & 0.5 & 0.12 & 15 & 143 \\
\hline Sulfamethoxazole & 23 & 18 & 2 & 0.17 & 28 & 284 \\
\hline Acetaminophen & 14 & 11 & 2 & 0.1 & 95 & 298 \\
\hline Benzafibrate & 13 & 10 & 0.5 & 0.2 & 2 & 3.6 \\
\hline Trimethoprim & 13 & 10 & 1 & 0.4 & 11 & 25 \\
\hline Sulfamethazine & 12 & 10 & 1 & 0.055 & 4.5 & 34 \\
\hline
\end{tabular}

Source: Ontario MOE, 2010.

Table 6: Frequency of Detection and Overall Concentration Data for the Most Common Untreated

Source Water Contaminants

\begin{tabular}{|l|c|c|c|c|c|c|}
\hline Compound & $\begin{array}{c}\text { Number of } \\
\text { Detections }\end{array}$ & $\begin{array}{c}\text { Detection } \\
\text { Percentage } \\
(\%)\end{array}$ & $\begin{array}{c}\text { Detection } \\
\text { Limit } \\
\text { (ng/L) }\end{array}$ & $\begin{array}{c}\text { Median } \\
\text { (ng/L) }\end{array}$ & $\begin{array}{c}9^{\text {th }} \\
\text { Percentile } \\
\text { (ng/L) }\end{array}$ & $\begin{array}{c}\text { Maximum } \\
\text { (ng/L) }\end{array}$ \\
\hline Carbamazepine & 31 & $25 \%$ & 1 & 0.21 & 37 & 601 \\
\hline Ibuprofen & 19 & $15 \%$ & 0.5 & 0.33 & 12 & 25 \\
\hline Gemfibrozil & 18 & $15 \%$ & 1 & 0.5 & 2 & 4 \\
\hline BPA & 15 & $12 \%$ & 2 & 0.14 & 17 & 99 \\
\hline
\end{tabular}

Source: Ontario MOE, 2010.

For the most frequently detected contaminants, the MOE compared relative concentrations of compounds in source water samples against the finished water samples (Ontario MOE, 2010). Concentrations for finished water samples were consistently lower, which suggested that Ontario's 
water treatment plants reduce "the most frequently detected compounds to some degree. However, these observations were restricted to parent compounds and did not consider metabolites or degradation products" (p.1). Therefore, Ontario's wastewater treatment plants are able to remove some, but not all, of the PhACs. The level of elimination and degradation during the treatment processes in Ontario is unknown. This evidence was published in 2010, and no public report or research paper from the MOECC to follow-up on this study has been performed. However, in 2011 the Ministry of the Environment worked with $\mathrm{CH} 2 \mathrm{M}$ Hill to complete a report on technologies to reduce nonconventional contaminants at municipal sewage treatment plants (which included PhACs). The report, entitled Literature Review and Jurisdictional Practices of Technologies to Reduce Non-Conventional Contaminants at Municipal Sewage Treatment Plants, was shared with this author by multiple study participants during the expert consultation. While experts claimed this report is in the public domain, it could not be located with conventional internet search tools. It is discussed in further detail in section 4 of this study.

\subsubsection{Hospital and Long-Term Care Home Effluent}

In 2012, the first study done on Canadian hospital effluent was published; it evaluated nine PhACs from two hospitals and two long-term care homes in southern Ontario (Khan and Nicell, 2015; Riaz ul Haq et al., 2012). The goal of this study was to measure the "occurrence, mass flows and day-today variability of pharmaceutical compounds in healthcare facility effluents, and investigate the relative contributions of target pharmaceuticals by healthcare facilities to the overall mass loading of the respective WWTPs [wastewater treatment plants]" (Riaz ul Haq et al., 2012, p. 141). The authors found that healthcare facilities contributed a large proportion of overall loading for antibiotic compounds in municipal wastewater treatment plants (ciprofloxacin from long-term care homes and hospitals contributed $37 \%$ and $26.7 \%$, respectively, to overall loading - see Table 7$)$. The higher levels of antibiotics in hospital effluent are likely because a large amount of antibiotics are administered in 
hospitals, which is not surprising; in 1999, about one quarter of the antibiotics administered to

Europeans were consumed within hospitals (Kummerer, 2001).

Table 7: Loading of Select PhACs From Two Hospital and Two Long-Term Care Facilities (\% Averaged Over One Week)

\begin{tabular}{|c|c|c|c|c|c|c|c|c|}
\hline \multirow[b]{2}{*}{ Target compound } & \multicolumn{2}{|c|}{ HS, to WWTP-HS, } & \multicolumn{2}{|c|}{$\mathrm{HS}_{2}$ to WWTP-HS } & \multicolumn{2}{|c|}{ LTC, to WWTP-LTC, } & \multicolumn{2}{|c|}{ LTC $_{2}$ to WWTP-LTC 2} \\
\hline & Min & Max & Min & Max & Min & Max & Min & $\operatorname{Max}$ \\
\hline Ciprofloxacin & 7.5 & 26.7 & $<1$ & $<1$ & $<1$ & 2 & $<1$ & 37 \\
\hline Sulfamethoxazole & 2 & 5 & 2 & 5.6 & $<1$ & 1 & $<1$ & 2 \\
\hline Trimethoprim & 1.5 & 3 & 3. & 8.6 & $<1$ & 4.5 & 1 & 12 \\
\hline Acetaminophen & 2 & 3 & $<1$ & $<1$ & $<1$ & $<1$ & 1 & 2 \\
\hline Carbamazepine & $<1$ & 1. & $<1$ & $<1$ & $<1$ & $<1$ & $<1$ & 1 \\
\hline Metoprolol & 2.5 & 13 & $<1$ & $<1$ & $<1$ & 4.5 & $<1$ & 2 \\
\hline Venlafaxine & 2 & 3 & $<1$ & 3.5 & $<1$ & 1 & $<1$ & 2 \\
\hline $\mathrm{N}$-desmethylvenlafaxine & 2 & 6 & $<1$ & $<1$ & $<1$ & $<1$ & $<1$ & 1 \\
\hline$O$-desmethylvenlafaxine & 1 & 3 & $<1$ & $<1$ & $<1$ & $<1$ & $<1$ & 2 \\
\hline
\end{tabular}

Source: Riaz ul Haq et al., 2012

In 2015, Khan and Nicell also published a paper that sought to quantify the exposure of Canadians to pharmaceuticals based on predicted concentrations of PhACs in Canada, derived from Canada-specific prescription data. As part of their analysis, the authors evaluated whether or not hospitals were an important point source for these contaminants based on hospital prescription rates for each evaluated PhAC. The observed environmental loading from hospitals accounted for less than $10 \%$ of the total environmental load from all sources considered, yet hospitals were an important point source for certain PhACs like antibiotics, which corroborates the 2012 findings by Riaz ul Haq et al. Khan and Nicell concluded that more monitoring and measurements are needed.

This leads one to consider what effect the loading of antibiotics into municipal wastewater streams could have on the environment. As mentioned earlier, some scientists believe that antibiotics may accumulate in the environment and contribute to antibiotic resistance if gene transfer to pathogenic bacteria occurs (Kim and Aga, 2007). In terms of human health, vulnerable members of the 
population could be exposed to trace amounts of antibiotics in the water, such as infants consuming formula that was mixed with drinking water (Collier, 2012). In terms of the environment, antibiotics can negatively affect the population of native denitrifying bacteria in soil, which are important for soil health (Underwood et al., 2011). However, as indicated by Khan and Nicell (2015), more monitoring and measurement work must be done to evaluate the discharge of effluent from hospitals and long-term care homes in Ontario, particularly with respect to antibiotics.

\subsubsection{Environmental Effects of PhACs}

PhACs in the water cycle have been identified as a potential concern for the natural environment for some time (Daughton and Ternes, 1999; Fram and Belitz, 2011). Over the last decade, the environmental impacts of PhACs have been explored in more depth (Fent et al., 2006; Sumpter, 2009; Arnold et al., 2013). This section therefore focuses on reported adverse environmental effects in Ontario from exposure to PhACs.

Since PhACs are designed to influence biological activity at low concentrations, the potential for these contaminants to influence non-target wildlife is a significant environmental concern (Arnold et al., 2013). One specific example was documented by Kidd et al. in 2007, where the authors investigated whether low-level, chronic exposure to a synthetic estrogen could have an adverse impact on populations in the wild. The study took place in the Experimental Lakes Area in northwestern Ontario. The fathead minnow (Pimephales promelas), a common North American fish, was exposed to low

concentrations (5-6 ng $\left\llcorner^{-1}\right.$ ) of $17 \alpha$-ethynyl estradiol (EE2), which is a common synthetic estrogen used in female birth control pills or hormone replacement therapy, over the course of several years. Reproductive failure in the population began after the second season of hormone additions and continued for two years following the final addition of hormones to the lake. Feminization of male fish, changes on gonadal development, and an observed change in the vitellogenin (a precursor protein for 
female egg production) were observed and are all believed to be a factor causing the collapse of this fish population. Such observations demonstrate that concentrations of estrogens and related compounds in freshwaters can seriously impact the sustainability of natural populations. A recognized case of PhACs influencing aquatic organisms in the wild can be found further afield in the United Kingdom, where the feminization of male fish in rivers was associated with the steroid estrogens from domestic sewage (Gross-Sorokin et al., 2005).

In 2012, Ahmed Al-Ansari from the University of Ottawa published a PhD thesis that examined bioaccumulation of $17 \alpha$-ethyl estradiol (EE2). Using data collected by field and laboratory work, AlAnsari found evidence of bioaccumulation, with an average measurement of $1.5 \mathrm{ng} / \mathrm{g} \mathrm{EE} 2$ in the shorthead redhorse suckers (Moxostoma macrolepidotum) of Ontario's St. Clair River.

Municipal wastewater effluent has also been shown to have an effect on freshwater wildlife, and one specific example of this can be found in field-deployed freshwater mussels in Ontario's Grand River (Gillis et al., 2014). Ontario's Grand River acts as a large drainage basin near the northern shore of Lake Erie and this watershed is home to thirty municipal wastewater treatment plants. This area has historically been considered one of the most important habitats for freshwater mussels in Canada; over twenty-five different mussel species call it home. In recent years, however, the population diversity of native mussels has decreased. Gillis et al. (2014) examined the direct impact of municipal wastewater effluent on freshwater mussels in the Grand River. Caged mussels were deployed by researchers both upstream and downstream of a municipal wastewater treatment's effluent stream. The wastewater treatment plant serves approximately 230,000 people and has a secondary (activated sludge) treatment process. After the mussels were exposed to the effluent stream for four weeks there was an observed increase in physiological stress. The notable difference between upstream and downstream mussels indicated that wild mussels with chronic exposure to municipal wastewater effluent streams in this location would be negatively impacted by the wastewater effluent stream. 
These examples show that untreated municipal wastewater effluent for Ontario can stress and harm ecosystems, while specifically $17 \alpha$-ethyl estradiol can bioaccumulate in native Ontario fish species and result in male fish feminization which can seriously impact the sustainability of natural fish populations. This leads one to consider what type of risk PhACs pose to the environment, and what information gaps remain for this topic.

\subsubsection{Information Gaps Documented During the Literature Review}

While the technologies to detect PhACs have improved and numerous reports that measured PhACs exist, there are still several gaps in our knowledge. First, the literature has identified a need to systematically collect data and define baseline concentration levels for various PhACs in the environment (Becker, 2010; Riaz ul Haq et al., 2012; Khan and Nicell, 2015). Published articles typically focus on only a handful of PhACs at a time, which is not representative of real conditions in the natural environment; reported concentration data are incomplete for several widely prescribed PhACs; and inconsistent analytical methods and reporting formats are used across different studies, which limit the ability to combine studies and extrapolate results (Kostich et al., 2014). Inconsistent reporting and measurement techniques make comparisons between different published papers especially difficult and in certain cases some previously published data could be unreliable. ${ }^{3}$ For example, in 2003 Vanderford et al. published a paper that outlined a method to measure endocrine disruptors, pharmaceuticals, and personal care products in water using Liquid Chromatography/Tandem Mass Spectrometry (LC-MS/MS). However, in 2006, Vanderford and Snyder, two of the original authors from the 2003 publication, demonstrated a potential for false measurements when using their previously published method and

\footnotetext{
${ }^{3}$ In recent years, there has been more emphasis on standardizing analytical methods and identifying and prioritizing the PhACs of most environmental concern. For example, in 2007 the U.S. EPA's Office of Water established Method 1694, which is a lab-validated and peer-reviewed screening method for 73 pharmaceuticals or personal care products; it essentially acts as a presence/absence test. In 2008, Kostich and Lazorchak began work prioritizing PhACs of the most potential environmental impact, and with fellow researcher Batt they published an analytical method to target these priority PhACs (Kostch and Lazorchak, 2008; Batt et al. 2008).
} 
the authors recommended using isotope dilution to correct for signal variability. There may also be an opportunity for wastewater plant operators to undertake a systematic sampling process to form a baseline dataset, if a comprehensive dataset does not already exist. Justice O'Connor's Recommendation 32 from the Walkerton Inquiry stated that the "provincial government should support major wastewater plant operators in collaborative studies aimed at identifying practical methods of reducing or removing heavy metals and priority organics (such as endocrine disruptors) that are not removed by conventional treatment" (O'Connor, 2002, p. 23).

Second, the precautionary principle states that "where there are threats of serious or irreversible damage, lack of full scientific certainty shall not be used as a reason for postponing costeffective measures to prevent environmental degradation" (United Nations General Assembly, 1992). This principle is reaffirmed in the Canadian Environmental Protection Act, 1999. So while additional research into this problem is ongoing and certainly beneficial, the fact that PhACs have influenced some aquatic organisms suggests that management action should at least be considered. There is therefore a need to determine if experts in this area are satisfied with the status quo. In 2006, two Ontario academics, Doerr-MacEwen and Haight, published a report to "evaluate the scope of the issue and possible management strategies from the perspectives of expert stakeholders, drawn from government, academia, and the pharmaceutical and consulting industries" (p. 853). Experts included those associated with universities, government, industry, and consulting. Their interviewees generally acknowledged PhACs are a concern, and several suggestions for governments interested in managing the risks of PhACs were put forward. Almost one decade later, Ontario has implemented just two of the suggested management strategies (O. Reg. 298/12, Ontario's pharmaceutical return program, and the last primary wastewater treatment plant in Ontario has been upgraded to secondary treatment), and much work has been published on this topic (Google Scholar shows over 100,000 results on this topic for the period covering 2007 and 2015; search term: "pharmaceuticals" AND "environment" AND "risk"). 
Yet no real follow-up action has been taken in Ontario, nor has any subsequent study been performed to see if stakeholders still believe more management action could be taken.

This lack of policy direction related to PhACs in Ontario water, combined with the fact that some policy action has been produced in British Columbia (discussed further in section 2.3 of this thesis), is therefore one of the driving forces behind this research. In the two following sections, risk management principles are examined to see how they may apply to PhACs in the environment, and then existing legislation and policies in Ontario and abroad are examined.

\subsection{A Review of Risk Management Principles Related to PhACs in the Environment}

The heart of this investigation is centered on risk and whether or not there is consensus among Ontario stakeholders regarding the environmental risks that PhACs pose, and whether or not Ontario should take action to manage this risk. The following section therefore reviews concepts related to defining environmental risks, understanding uncertainty when evaluating risk, and how the precautionary principle can help incorporate risk analysis/management when making environmental decisions and developing public policies.

What is "risk"? The definition of this term is subject to debate across different professional fields (Pate-Cornell, 1996; Callreus, 2005; Smith and Fischbacher, 2009). One broad definition of risk is "the probability of a future loss" (Byrd and Cothern, 2000). However, this definition can oversimplify certain issues because risk is a complex topic that involves three key considerations: the frequency, consequence, and perception of a loss after an event (Canadian Standards Association, 1997). The Canadian Standards Association defines risk as "the chance of injury or loss as defined as a measure of the probability and severity of an adverse effect to health, property, the environment, or other things of value" (p. 3). This definition corresponds with many published, peer-reviewed articles on environmental 
science and policy (Pate-Cornell, 1996; Kriebel et al., 2001; Mahmoudi et al., 2013), and is consequently used in this study.

Even with a definition for risk, incorporating risk considerations and uncertainty into decisionmaking is difficult. As part of the 1990 Clean Air Act Amendments in the United States, the Presidential/Congressional Commission on Risk Assessment and Risk Management (the "Commission") was formed to investigate and develop a process for how risk assessments would be used by the US Environmental Protection Agency for developing air quality regulations (The Presidential/Congressional Commission on Risk Assessment and Risk Management, 1997). Up until 1990, traditional evaluations had focused on a more specific chemical-by-chemical / medium-by-medium / risk-by-risk strategy, rather than on the goal to reduce overall collective risk. The Commission assembled in 1994 and included experts from a variety of different fields, such as public health and environmental organizations, academia, public policy, and industry. Three years later, in their 1997 final report, the Commission set out their developed risk management framework (see Figure 3). This framework defines a six-stage scalable process that:

- "Enables risk managers to address multiple relevant contaminants, sources, and pathways of exposure, so that threats to public health and the environment can be evaluated more comprehensively than is possible when only single chemicals in single environmental media are addressed.

- $\quad$ "Engages stakeholders as active partners so that different technical perspectives, public values, perceptions, and ethics are considered.

- $\quad$ "Allows for incorporation of important new information that may emerge at any stage of the risk management process" (The Presidential/Congressional Commission on Risk Assessment and Risk Management, 1997, p.i).

In this framework, an assessment of risks and options is undertaken once a problem is identified and it is during this initial stage that scientific knowledge is considered. Scientific evidence is therefore formally incorporated during the risk management process. (The Canadian Standards Association's risk management framework is similar in structure and shown in Figure 4). Yet, many experts often deal with complex systems that are difficult to understand and have some associated uncertainty. 
Environmental scientists in particular deal with biological systems that involve many different interactions, which can make it difficult to prove causation (Kriebel et al., 2001). Accurate communication and interpretation across different disciplines can thus be challenging.

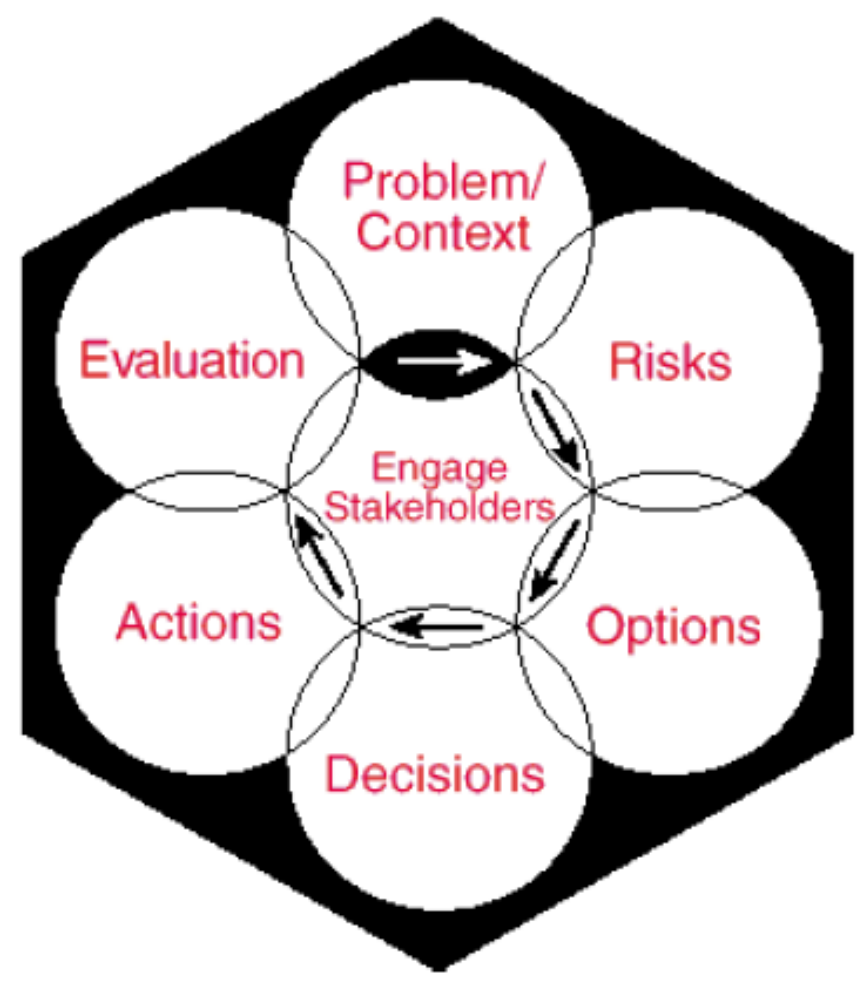

Figure 3: Risk Management Framework

Source: The Presidential/Congressional Commission on Risk Assessment and Risk Management, 1997 


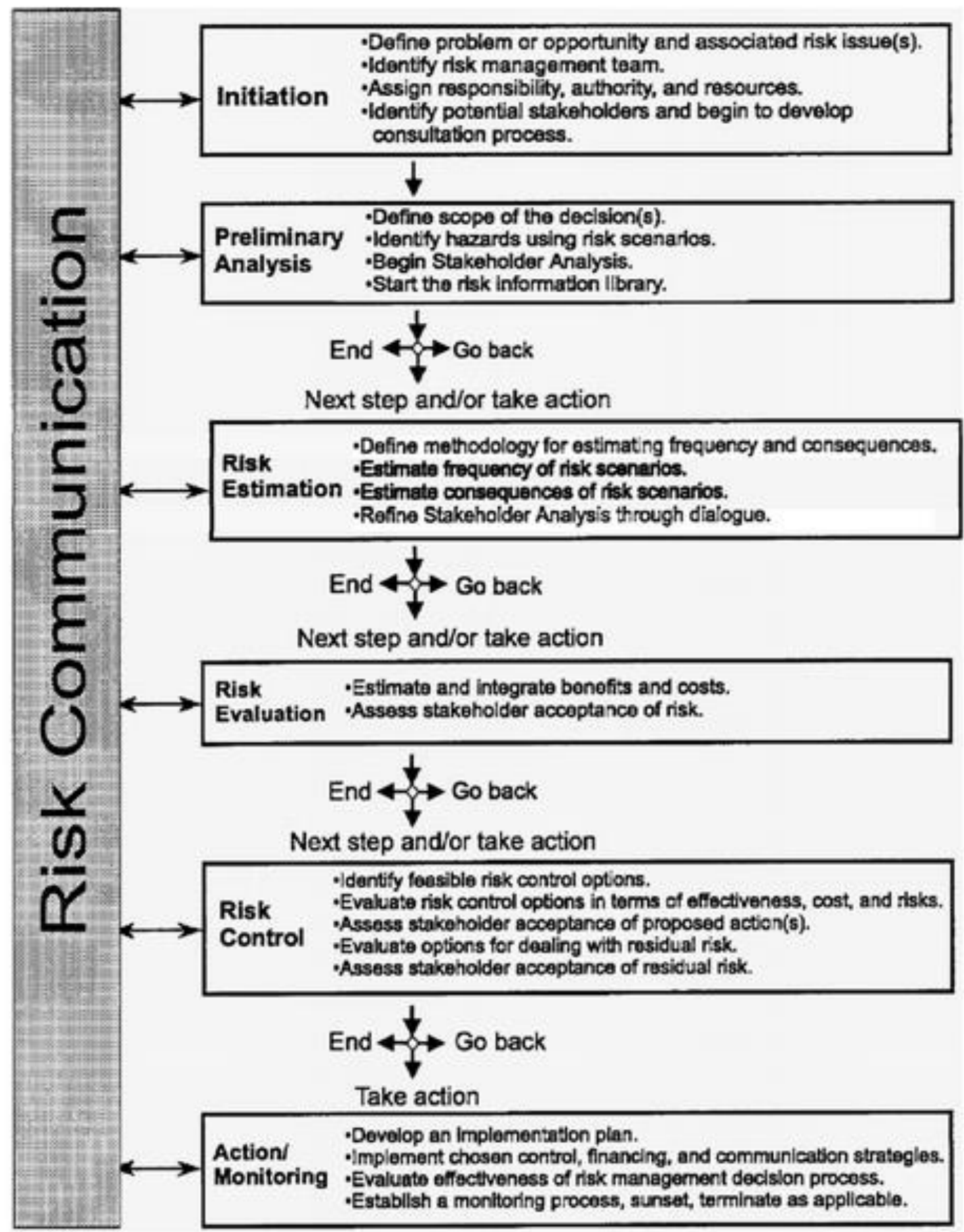

Figure 4: Steps to a Risk Management Decision-Making Process

Source: Canadian Standards Association, 1997.

Given this challenge, the precautionary principle can act as a guide during decision making when there is a certain level of risk and scientific uncertainty (Callreus, 2005). It states that "where there are 
threats of serious or irreversible damage, lack of full scientific certainty shall not be used as a reason for postponing cost-effective measures to prevent environmental degradation" (United Nations General Assembly, 1992). It can encourage scientists to examine whole systems, multiple causal relationships, and collaborate across disciplines. Central concepts within the precautionary principle include: taking preventive action in times of uncertainty; assigning proponents with the burden of proof; exploring alternatives to the potentially harmful activities; and increasing public participation and engagement during the decision-making process (Kriebel et al., 2001; Tickner and Geiser, 2004).

Given the evidence that trace concentrations of PhAC can have a negative effect on the environment, it is important to consider how this knowledge might be incorporated into decisionmaking that affects waterways and the role of the precautionary principle in that decision-making. The next section of this thesis examines what legislation and policies exist in Ontario that are specifically related to municipal wastewater treatment and discharge, as this is believed to be the primary source of PhACs to the environment. The section also includes an examination of certain jurisdictions that have attempted to manage PhACs in the environment. British Columbia is particularly noteworthy because it is a Canadian province that developed a Water Quality Guideline for the pharmaceutically active $17 \alpha-$ ethinylestradiol in 2009 (Nagpal \& Meays, 2009). Although not legally binding, the Water Quality Guideline must be considered by British Columbia's Ministry of the Environment for any decision that is made that could affect water quality (Water Protection \& Sustainability Branch, 2015). 


\subsection{Review of Relevant Legislation and Policies in Ontario and Other Selected Jurisdictions}

Environmental policies and programs in Canada are primarily led at the provincial level, and discharge from municipal facilities falls under provincial jurisdiction. Treatment requirements for Ontario's municipal sewage treatment facilities were reviewed in detail. However, since Canada also has a federal government and municipal governments, Ontario's legislation and policies were examined. The power for Ontario municipalities to pass sewer use by-laws, under the Municipal Act, 2001, was also reviewed.

In Canada, all three levels of government are involved in wastewater management and regulation. Municipalities provide wastewater treatment and can control what is discharged into the sewer through sewer use by-laws (CCME, 2006). Since provinces have legislative authority over municipal institutions, the discharge from municipal wastewater treatment facilities falls directly under provincial jurisdiction, hence the province is responsible for regulating wastewater treatment plants in Ontario (Ontario Ministry of the Environment and Energy, 1994). Adding to this complexity, wastewater effluent quality standards can be set by the federal government (Environment Canada, 2015).

In Ontario, wastewater treatment requirements for municipal and private sewage treatment facilities that discharge to surface waters are set out under the province's Guideline F-5 and Procedure F5-1. The discharge limits for sewage treatment plants vary depending on the receiving water. These documents address different design objectives, including biological oxygen demand $\left(\mathrm{BOD}_{5}\right)$, suspended solids, total phosphorous, and total ammonia nitrogen levels (the guidelines do not require the removal

or monitoring of pharmaceutical products). The assigned limits are based on the assimilative capacity of the receiving water, and specific limits are contained within each facility's Certificate of Approval. The Great Lakes' natural assimilative capacity for nitrogen introduces a specific issue for bordering jurisdictions, including Ontario. 
Under the direction of the International Joint Commission, [wastewater treatment plants] that discharge into the Great Lakes are required to reduce phosphorus, rather than nitrogen, as the limiting nutrient to avoid eutrophication in surface waters.

Because of the high assimilative capacity of the Great Lakes, most STPs discharging directly to them do not need to nitrify. In Ontario, then, there are many plants that nitrify and many plants that do not nitrify nor reduce total nitrogen (CH2M Hill, 2011 p. 2-3).

The Ontario Ministry of the Environment and Climate Change also maintains Provincial Water Quality Objectives that can be used to set wastewater treatment plant effluent limits in Certificates of Approval (CH2M Hill, 2011).

In addition to these guidelines, numerous Ontario municipalities have passed sewer use by-laws under Ontario's Municipal Act, 2001 (Kingsmore, 2013). Municipalities can set limits on what is discharged into local sewer systems through their by-laws. It is difficult to determine acceptable limits for PhACs in sewer systems because the concentrations that cause adverse effects have not been established; "this makes it difficult for municipalities to set limits for PhACs in wastewater discharged to sewers. It is also challenging to monitor whether households are flushing drugs down the drain/disposing in the garbage so enforcement would be an issue" (Kingsmore, 2013, p. 59). ${ }^{4}$

At the provincial level, O. Reg. 298/12, which manages post-consumer PhACs and sharps, came into force in 2012 (a sharp refers to needle, lancet, or other similar instrument for medical purposes) (Kingsmore, 2013). Under this regulation, a collection system in Ontario must be operated by the producers of pharmaceuticals and sharps. This is a form of extended producer responsibility program, where producers can design and implement their own waste diversion programs as long as it meets the requirements set out under the regulation (Environmental Commissioner of Ontario, 2013). While this

\footnotetext{
${ }^{4}$ In 1998, the Ministry of the Environment posted a policy proposal on Ontario's Environmental Registry to develop a Model Sewer Use By-Law (Ontario Ministry of the Environment, 1998). This built upon the 1988 version of a Model by-law for discharge to sewers. This policy proposal remains open on the Environmental Registry. As of 2004, about 260 of Ontario municipalities used by-laws and there was a considerable amount of variability between different municipal by-laws, some used MOE's 1988 Model, while other municipalities set their own limits (Environmental Commissioner of Ontario, 2004).
} 
does not directly influence policies related to PhACs in wastewater, it is a tool to reduce that amount of PhACs that are improperly disposed down drains.

Indeed, another tool that could help influence policy is Ontario's Drinking Water Surveillance Program (DWPS) (Ontario Ministry of the Environment and Climate Change, 2015). The Ministry of the Environment and Climate Change (MOECC) operates this voluntary monitor program in partnership with municipalities to collect data on untreated source (raw) water, treated drinking water and water from the distribution system for various Ontario locations. Each year, multiple samples are collected and tested for organic, inorganic, and radiological parameters, including emerging and unregulated contaminants. After reviewing the annual data for the $100,000+$ samples collected in 2012 , this author notes that the DWPS does not test or collect data for PhACs or hormones (available from Ontario's Open Data website: https://www.ontario.ca/data/drinking-water-surveillance-program). These contaminants could presumably be integrated into the water testing process because the DWPS already tests for other emerging and unregulated contaminants.

The federal government could regulate PhACs in a number of ways. It enforces the Fisheries Act, for example. Section 36(3) of this Act prohibits the release of deleterious substances into water frequented by fish. "This prohibition has been interpreted broadly by the courts" and can apply significant penalties even if an activity was approved by Fisheries and Oceans Canada or by provincial regulations (Ignasiak et al., 2014). However, there is no evidence that the Act has been used to apply to PhACs in the environment.

The federal government also enforces the Canadian Environmental Protection Act, 1999 (CEPA 1999). Under CEPA 1999, compounds like PhACs that are introduced into the Canadian marketplace have their environmental effects assessed under the New Substances Notification Regulations (NSNR) (Environment Canada, 2013). However, the NSNR "were developed with industrial substances in mind, 
such as floor cleaners and fire retardants, not substances regulated under the Food and Drugs Act, such as pharmaceuticals and cosmetics," so Environment Canada began developing environmental assessment regulations in 2001 that can address environmental concerns of new PhACs and cosmetics introduced into the Canadian marketplace (Environment Canada, 2013b). A working group was developed in 2006 to provide strategic advice on these new regulations; at the time of writing, these regulations have not been developed.

In the fall of 2015, the fourth session of the International Conference on Chemicals Management was held in Geneva (Environment and Climate Change Canada, 2016). Health Canada led the Canadian delegation, and in the conference they:

- " "adopted the "Overall Orientation and Guidance" for achieving the Strategic Approach to International Chemicals Management's 2020 goal for the sound management of chemicals, calling on all stakeholders to pursue additional initiatives;

- $\quad$ "initiated an intersessional process to prepare recommendations on the Strategic Approach beyond 2020, including possible measurable objectives in support of the post-2015 sustainable development agenda, and an independent evaluation of the Strategic Approach;

- $\quad$ "recommitted to continue work on existing emerging policy issues and other issues of concern. including endocrine-disrupting chemicals, lead in paint, hazardous substances in electrical and electronic equipment, nanotechnology and manufactured nanomaterials, perfluorinated chemicals, and chemicals in products, including a voluntary program on chemicals in products; and

- $\quad$ "agreed to work on pharmaceuticals in the environment as an emerging issue and on highly hazardous pesticides as an important area of concern." [emphasis added].

It is too soon to know how this will transpire, and if meaningful action will be taken, since this commitment was made only a few months ago.

\subsubsection{Policies from Other Selected Jurisdictions}

The section examines how other jurisdictions have approached managing PhACs in the environment. The following is not an exhaustive jurisdictional scan, rather it is a summary of three jurisdictions' policies or management strategies related to PhACs that differ from Ontario's. These 
jurisdictions were chosen based on research that suggested that these are some of the only jurisdictions formally acting to address this issue.

The selection of jurisdictions is supported by the $\mathrm{CH} 2 \mathrm{M}$ Hill report, discussed in section 4.4 of this thesis. Briefly, the 2011 report was commissioned by Ontario's Ministry of the Environment and Climate Change to perform a jurisdictional scan of practices for technologies to reduce non-conventional contaminants, such as PhACs. Sweden's environmental classification system for PhACs was noted. Switzerland's examination of a toilet to separate urine from centralized wastewater treatment plants was also highlighted. Therefore, Switzerland and Sweden were examined as jurisdictions that may have a public policy related to PhACs in place. While not mentioned specifically in the $\mathrm{CH} 2 \mathrm{M}$ Hill report, British Columbia was selected because it is a Canadian province that is typically considered a leader in environmental policies and has taken specific actions to reduce one PhAC.

\subsubsection{British Columbia}

In 2009, British Columbia published a Water Quality Guideline for the pharmaceutically active 17a-ethinylestradiol (Nagpal \& Meays, 2009). The report notes that PhACs are: globally distributed and ubiquitous; designed to alter biological functions; associated with influencing non-target organisms; and chronically toxic at concentrations found in the environment. Nagpal and Meays' Technical Report for the British Columbia government outlined evidence that estrogens and hormone regulators may negatively affect the environment, reviewed toxicity studies and data from the scientific literature, and included the following guideline:

For the protection of freshwater aquatic life, it is recommended that the 30-day average concentration of $17 \alpha$-ethinylestradiol (EE2) in water, based on 5 weekly samples, should not exceed $0.5 \mathrm{ng} \mathrm{L}^{-1}$ with no single value to exceed $0.75 \mathrm{ng} \mathrm{L}^{-1}$ (no more than $50 \%$ above the guideline value) (p.17). 
One specific example referred to in Nagpal and Meays' Technical Report is evidence from the experiment conducted in Ontario in 2007 by Kidd et al., where the authors investigated whether or not low-level chronic exposure to EE2 could have an adverse impact on wild fish populations. The study took place in northwestern Ontario's Experimental Lakes Area and, as discussed in section 2.1.8 of this thesis, reproductive failure in the population began after the second season of EE2 additions and continued for two years following the final addition of EE2 to the lake. Although not legally binding, the Water Quality Guideline must be considered by British Columbia's Ministry of the Environment when making any decision that could affect water quality (Water Protection \& Sustainability Branch, 2015).

\subsubsection{Sweden}

Labelling strategies and information dissemination are one way to address environmental concerns, and this is true in Sweden for PhACs (Stockholms Läns Landsting, 2014). Stockholm County Council recognizes that reducing the amount of PhACs in the environment is an important initiative, especially because of the precautionary principle. In 2003, the Environmental Department initiated the environmental hazard assessment, which classified PhACs according to their environmental risk and environmental hazard.

During 2005, the classification was extended to also cover an environmental risk assessment carried out by The Swedish Association of the Pharmaceutical Industry... The classification system is used in considering the environmental impact of ... pharmaceuticals for common diseases in Stockholm County Council, issued by the Drug and Therapeutics Committee. The classification is also available at the website ww.janusinfo.se/environment (Stockholms Läns Landsting, 2014, p. 1).

Although this program is voluntary, the majority of pharmaceutical companies have chosen to participate in the program ( $\mathrm{CH} 2 \mathrm{M}$ Hill, 2011). Environmental risk is based on the ratio between predicted environmental concentration of the substance in natural water systems (PEC) and the highest concentration of the substance that does not have a harmful effect on the environment (PNEC). Risk 
can range from insignificant $(\mathrm{PEC} / \mathrm{PNEC}<0,1)$ to high $(\mathrm{PEC} / \mathrm{PENC}>10)$. The only listed $\mathrm{PhAC}$ to receive a high risk assessment is ethinylestradiol, the same PhAC for which the British Columbian government has issued a Water Quality Guideline. This ranking system is available for medical doctors and patients, so both groups can consider the environmental impacts of medications.

\subsubsection{Switzerland}

In 2015, PhACs as pollutants were discussed at the fourth International Conference on Chemicals Management in Geneva, Switzerland (UNEP, 2015). Since only a fraction of chemicals have been extensively studied to understand their effects on the environment and human health, governments, industry, and NGOs met to commit to work on preventing unnecessary deaths and illnesses from exposure to harmful chemicals by assuring proper management of chemicals by 2020 . Environmentally persistent PhAC pollutants were one of six priority policy issues identified as requiring urgent action to protect human health.

In 2013, a paper was published that discussed a large-scale pilot project in Lausanne, Switzerland (Margot et al. 2013). The pilot plant used oxidation by ozone followed by sand filtration, and powdered activated carbon adsorption followed by a very fine filtration process. The researchers found both treatments significantly improved effluent quality, but "the PAC-UF treatment, despite its current higher cost, was considered to be the most suitable option, enabling good removal of most micropollutants and macropollutants without forming problematic by-products, the strongest decrease in toxicity and a total disinfection of the effluent" (p. 480). By performing this pilot, Swiss researchers were able to determine how an unconventional wastewater treatment plant would perform and remove PhACs, which can help Swiss policy-makers assess whether or not it is worthwhile to pursue this technology on a larger scale. 


\subsection{Summary of Literature Review}

Overall, there does not appear to be a clear policy leader in managing PhACs in the environment, and the actions taken by different jurisdictions demonstrate that there is still much uncertainty when it comes to regulating PhACs. For example, Sweden's voluntary rating program for PhACs is one way to increase the amount of information available for PhACs, but it is a voluntary information program only and does not directly reduce the amount of PhACs being released into the environment. British Columbia's guideline demonstrates a real concern related to the effects of $17 \alpha-$ ethinylestradiol (EE2), and while having a guideline in place is a start, the guideline itself is not legally binding.

It does seem, however, that several steps could be taken in Ontario to increase our level of understanding for PhACs in the environment, and to increase the public's awareness of this issue. Ontario has a water monitoring system in place that was used once before to monitor for select PhACs. It could then, arguably, be modified to include PhACs - at least priority PhACs like 17 $\alpha$-ethinylestradiol (EE2) - which may prove useful to scientists, policy-makers, and even the general public who want to know more PhACs in the environment. The provincial government could also perform a cost-benefit analysis on requiring nitrification processes for wastewater treatment plants that discharge to the Great Lakes, since these wastewater treatment plants do not typically contain this stage of wastewater treatment, but this is a stage during wastewater treatment when some PhACs are reduced. In addition, if municipal governments want to show action, they could consider passing by-laws that restrict PhACs from improper disposal through garbage and wastewater streams. Municipalities could also perform education campaigns on the proper disposal of PhACs (e.g., the "I Don't Flush" campaign, which is performed in partnership with York Region, Region of Peel, and support from the Health Products Stewardship Association).

Overall, this section has demonstrated that some jurisdictions have publicly acknowledged that PhACs in the environment pose some risk to aquatic organisms. While it is clear that some actions are 
needed to minimize risk, there is uncertainty about what action to take and how soon this action should be taken. Given this situation, this thesis sought to learn what experts currently believe can or should be done. 


\section{Evaluation Framework and Data Collection}

The literature review revealed that while the risks from PhACs in the environment are real, and some jurisdictions are taking action to address these risks, there is uncertainty about what to do and how soon to act. Hence, the next step in this research was to ask Ontario experts for their views on how to proceed.

Consulting with experts builds upon work performed by Doerr-MacEwen and Haight in 2006. In their work, information was collected from twenty-seven experts - twelve Canadian, five American, and ten European experts - who were selected through purposive sampling "to evaluate the scope of this issue [PhACs in the environment] and possible management strategies from the perspectives of... government, academia, and the pharmaceutical and consulting industries, involved in scientific research or policy and management activity, from Canada, the United States, and Europe" (Doerr-MacEwen and Haight 2006, p. 853). For their work, nine university professionals, twelve government professionals, and six industry professionals were consulted using structured interviews in person when possible, otherwise by telephone or email. Experts were chosen based on their professional background and experience, and therefore their results were not statistically significant but rather representative of the views for certain specialists. Doerr-MacEwen and Haight found that experts generally believed PhACs posed a concern for both ecosystem health and human health, though the primary concern was ecosystem health. The most effective management strategies identified included: using advanced wastewater treatment technologies, reducing over-prescriptions through educating medical professionals, and requiring all municipal wastewater treatment plants to perform secondary wastewater treatment.

These findings from 2006 act as a baseline for this thesis. Now, ten years later and with more scientific knowledge available, this study seeks to understand the perceived risk of pharmaceuticals to 
Ontario's aquatic environment, and to identify the challenges and opportunities for government action

to address this issue. Information that could answer this question has been gathered through an

extensive literature review provided in the previous chapter. Some of the most important observations

made thus far are outlined below:

a. PhACs have since been detected in water throughout the developed world, yet no consensus has been reached regarding the level of risk that PhACs pose to the environment (Doerr-MacEwen and Haight, 2006).

b. Effluent from wastewater treatment plants has been shown to contain PhACs and negatively affect freshwater wildlife (Gross-Sorokin et al., 2005; Fent et al., 2006; Kidd et al., 2007; Gillis et al., 2014).

c. Regulations dictate the level of wastewater treatment required for a certain region; there is no universal worldwide standard technology used to treat wastewater before it is released into the environment, however, Ontario requires secondary wastewater treatment in municipal wastewater plants (Ontario Ministry of the Environment and Energy, 1994; Lou et al., 2014).

d. It is difficult to combine studies and extrapolate results from literature; different studies may use different analytical methods to measure concentrations of contaminants (Kostich et al., 2014).

e. Measuring the level of risk for something depends on the probability and severity of an adverse effect to something of value, which in this case is the environment; however, biological systems involve many different interactions, which make it challenging to prove causation and therefore difficult to determine the probability and severity of an adverse effect (Kriebel et al., 2001).

f. Both British Columbia and Sweden have implemented policies that recognize certain PhACs pose a risk to the environment, particularly ethinylestradiol (Nagpal \& Meays, 2009, Stockholms Läns Landsting, 2014).

With this information, this thesis builds on the baseline information collected by Doerr-

MacEwen and Haight in 2006 and aims to reassess stakeholders' opinions. The next two chapters

provide the following information:

- An overview of how this study contacted its expert consultation;

- A summary of what information was collected during this consultation, including how it compares both to the literature review and the materials collected by Doerr-MacEwen and Haight in 2006;

- A summary of all significant findings collected during this research study; and finally,

- An outline of possible future next steps and/or considerations for researchers or public policy decision-makers. 


\subsection{Consultation with Stakeholders}

Stakeholder consultations are an important part of risk management (Canadian Standards Association, 1997; The Presidential/Congressional Commission on Risk Assessment and Risk Management, 1997). A stakeholder is either an individual, group, or organization that could be affected by an activity or policy decision (Canadian Standards Association, 1997). The following section provides an overview of the consultation with Ontario stakeholders for the topic of PhACs in water and the risk that these contaminants might pose to the environment.

\subsection{Methods}

As a first step for this consultation, a submission to Ryerson University's Ethics Committee was prepared. A copy of the recruitment materials, questionnaire, and interview guide for follow-up discussions was sent to Ryerson University's Ethics Committee. Refer to the Appendix A for a copy of all documents. This application received approval from the Chair of the Research Ethics Board on July 3, 2015 (REB \# 2014-266).

The original intent was to recruit participants using a snowball method. Replicating the recruitment method from Doerr-MacEwen and Haight's study, taken from Doerr-MacEwen's PhD thesis, publicly available information would be used to identify key initial contacts within different sectors using published literature. Specifically, experts were identified based on their contributions to published, peer-reviewed scientific papers and attendance at conferences and workshops (the attendance lists for government-hosted workshops on this topic are generally public, such as the workshop hosted by the Ontario provincial government in 2007, entitled Pharmaceuticals and Personal Care Products (PPCPS) in the Canadian Environment: Research and Policy Directions). Industry magazines (e.g., Water Canada) were also used to identify experts. Finally, websites for academic institutions, government offices, and municipal offices also helped identify experts (e.g., www.infogo.gov.on.ca and www.ec.gc.ca/scitech/default.asp?lang=En\&n=9D4E3F0C-1\&letter=A). 
After this, subsequent participants were to be recruited via the snowball method, where study participants refer the researcher to other potential participants. A snowball sample is not random and instead allows a researcher to target a specific group of individuals. The snowball approach was deemed appropriate for the topic under investigation because the study sought information from a specialized group of individuals in Ontario. The snowball sample is non-representative and can potentially lead to bias if experts refer only other like-minded experts to participate in the study. This potential bias was going to be addressed by carefully selecting the initial study participants using two criteria questions prior to contacting participants: (1) In which sector is this expert employed? (2) Based on previous work projects or already published material by this expert, does the expert appear to have a positive, negative, or neutral view of this environmental topic?

This initial approach had to be amended, however, because the original rate of referral for this study was relatively poor. During the initial recruitment phase for this study ("Phase 1" took place in August and September of 2015), fourteen recruitment letters were sent to contacts as identified, but only four agreed to participate in this study, and the snowball method produced only three successful referrals. Based on this low conversion rate, a second recruitment phase was undertaken in fall 2015 and early 2016 ("Phase 2" ran from October 2015 to January 2016). During the second phase of recruitment, eleven recruitment letters were sent to experts. Three more experts for this study were successfully recruited, and no new experts were acquired by way of the snowball method.

Hence, in total, ten experts initially agreed to participate in this research. Three experts withdrew from the study, therefore only seven questionnaires were completed by experts in Ontario. (Of note, while the PhD thesis by Doerr-MacEwen recruited twenty-seven experts, only twelve were based in Canada. Therefore, recruiting seven experts for this study appears reasonable because this study focused on management opportunities for human pharmaceuticals in Ontario's environment, and recruited experts from Ontario only). Combined, the group's total number of years of experience is fifty, 
and the median number of years of experience in their current roles is seven. These numbers are conservative because the question asked respondents how long they have been working in their current position, not how long they have been working in this field of specialization.

Two follow-up interviews were completed with two of the seven questionnaire respondents. The purpose of the follow-up interviews was to clarify earlier responses; hence, other follow-up interviews were unnecessary because no other responses required clarification.

A summary of recruitment efforts and results is shown in Table 8. As shown on the table, these experts represented a variety of different viewpoints. The majority of study participants were recruited through purposive sampling, which matches the recruitment method used in Doerr-MacEwen and Haight's study from 2006.

Table 8: Summary of Recruitment

\begin{tabular}{|c|c|c|c|c|c|c|c|}
\hline 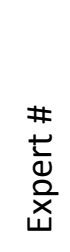 & 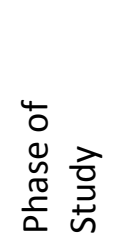 & 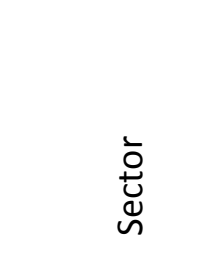 & 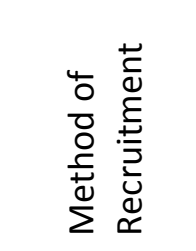 & $\begin{array}{ll}\frac{7}{0} & \frac{\pi}{\sqrt{0}} \\
\frac{0}{0} & \frac{d}{4} \\
i \frac{1}{4} & 0\end{array}$ & 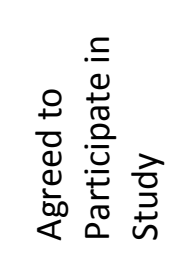 & 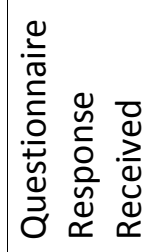 & 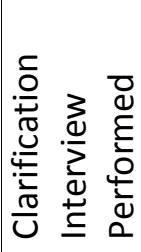 \\
\hline 1 & 1 & Government & Email & Environmental Toxicology & No & & \\
\hline 2 & 1 & University & $\begin{array}{l}\text { Email \& } \\
\text { Telephone }\end{array}$ & Drinking water treatment & $\begin{array}{l}\text { No } \\
\text { response }\end{array}$ & & \\
\hline 3 & 1 & Government & Email & Wastewater Operations & No & & \\
\hline 4 & 1 & University & Email & Drinking water treatment & Yes & Yes & Yes \\
\hline 5 & 1 & University & $\begin{array}{l}\text { Email \& } \\
\text { Telephone }\end{array}$ & Drinking water treatment & $\begin{array}{l}\text { No } \\
\text { response }\end{array}$ & & \\
\hline 6 & 1 & $\begin{array}{l}\text { University \& } \\
\text { Industry }\end{array}$ & $\begin{array}{l}\text { Email \& } \\
\text { Telephone }\end{array}$ & Drinking water treatment & $\begin{array}{l}\text { No } \\
\text { response }\end{array}$ & & \\
\hline 7 & 1 & Industry & Email & Wastewater operations & No & & \\
\hline 8 & 1 & Industry & $\begin{array}{l}\text { Email \& } \\
\text { Telephone }\end{array}$ & Pharmaceutical Science & Yes* & No & \\
\hline 9 & 1 & Government & Email & Risk Assessment & No & & \\
\hline 10 & 1 & Industry & Email & $\begin{array}{l}\text { Drinking water \& } \\
\text { environmental } \\
\text { contaminant treatment }\end{array}$ & Yes & Yes & \\
\hline 11 & 1 & Government & Referral & Wastewater Engineering & Yes & Yes & \\
\hline
\end{tabular}




\begin{tabular}{|c|c|c|c|c|c|c|c|}
\hline 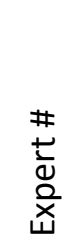 & 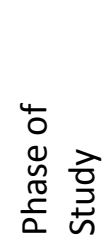 & 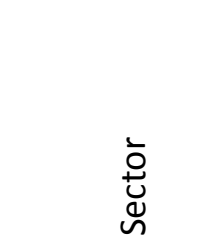 & 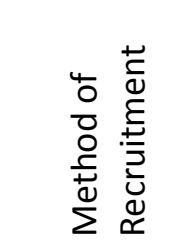 & 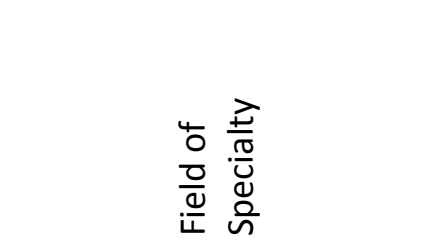 & 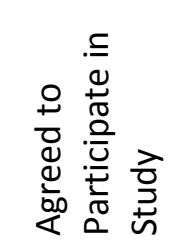 & 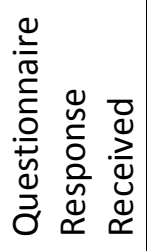 & 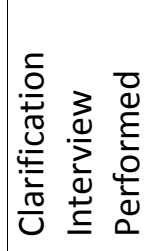 \\
\hline 12 & 1 & Government & Referral & $\begin{array}{l}\text { Environmental } \\
\text { Engineering and } \\
\text { Chemistry }\end{array}$ & Yes & Yes & \\
\hline 13 & 1 & Industry & Referral & $\begin{array}{l}\text { Wastewater treatment } \\
\text { plant process engineering } \\
\text { and facility design }\end{array}$ & Yes & Yes & Yes \\
\hline 14 & 1 & University & $\begin{array}{l}\text { Email \& } \\
\text { Telephone }\end{array}$ & Environmental Toxicology & Yes* & No & \\
\hline 15 & 1 & Government & $\begin{array}{l}\text { Email \& } \\
\text { Telephone }\end{array}$ & $\begin{array}{l}\text { Ecotoxicology and } \\
\text { Immunotoxicology }\end{array}$ & $\begin{array}{l}\text { No } \\
\text { response }\end{array}$ & & \\
\hline 16 & 1 & University & $\begin{array}{l}\text { Email \& } \\
\text { Telephone }\end{array}$ & Water quality protection & $\begin{array}{l}\text { No } \\
\text { response }\end{array}$ & & \\
\hline 17 & 1 & Industry & Email & Water quality & No & & \\
\hline 18 & 2 & Industry & $\begin{array}{l}\text { Email \& } \\
\text { Telephone }\end{array}$ & Engineer & $\begin{array}{l}\text { No } \\
\text { response }\end{array}$ & & \\
\hline 19 & 2 & University & $\begin{array}{l}\text { Email \& } \\
\text { Telephone }\end{array}$ & $\begin{array}{l}\text { Environmental } \\
\text { Engineering }\end{array}$ & $\begin{array}{l}\text { No } \\
\text { response }\end{array}$ & & \\
\hline 20 & 2 & University & $\begin{array}{l}\text { Email \& } \\
\text { Telephone }\end{array}$ & $\begin{array}{l}\text { Wastewater treatment } \\
\text { technologies and } \\
\text { engineering }\end{array}$ & No & & \\
\hline 21 & 2 & Government & Email & $\begin{array}{l}\text { Environmental public } \\
\text { policy }\end{array}$ & Yes & Yes & \\
\hline 22 & 2 & $\begin{array}{l}\text { Municipal } \\
\text { Utility }\end{array}$ & $\begin{array}{l}\text { Email \& } \\
\text { Telephone }\end{array}$ & Wastewater treatment & $\begin{array}{l}\text { No } \\
\text { response }\end{array}$ & & \\
\hline 23 & 2 & $\begin{array}{l}\text { Municipal } \\
\text { Utility }\end{array}$ & $\begin{array}{l}\text { Email \& } \\
\text { Telephone }\end{array}$ & Wastewater treatment & $\begin{array}{l}\text { No } \\
\text { response }\end{array}$ & & \\
\hline 24 & 2 & $\begin{array}{l}\text { Municipal } \\
\text { Utility }\end{array}$ & $\begin{array}{l}\text { Email \& } \\
\text { Telephone }\end{array}$ & Wastewater treatment & $\begin{array}{l}\text { No } \\
\text { response }\end{array}$ & & \\
\hline 25 & 2 & Pharmacist & $\begin{array}{l}\text { Email \& } \\
\text { Telephone }\end{array}$ & Clinical pharmacology & $\begin{array}{l}\text { No } \\
\text { response }\end{array}$ & & \\
\hline 26 & 2 & Pharmacist & Email & Pharmacist & Yes & Yes & \\
\hline 27 & 2 & $\begin{array}{l}\text { Municipal } \\
\text { Utility }\end{array}$ & Email & Wastewater treatment & Yes & No** & \\
\hline 28 & 2 & $\begin{array}{l}\text { Municipal } \\
\text { Utility }\end{array}$ & $\begin{array}{l}\text { Email \& } \\
\text { Telephone }\end{array}$ & Wastewater treatment & $\begin{array}{l}\text { No } \\
\text { response }\end{array}$ & & \\
\hline
\end{tabular}

* Withdrew without reason and no response upon follow-up.

** Voluntarily withdrew from this study. 
The structured questionnaire was created by this author and can be found in Appendix A. All participants received the same version of the questionnaire. Questions were based on Doerr-MacEwen and Haight's findings from 2006, and this author's findings from the literature review (refer to the itemized list in section 3 for a summary), including this author's identified information gaps related to data collection uncovered during the literature review (discussed in section 2.1.9 of this thesis). In addition, if experts had any other opinions related to the thesis question under investigation, or any other aspect of this study, they were asked to provide further details. The questionnaire also asked experts about their backgrounds, baseline level of knowledge for this subject area, and knowledge about actions taken in other jurisdictions.

The questionnaires were designed to be answered at the convenience of the participants and to take approximately 30 minutes to complete. This amount of time allowed professionals to complete this work during a normal day in the office. In the event that an answer was confusing, or required further follow-up discussions, an interview guide was developed to assist this author with performing any necessary follow-up discussions (see Appendix A). Two optional follow-up interviews were conducted, one face-to-face (expert \# 4) and the other by phone (expert \# 13).

\subsection{Summary of Expert Consultation}

The experts included in this study were: one industry consultant working in the area of wastewater treatment plant process engineering and facility design; three staff from within government offices (two at the provincial level working in wastewater engineering and environmental public policy, and one at the federal level working in environmental engineering and chemistry with a specific focus on wastewater treatment); one industry expert who specializes in environmental contaminant treatment; one pharmacist; and one academic expert specializing in drinking water treatment. Several municipal utilities were also contacted, however, only one responded to this author's numerous inquiries. That municipal utility expert agreed to participate in the study, but after spending some time working on the 
questionnaire, the expert indicated that they were unfamiliar with this subject matter and subsequently withdrew from the study. The expert referred this author to an external consulting firm for more technical expertise and knowledge; the referred consulting firm was the same that participated in Phase 1 of this study.

Once questionnaires were received, they were numbered and author information was stripped, so that a blind analysis could be conducted. For the blind analysis, answers were then taken from the numbered questionnaires and placed into a Microsoft Excel document. Information from each numbered respondent was considered separately by looking at how the collected information compared to published literature. Answers were then cross-checked against those from other participants in order to identify similarities and differences in responses. Two questionnaires contained responses that required clarification, therefore two follow-up interviews were performed. As a final step, author information was reintroduced, and results were summarized (see section 4). 


\section{Findings Collected During Expert Consultation}

\subsection{Risk PhACs pose to the Aquatic Ecosystem and/or Human Health}

One of the initial survey questions asked participants to indicate if they are familiar with trace concentrations of PhACs in the environment. The question then asked participants if trace concentrations of PhACs could pose a risk to certain receptors (e.g., the aquatic ecosystem, the general human population, and/or vulnerable members of society such as the elderly, infants, and those with compromised immune systems). If a risk was posed to a receptor, experts were asked to rate this risk using a scale of $0-5$ (where $0=$ no risk, 5 = highest risk).

As expected - because experts were identified through purposive sampling or referrals - all study participants were familiar with the issue of PhACs being detected throughout the water cycle at low concentrations. All but one participant indicated that trace PhACs in the water cycle pose a risk to aquatic ecosystems. The median assigned level of risk to aquatic ecosystems was 3 out of 5; one respondent indicated the level of risk was 4 out of 5, which was the highest assigned level of risk to any of the identified receptor types.

Experts were divided on whether or not trace PhACs pose a risk to human health. Two respondents indicated no, two were uncertain, and three indicated yes. Most participants assigned a rating of 1 out of 5 to the level of risk posed by trace PhACs to the general human population. The highest identified level of risk for this receptor type was 2 out of 5.

Some consensus was reached when asked if PhACs pose a threat to vulnerable human populations (e.g., the elderly, the very young, or those with suppressed immune systems). Four experts indicated yes, and assigned a median risk score of 2.75 out of $5 .^{5}$ Two of the other participants indicated

\footnotetext{
${ }^{5}$ Respondent indicated the risk was 2-3, so this author assigned a rating of 2.5. Of the four experts who indicated yes, rating of risk was: $3,3,2$, and 2.5 .
} 
uncertainty as to whether or not PhACs could affect vulnerable populations. The remaining expert indicated no risk was expected for vulnerable populations exposed to trace levels of PhACs.

\subsection{PhACs and the Precautionary Principle}

As outlined in section 2.2 of this thesis, this author has found scientific evidence showing trace PhACs can have a negative effect on the environment. This author therefore believes that the latest scientific knowledge on PhACs in the environment should be incorporated into decision-making that affects waterways, and possible management actions should be considered using the precautionary principle. All experts were asked about their views of the precautionary principle as it relates to PhACs in the environment; answers from experts were mixed.

Two experts indicated that the precautionary principle should not apply to PhACs in the environment and each expert provided a slightly different rationale. One expert (\#11), indicated that the impacts to certain aquatic organisms can be reversed, thus not meeting part of the definition of the precautionary principle ("where there are threats of serious or irreversible damage, lack of full scientific certainty shall not be used as a reason for postponing cost-effective measures to prevent environmental degradation" [United Nations General Assembly, 1992]). Expert \# 26 expert suggested that the concentration of PhACs at current levels does not pose a serious nor irreversible threat at this time: "No. First of all, 'threats of serious or irreversible damage' have less application to current level of pharmaceutical contaminants. Secondly, safety of those affected by environmental degradation should be emphasized over "cost-effective measures."

Conversely, four of the seven participants believed this issue in some way is related to the precautionary principle. Two felt it was straightforward and should indeed fall under the precautionary principle (see responses from experts \# 13 and \# 21 in Table 9). Three other respondents agreed that, in principle, the precautionary principle should be applied to PhACs in the environment, but as expert \# 4 
put it, "In principle, yes, but the devil is in the details: in my opinion the 'threat of serious or irreversible damage' is not clear at the concentrations present. The studies done at the experimental lakes certainly showed the potential for damage at high concentrations, but extrapolating to typical concentrations is uncertain" [emphasis added]. Expert \# 13 also emphasized that more information is needed to address this problem: "Yes. Since there is a potential for pharmaceuticals to be an actual threat although we are still trying to figure that out."

Difficulty extrapolating results, a limited supply of water and money, and the fact that some PhACs are critical for human health, are all factors that complicate application of this principle to management of PhACs in the environment.

Table 9: View of the Precautionary Principle as it Relates to PhACs in the Environment (Responses to Question \# 8)

\begin{tabular}{|c|l|}
\hline $\begin{array}{c}\text { Expert } \\
\#\end{array}$ & $\begin{array}{l}\text { Comments on whether or not the precautionary principle applies to PhACs in } \\
\text { the environment }\end{array}$ \\
\hline 4 & $\begin{array}{l}\text { In principle, yes, but the devil is in the details: in my opinion the "threat of serious or } \\
\text { irreversible damage" is not clear at the concentrations present. The studies done at the } \\
\text { experimental lakes certainly showed the potential for damage at high concentrations, but } \\
\text { extrapolating to typical concentrations is uncertain. }\end{array}$ \\
\hline 10 & $\begin{array}{l}\text { Yes, in an ideal world in which water and money are unlimited, the precautionary } \\
\text { principle would be applied. However, in cases where acute water scarcity exists, and the } \\
\text { danger of not having sufficient water supply exists, then scientists must apply the best } \\
\text { knowledge available to make informed decisions about risk. In potable reuse, for } \\
\text { example, it could be claimed that not enough is known about the ultra-low levels of } \\
\text { contaminants that may be found in recycled water, despite treatment with RO and UV- } \\
\text { oxidation. However, the water supply is critical, and our best knowledge and the best } \\
\text { treatment processes, the water is safe to use in indirect and direct potable applications. }\end{array}$ \\
\hline 11 & $\begin{array}{l}\text { No. Although the weight of evidence is suggesting that certain pharmaceuticals (e.g., } \\
\text { estrogens) can cause serious impacts (e.g., fish population decline), the impacts are } \\
\text { reversible (see Kidd, K. 2007, National Academy of Science 104:8897-8901). }\end{array}$ \\
\hline 12 & $\begin{array}{l}\text { The precautionary principle should be applied to any anthropogenic substances or } \\
\text { activities since human activities have been demonstrated to have such high potential for } \\
\text { causing environmental degradation. However pharmaceutical substances that are }\end{array}$ \\
\hline
\end{tabular}




\begin{tabular}{|c|l|}
\hline $\begin{array}{c}\text { Expert } \\
\#\end{array}$ & $\begin{array}{l}\text { Comments on whether or not the precautionary principle applies to PhACs in } \\
\text { the environment }\end{array}$ \\
\hline 13 & $\begin{array}{l}\text { Yes. Since there is a potential for pharmaceuticals to be an actual threat although we are } \\
\text { still trying to figure that out. }\end{array}$ \\
\hline 21 & $\begin{array}{l}\text { Yes, it applies. Research has linked trace levels of pharmaceuticals to impacts on aquatic } \\
\text { biota. The work of Dr. Chris Metcalfe (Trent) has shown the issue is evident in Ontario. }\end{array}$ \\
\hline 26 & $\begin{array}{l}\text { No. First of all, "threats of serious or irreversible damage" have less application to current } \\
\text { level of pharmaceutical contaminants. Secondly, safety of those affected by } \\
\text { environmental degradation should be emphasized over "cost-effective measures" }\end{array}$ \\
\hline
\end{tabular}

\subsection{Familiarity with Wastewater Treatment Plants in Ontario}

Except for expert \# 26 (the pharmacist involved in this study) all participants were familiar with wastewater treatment plants in Ontario. When asked if Ontario's wastewater treatment plants adequately eliminate the majority of pharmaceutical products from wastewater, responses were mixed from experts familiar with this issue (see Table 10). Expert \# 21, who works outside of the water treatment and/or wastewater treatment fields, indicated that removal of PhACs in Ontario's WWTP was either unlikely or not sufficient, " I'm not aware of any wastewater treatment plants in Canada equipped to address pharmaceutical wastes." Whereas the four other experts who work in some way in areas related to water or wastewater treatment (experts \# 4, 10, 11, and 13) all indicated that Ontario's WWTPs remove a meaningful amount of PhACs. Given the results from this study's literature review, which found numerous studies that showed PhACs being reduced in large quantities during conventional wastewater treatment processes (refer to Table 1), the answer from expert \# 21 is therefore surprising. The response suggests that performance of wastewater treatment plants is not clearly communicated to policy experts outside of the technical field of wastewater treatment.

In terms of the information that was collected in response to question nine, expert \# 4 offered important new insight for this topic. In their response, they indicated that "...the disappearance of 
chlorine in favour of UV disinfection will lead to a greater release of PPCPs in the future..." During a follow-up interview, expert \#4 was asked what is driving this trend. The expert indicated that a regulatory change that places a limit on how much chlorine can enter the environment is responsible for this phenomenon because chlorine can form chlorinated by-products when it interacts with organic matter. Chlorinated wastewater effluent is CEPA Toxic, and was added to the CEPA Toxic Schedule 1 in November 1999 (Environment and Climate Change Canada, 2016).

Expert \# 13 indicated that wastewater treatment plants using activated sludge for nitrification, or a biological nutrient removal process, can enhance the removal rate of PhACs. During a follow-up interview, Expert \#13 was asked if nitrification could also be enhanced by extending the solids retention time, which was something identified during the literature review and discussed in sections 2.1 .1 and 2.1.2. The expert indicated that an increase in solids retention time is not a simple modification in plant operation. Instead, because of the intimate relationship between the concentration of mixed liquor suspended solids and clarifier volume, one would need to perform capital construction (e.g., add more bioreactors to increase volume). 
Table 10: Knowledge of Ontario's WWTP and their Ability to Reduce/Eliminate PhACs (Responses to Question \# 9)

\begin{tabular}{|c|c|c|c|}
\hline $\begin{array}{c}\text { Expert } \\
\qquad \#\end{array}$ & $\begin{array}{c}\text { Familiar } \\
\text { with } \\
\text { WWTPs }\end{array}$ & $\begin{array}{l}\text { Do WWTPs adequately eliminate the } \\
\text { majority of PhACs from wastewater, so } \\
\text { that trace PhACs do not pose a serious } \\
\text { threat? } \\
\text { Five optional responses: } \\
\text { yes, maybe, unsure, not likely, no }\end{array}$ & Additional Comments \\
\hline 4 & Yes & Yes & $\begin{array}{l}\text { From a purely quantitative perspective, much of the total mass of } \\
\text { pharmaceuticals is eliminated by biological treatment and chlorine, but a lot of } \\
\text { PPCPs survive treatment so the elimination-although maybe a "majority" -is } \\
\text { far from complete. The disappearance of chlorine in favour of UV disinfection } \\
\text { will lead to a greater release of PPCPs in the future. However, the question asks } \\
\text { whether existing treatment "adequately" eliminates the majority of the PPCPs. } \\
\text { "Adequately" implies reduction to an extent that reduces the threat of } \\
\text { environmental damage to an acceptable level. I do not believe that we know } \\
\text { yet what this level is. A simple majority (51\%) might not be enough. }\end{array}$ \\
\hline 10 & Yes & Maybe & $\begin{array}{l}\text { I answer "maybe" because research shows that some compounds are well } \\
\text { removed with conventional processes and some are not. Advanced treatment } \\
\text { with membranes or advanced oxidation or ozone can remove a larger } \\
\text { percentage of compounds but advanced treatment is not widely applied. } \\
\text { Therefore, water discharged to receiving waters will contain trace } \\
\text { pharmaceuticals. The health impact on humans or ecosystems is unknown at } \\
\text { this time. }\end{array}$ \\
\hline 11 & Yes & Maybe & Generally yes, but mostly compound specific. See WEFTEC paper attached. \\
\hline
\end{tabular}




\begin{tabular}{|c|c|c|c|}
\hline $\begin{array}{l}\text { Expert } \\
\quad \#\end{array}$ & $\begin{array}{c}\text { Familiar } \\
\text { with } \\
\text { WWTPs }\end{array}$ & $\begin{array}{l}\text { Do WWTPs adequately eliminate the } \\
\text { majority of PhACs from wastewater, so } \\
\text { that trace PhACs do not pose a serious } \\
\text { threat? } \\
\text { Five optional responses: } \\
\text { yes, maybe, unsure, not likely, no }\end{array}$ & Additional Comments \\
\hline 12 & Yes & Unlikely & $\begin{array}{l}\text { It is important to remember that Ontario wastewater treatment plants were } \\
\text { designed for, and effectively accomplish, the removal of oxygen demand, } \\
\text { suspended solids, nutrients, and pathogens for protection of human health and } \\
\text { the receiving environment. They were not designed to remove contaminants at } \\
\text { the ppb or ppt levels; however some types of treatment appear to be effective } \\
\text { for some types of contaminants. }\end{array}$ \\
\hline 13 & Yes & Yes & $\begin{array}{l}\text { Yes for plants that employ nitrifying activated sludge treatment process, or a } \\
\text { biological nutrient removal (BNR) process. Plants that employ secondary } \\
\text { treatment without nitrification or employ trickling filters do not do as well. } \\
\text { Current research also shows there is a marginal additional improvement of BNR } \\
\text { processes over just nitrification. The statement that the majority meaning >50\% } \\
\text { of measured compounds are removed is supported by current research. } \\
\text { However, the definition of "adequate" is subject to debate. } \\
\text { There are of course many pharmaceuticals (and other comparable compounds } \\
\text { of human origin) that are removed little or not at all through the above } \\
\text { processes }\end{array}$ \\
\hline 21 & Yes & No & $\begin{array}{l}\text { I'm not aware of any wastewater treatment plants in Canada equipped to } \\
\text { address pharmaceutical wastes. }\end{array}$ \\
\hline 26 & No & Not sure & $\begin{array}{l}\text { Not familiar with wastewater treatment process in Ontario, hence cannot } \\
\text { comment }\end{array}$ \\
\hline
\end{tabular}




\subsection{Management Strategies in Ontario and Abroad}

One question posed to participants was "Are you aware of any current or proposed actions/ programs/legislation, which apply in Ontario, that help manage the amount of PhACs being released into the environment?" (question ten). Most of the participants could not identify any management strategies in Ontario (experts \# 4, 10, 12, and 21), and answered "No" to the question without providing any additional information. However, three experts did point to some management programs. The pharmacist (expert \# 26) pointed to Ontario's pharmaceutical return program (O. Reg. 298/12) and its Steri-cycle program (a safe needle disposal program) as an effective and safe way to dispose of PhACs and other biological materials. Although the expert noted that "Not all patients are aware of [Ontario's pharmaceutical return program] \& there is a cost for pharmacy to run this program." The consultant who specializes in wastewater treatment plant process engineering and facility design (expert \# 13) provided a comprehensive answer, shown in Table 11. Of particular importance, this expert indicated that Ontario's municipal wastewater treatment plants now all use secondary water treatment technology, "The recent upgrade of the Cornwall WWTP was the last of the primary treatment plants to be upgraded." The government wastewater engineering expert (expert \# 11) pointed this author to a report that $\mathrm{CH} 2 \mathrm{MHill}$ performed for the Ontario Ministry of the Environment in 2011, which is the same report referred to in the last row of Table 11.

Table 11: Expert \# 13's Response to Question \# 10 - Ontario's Management Strategies for PhACs before Entering the Environment

\begin{tabular}{|l|l|c|}
\hline Action/Program/Legislation & \multicolumn{1}{|c|}{ Description } & Do you think this is effective? \\
\hline $\begin{array}{l}\text { Ontario's pharmaceutical } \\
\text { return program. }\end{array}$ & $\begin{array}{l}\text { In 2012, O. Reg. 298/12 was } \\
\text { passed. It requires a } \\
\text { pharmaceutical collection } \\
\text { system, operated by } \\
\text { producers, to run in } \\
\text { Ontario. }\end{array}$ & $\begin{array}{c}\text { Yes because it diverts } \\
\text { pharmaceuticals from the } \\
\text { wastewater stream. Once } \\
\text { diluted in WW, they are much } \\
\text { harder to remove before } \\
\text { discharge to the environment. }\end{array}$ \\
\hline
\end{tabular}




\begin{tabular}{|c|c|c|}
\hline Action/Program/Legislation & Description & Do you think this is effective? \\
\hline $\begin{array}{l}\text { The requirement for a } \\
\text { minimum of secondary } \\
\text { treatment in Ontario }\end{array}$ & $\begin{array}{l}\text { The recent upgrade of the } \\
\text { Cornwall WWTP was the } \\
\text { last of the primary } \\
\text { treatment plants to be } \\
\text { upgraded. }\end{array}$ & $\begin{array}{l}\text { Yes, because secondary } \\
\text { treatment provides a } \\
\text { significant improvement in } \\
\text { removals compared to primary } \\
\text { treatment. }\end{array}$ \\
\hline $\begin{array}{l}\text { Federal Wastewater Systems } \\
\text { Effluent Regulations }\end{array}$ & $\begin{array}{l}\text { Requires effluents to be not } \\
\text { acutely toxic, }\end{array}$ & $\begin{array}{l}\text { Yes because it requires some } \\
\text { level of removal of ammonia } \\
\text { as a typical toxicant. The } \\
\text { removal of some ammonia } \\
\text { means there is a secondary } \\
\text { level of treatment which is a } \\
\text { significant improvement over } \\
\text { primary treatment for the } \\
\text { removal of pharmaceuticals. }\end{array}$ \\
\hline $\begin{array}{l}\text { Refer to Task } 5 \text { on Source } \\
\text { Control in the Non- } \\
\text { conventional contaminants } \\
\text { report that } \mathrm{CH} 2 \mathrm{M} \text { did for the } \\
\text { Ministry. }\end{array}$ & & \\
\hline
\end{tabular}

* Author's note: this report is discussed in further detail below because it was also referred to by two experts for question \# 11.

When asked if experts were aware of actions/programs/legislation used elsewhere to reduce the amount of PhACs released into the environment, three experts were not aware of any relevant actions from elsewhere (experts \# 10, 12, 26).

Two experts referred this author to Switzerland, which was also a jurisdiction chosen by this author as part of this study's jurisdictional review, see section 2.3.4. Expert \# 4 believed that regulations were recently developed for the release of PhACs and personal care products, while expert \# 21 stated "Pilot-scale approaches in Switzerland to use activated carbon on wastewater in Lausanne 
http://www.ncbi.nlm.nih.gov/pubmed/23751332. I believe that there are also full-scale activated carbon controls in place in a WWTP for Lake Constance, Switzerland; but a quick skim did not find it."

Finally, two experts once again pointed this author to the report by $\mathrm{CH} 2 \mathrm{M}$ Hill for the Ministry of the Environment (experts \# 11 and 13). The non-conventional contaminants (NCCs) report prepared by CH2M Hill for Ontario's MOE in 2011, entitled Literature Review and Jurisdictional Practices of Technologies to Reduce Non-Conventional Contaminants at Municipal Sewage Treatment Plants and hereafter referred to as the "CH2M Hill report" , was shared with this author by multiple study participants. While experts claimed this report is in the public domain, it could not be located with conventional internet search tools. The study included PhACs as part of their overall analysis of nonconventional contaminants:

NCCs [non-conventional contaminants] are defined as potentially harmful pollutants that are present in sewage as a result of industrial, commercial, institutional, agricultural, and domestic activities in the sewershed. This includes metals, pharmaceuticals, personal care products, natural and synthetic hormones, flame retardants, pesticides, and other "legacy" compounds that are persistent, bioaccumulative, and toxic, including those that induce an endocrine disrupting effect (e.g., bisphenol A). Conventional contaminants, including oxygen demanding matter, total suspended solids, total phosphorus, total ammonia nitrogen, organic nitrogen, nitrites and nitrates, total residual chlorine, and pathogenic microorganisms are not included in the definition of NCCs (emphasis added, p. 1-1).

Task 5 of the $\mathrm{CH} 2 \mathrm{M}$ Hill report provided a jurisdictional review of various source control methods for NCC compounds, and evaluated these source control methods within the context of their effectiveness to reduce NCCs from municipal sewage prior to conventional centralized treatment. Part of the jurisdictional review involved a summary of activities within Ontario or that affect Ontario, while the other part involved looking around the globe. Selected activities and policies that apply in Ontario are highlighted below:

- Canada's Chemical Management Plan: contains several measures to ensure management of various chemicals in Canada, including regulations to address environmental risks posed by PhACs and personal care products. 
- Ontario Ministry of the Environment's Industrial Sewer Use Best Management Practices: best management practices are guidance documents that provide direction on pollution prevention and pre-treatment options. Chemical manufacturing, which includes PhAC and medicine manufacturing, is captured under this policy.

- Municipal Household Hazardous Waste and Pharmacy Return Program: Ontario amended its MHSW program in 2010 to include additional products like PhACs. (This policy was revoked and superseded by O. Reg. 298/12, discussed in section 2.3.)

- Sewer Use By-Laws: are discussed as municipal or regional by-laws that can control the release of NCCs into municipal wastewater streams. The $\mathrm{CH} 2 \mathrm{M}$ Hill report found no evidence of bylaws in Ontario that limit PhACs.

The $\mathrm{CH} 2 \mathrm{M}$ Hill report highlighted the following relevant activities and policies from other jurisdictions:

- PILLS Project (Germany, Netherlands, Luxembourg, Switzerland, United Kingdom, France): a research program that is based out of the European Union, Pharmaceutical Input and Elimination from Local Sources (PILLS) analyzes pre-treatment options for wastewaters that contain pharmaceutical products, such as healthcare facilities. The project ran from 2009 and 2011, with a goal to determine if "end-of-pipe" approaches are reasonable.

- The Novaquatis "NoMix" Toilet Project: the Swiss Federal Institute of Aquatic Science and Technology (Eawag) examined the feasibility of source separation for urine through a special "NoMix" toilet. The project considered a centralized treatment plant for the separated urine.

- Pharmaceutical return programs: various PhAC return programs were highlighted from across Canada and around the world.

- Environmental Classification of PhACs: Sweden's Environmental Classification and Information System for PhACs is discussed in the $\mathrm{CH} 2 \mathrm{M}$ Hill report, and already covered in section 2.3.3 of this thesis.

- Public Education Programs: various public education programs are discussed, including the UK's "Safe Medicine Cabinet" website that provides information on the safe handling and disposal of various medications.

This list supports the findings from this thesis' literature review. Specifically, Canada has several municipal, provincial, and federal tools that can influence which contaminants enter municipal wastewater treatment plants. In addition, several international jurisdictions have piloted or explored methods to reduce the amount of PhAC input into local waterways. PhAC return programs and educational campaigns appear to be a universal approach used to raise awareness about the environmental effects of PhACs in the environment.

Participants were also asked if Ontario should take further action to reduce the release of PhACs into the environment. Their answers are provided in Table 12; a variety of opinions were expressed. Some experts believed educational campaigns around pharmaceutical take back programs would be 
beneficial, while others felt more research is needed to be sure of the cause and effect relationship that trace PhACs pose to the environment and/or human population, as stated by expert \# 11, "More research is needed to link presence and concentrations to effects."

However, expert \# 13 explained " A lot of the source control programs are voluntary and therefore may not achieve the level of diversion/control that is desired. A requirement that all plants provide nitrification as a minimum level of treatment would help to improve removals at wastewater treatment plants." As discussed in section 2.3, under direction from the International Joint Commission, sewage treatment plants that release their discharge into the Great Lakes must reduce phosphorous (not nitrogen) as the limiting nutrient to avoid eutrophication in surface waters. This rule applies to plants discharging directly to the Great Lakes because of the lakes' high assimilative capacity for nitrogen.

Table 12: Experts' Responses When Asked if Ontario Needs Further Actions / Programs / Legislation in Ontario Related to PhACs and the Environment (Question $10 \mathrm{~b}$ )

\begin{tabular}{|c|l|}
\hline Expert \# & $\begin{array}{c}\text { Does Ontario need to take further action to manage PhACs being released into the } \\
\text { environment? }\end{array}$ \\
\hline 4 & $\begin{array}{l}\text { As per my answer to the "precautionary principle" question, I am not yet convinced of } \\
\text { whether PPCPs represent a "serious" threat to the environment at the amounts } \\
\text { present. As such, I am on the fence on this question. }\end{array}$ \\
\hline 10 & $\begin{array}{l}\text { I don't. Conventional treatment and disinfection is adequate in my opinion. There are } \\
\text { steps that could be taken on the drinking water side that could enhance public health } \\
\text { (e.g. advanced treatment with UV or carbon) }\end{array}$ \\
\hline 11 & No. More research is needed to link presence and concentrations to effects. \\
\hline
\end{tabular}




\begin{tabular}{|c|l|}
\hline Expert \# & \multicolumn{1}{|c|}{$\begin{array}{c}\text { Does Ontario need to take further action to manage PhACs being released into the } \\
\text { environment? }\end{array}$} \\
\hline 12 & $\begin{array}{l}\text { Expansion and public awareness of pharmaceutical take-back programs is very } \\
\text { important because this eliminates one source of contaminants to the wastewater } \\
\text { stream. Increasing the awareness of the medical profession of the environmental } \\
\text { implications of unnecessary pharmaceutical use should also be pursued. Management } \\
\text { of unused pharmaceuticals in hospitals, nursing homes etc. should probably also be } \\
\text { examined. These actions would all target sources of the problem. }\end{array}$ \\
\hline 13 & $\begin{array}{l}\text { A lot of the source control programs are voluntary and therefore may not achieve the } \\
\text { level of diversion/control that is desired. A requirement that all plants provide } \\
\text { nitrification as a minimum level of treatment would help to improve removals at } \\
\text { wastewater treatment plants. }\end{array}$ \\
\hline 21 & $\begin{array}{l}\text { Yes. } \\
\text { Yes. Further awareness of the "Ontario's pharmaceutical return program" is needed by } \\
\text { the general public, to reduce pharmaceutical contaminants. }\end{array}$ \\
\hline 26 & \\
\hline
\end{tabular}

\subsection{The Role of Government}

Overall, experts did no present a consensus opinion on whether additional action by the federal or provincial or municipal governments was needed to reduce the release of PhACs into the environment. Refer to the detailed table, Table 13, for full responses from experts when asked if federal, provincial, or municipal governments should take additional action to reduce the release of PhACs to the environment (Appendix A, survey question 14, for the original question).

In terms of possible action at the provincial level, expert \# 10 specifically indicated that no further action should be taken unless there is additional negative scientific evidence of the environmental effects of PhACs. Expert \# 21 identified Ontario as a wealthy province that should be responsible for protecting aquatic biota. Expert \# 13 raised an interesting point that contamination of water with PhACs is an "invisible" issue "... Of course this issue must compete with an assortment of other environmental issues that the Ministry must address. For example, eutrophication of lakes is a 
much more visual issue due to algae growth and decay on shores which prompts more action than an 'invisible' issue such as pharmaceuticals in water."

For possible action at the municipal level, several experts pointed out that municipalities have very little power and resources available to deal with PhACs as pollutants unless they are regulated to do so. Expert \# 21, however, pointed out that municipalities have direct control over municipal wastewater treatment plants, and they could therefore pilot technological solutions or implement sewer use by-laws, " As operators of WWTPs, municipalities have direct control; could impose by-law controls onto selected institutional customers; could also pilot technological solutions at the WWTPs." This expert also suggested there is an opportunity for more coordination on this issue if there was greater political interest at the federal level: "CCME [Canadian Council of Ministers of the Environment] could examine the state of the issue across Canada; identify geographic hot-spots where issues may be critical and opportunities to reduce the burden; but federal govt. unlikely to impose regulatory requirements nation-wide."

There was generally no consensus on what action should be taken by the federal government. One expert suggested more collaboration between federal and provincial governments could be beneficial (expert \# 11): "Provincial and federal resources should be pooled and findings shared." Another expert suggested the federal government could do more when approving PhACs, stating

The federal government should include in the approvals process of new drugs an assessment of what happens to the drug when it passes through the human body asis as well as its metabolites. Those that resist removal by standard wastewater treatment should be subject to greater scrutiny. Also, the government should continue to assess compounds as part of CEPA to determine if they require action as being "CEPA toxic". (expert \# 13) 
Table 13: Experts' Responses When Asked if Federal, Provincial, or Municipal Governments Should Take Additional Action to Reduce the Release of PhACs to the Environment (Question 14)

\begin{tabular}{|c|c|c|c|}
\hline $\begin{array}{c}\text { Expert } \\
\text { \# }\end{array}$ & $\begin{array}{l}\text { Gov't } \\
\text { Level }\end{array}$ & $\begin{array}{l}\text { Level of } \\
\text { Importance to } \\
\text { Take Action }\end{array}$ & Comment \\
\hline \multirow{3}{*}{4} & Fed. & blank & Same answer as [Prov. - see field below]. \\
\hline & Prov. & blank & $\begin{array}{l}\text { This question can be read two ways: if you are asking about the need in general to better regulate the } \\
\text { emission of PPCPs into the environment, I am on the fence as per my previous answers. If you are } \\
\text { asking which jurisdiction should be responsible if at some point action is determined to be required, I } \\
\text { do not have enough background in constitutional law to give a good opinion. Traditionally it would fall } \\
\text { to the provincial governments, but given the movement of some of the recalcitrant PPCPs around } \\
\text { watersheds, it would be common for the pollutants to cross provincial boundaries and therefore } \\
\text { possibly be an issue for the federal government. }\end{array}$ \\
\hline & Muni. & blank & $\begin{array}{l}\text { I do not think that this is a municipal issue from a regulatory perspective. I am aware of municipalities } \\
\text { that are already voluntarily exploring ways to reduce the emission of PPCPs into the environment } \\
\text { during wastewater treatment, but such pollution is not local: it must be regulated at either the } \\
\text { provincial/federal levels if regulation is ultimately desired. }\end{array}$ \\
\hline \multirow{3}{*}{10} & Fed. & very unimportant & blank \\
\hline & Prov. & very unimportant & $\begin{array}{l}\text { Without additional scientific evidence that there are negative effects, government should not take } \\
\text { action. }\end{array}$ \\
\hline & Muni. & very unimportant & blank \\
\hline \multirow{3}{*}{11} & Fed. & $\begin{array}{l}\text { moderately } \\
\text { important }\end{array}$ & Provincial and federal resources should be pooled and findings shared. \\
\hline & Prov. & $\begin{array}{l}\text { moderately } \\
\text { important }\end{array}$ & The research results to date show only a minimal potential adverse impact on fish at the chronic level. \\
\hline & Muni. & $\begin{array}{l}\text { moderately } \\
\text { important }\end{array}$ & $\begin{array}{l}\text { Municipalities can update their sewer use bylaws to reflect new findings of the provincial / federal } \\
\text { research initiatives. }\end{array}$ \\
\hline 12 & Fed. & very important & $\begin{array}{l}\text { The federal government is in a better position to regulate substances in Canadian commerce as } \\
\text { discussed above. However there are health and social implications to these types of actions as well as } \\
\text { the fiscal implications noted above. }\end{array}$ \\
\hline
\end{tabular}




\begin{tabular}{|c|c|c|c|}
\hline $\begin{array}{l}\text { Expert } \\
\quad \#\end{array}$ & $\begin{array}{l}\text { Gov't } \\
\text { Level }\end{array}$ & $\begin{array}{l}\text { Level of } \\
\text { Importance to } \\
\text { Take Action }\end{array}$ & Comment \\
\hline & Prov. & $\begin{array}{l}\text { moderately } \\
\text { important }\end{array}$ & $\begin{array}{l}\text { I am not sure how much the provincial government can do to reduce releases of pharmaceuticals. } \\
\text { Substances in Canadian commerce are regulated at the federal level under CEPA } 1999 \text { and the Food } \\
\text { and Drug Act. Upgrading wastewater treatment plants to improve removal (no one technology has yet } \\
\text { demonstrated the ability to remove everything) will be extremely expensive and we apparently have no } \\
\text { money to repair existing infrastructure, let alone upgrade. }\end{array}$ \\
\hline & Muni. & very unimportant & As discussed above, municipal government has very little "power" to take additional actions. \\
\hline \multirow{3}{*}{13} & Fed. & $\begin{array}{l}\text { moderately } \\
\text { important }\end{array}$ & $\begin{array}{l}\text { The federal government should include in the approvals process of new drugs an assessment of what } \\
\text { happens to the drug when it passes through the human body as-is as well as its metabolites. Those that } \\
\text { resist removal by standard wastewater treatment should be subject to greater scrutiny. } \\
\text { Also, the government should continue to assess compounds as part of CEPA to determine if they } \\
\text { require action as being "CEPA toxic". }\end{array}$ \\
\hline & Prov. & $\begin{array}{l}\text { moderately } \\
\text { important }\end{array}$ & $\begin{array}{l}\text { It is moderately important. Of course this issue must compete with an assortment of other } \\
\text { environmental issues that the Ministry must address. For example, eutrophication of lakes is a much } \\
\text { more visual issue due to algae growth and decay on shores which prompts more action than an } \\
\text { "invisible" issue such as pharmaceuticals in water. }\end{array}$ \\
\hline & Muni. & very important & $\begin{array}{l}\text { The local municipalities are the best positioned for trying to improve source control. But in terms of } \\
\text { wastewater treatment, generally they don't have money to improve treatment unless it is to meet a } \\
\text { regulatory mandate. }\end{array}$ \\
\hline \multirow{3}{*}{21} & Fed. & $\begin{array}{l}\text { moderately } \\
\text { important }\end{array}$ & $\begin{array}{l}\text { CCME could examine the state of the issue across Canada; identify geographic hot-spots where issues } \\
\text { may be critical and opportunities to reduce the burden; but federal govt. unlikely to impose regulatory } \\
\text { requirements nation-wide. }\end{array}$ \\
\hline & Prov. & very important & $\begin{array}{l}\text { Ontario is a wealthy province with large population densities living on the edge of important fresh- } \\
\text { water lakes. Ontario has a responsibility to protect water quality for aquatic biota. }\end{array}$ \\
\hline & Muni. & very important & $\begin{array}{l}\text { As operators of WWTPs, municipalities have direct control; could impose by-law controls onto selected } \\
\text { institutional customers; could also pilot technological solutions at the WWTPs. }\end{array}$ \\
\hline \multirow[t]{2}{*}{26} & Fed. & $\begin{array}{l}\text { neither } \\
\text { important/ } \\
\text { unimportant }\end{array}$ & blank \\
\hline & Prov. & $\begin{array}{l}\text { neither } \\
\text { important/ }\end{array}$ & blank \\
\hline
\end{tabular}




\begin{tabular}{|c|c|c|c|}
\hline $\begin{array}{l}\text { Expert } \\
\quad \#\end{array}$ & $\begin{array}{l}\text { Gov't } \\
\text { Level }\end{array}$ & $\begin{array}{c}\text { Level of } \\
\text { Importance to } \\
\text { Take Action }\end{array}$ & Comment \\
\hline & & unimportant & \\
\hline & Muni. & $\begin{array}{l}\text { moderately } \\
\text { important }\end{array}$ & $\begin{array}{l}\text { Wastewater treatment is controlled by municipalities, hence municipal government should take control } \\
\text { of release of pharmaceuticals into the environment }\end{array}$ \\
\hline
\end{tabular}




\subsection{Removing PhACs from Wastewater Streams - Opportunities and Barriers}

A series of questions regarding experts' knowledge of barriers and opportunities to enhance PhAC removal rates within municipal wastewater treatment plants were asked. Every participant in some way stated that more action can be done to remove PhACs from wastewater streams; however, the high cost of removal was considered a key barrier and several experts pointed to lack of political interest.

For barriers, on one end of the spectrum, expert \# 26 indicated municipalities could do more, "however, cost-benefit analysis might be necessary before municipalities are willing to make any initiatives." This relatively optimistic outlook suggests that the costs should be considered by municipalities before they take additional action to reduce the PhACs entering the environment (e.g., education campaigns or investments in wastewater treatment plant infrastructure), and if cost were deemed to be too high, then action should not be pursued. At the other end of the spectrum, expert \# 21 stated "the province and the municipalities are not interested in pursuing this issue because of the cost implications; so it's easier not to do the monitoring." In this case, the relatively pessimistic view suggests that governments are unwilling to address this issue and are therefore not monitoring or collecting data because they do not want to have to take action. Expert \# 13 stated their beliefs succinctly "Certain compounds just do not degrade through typical or even advanced treatment processes. However, the most significant issues is just cost. Improvements to the level of treatment are significant and will not be implemented unless there is a regulatory requirement to do so." Expert \# 4 shared a similar observation: "The cost effectiveness of steps that [municipalities can] take is uncertain, so at the end of the day it becomes a political decision more than a technological decision. At present, I do not believe that there is a big enough political/public appetite to spend significant money on this issue." 
When asked about source monitoring and elimination options in hospitals, retirement homes, and other institutional settings where PhACs are administered, several suggested that focusing on these point sources could theoretically be beneficial. However, there is insufficient data at this time to know with certainty if targeting these point sources would be effective. As stated by expert \# 13: " it has been suggested that on-site pre-treatment of wastewater from these facilities would be beneficial...[however,] what is missing is some targeted monitoring, such as whether concentrations are substantially higher from hospitals and retirement homes to determine whether these locations are in fact significant contributors and whether pre-treatment would make sense. Also further assessing the removals by various wastewater treatment processes [is needed]." However, as discussed in the literature review, there have been recent targeted monitoring studies in Ontario for hospitals and longterm care facilities (Riaz ul Haq et al., 2012). This indicates that experts in Ontario may not be aware of the most current research being published on this topic.

Every participant indicated that more can be done, although the identified opportunities for action varied by participant. Several experts suggested that the relatively low-cost information campaigns would be beneficial because they can encourage people to follow proper disposal techniques (experts \# 10, 12, 13). As stated by expert \# 12 "... everything that goes down the drain goes into the environment in some form." This expert also indicated elsewhere that "Wherever possible, it would be cheaper and more effective to reduce contaminants at the source rather than try to remove them later," thus reinforcing the benefits of proper disposal for PhACs.

Different wastewater treatment plant technologies were also highlighted by several participants as one way to reduce the amount of PhACs entering the environment, however, as discussed above, the relatively high cost of technology upgrades makes the feasibility of using advanced wastewater treatment plant technology questionable. Chlorination, ozone, UV-oxidation, activated sludge, reverse 
osmosis, and membrane bioreactors were all suggested as technologies that could help reduce the PhAC loading from wastewater treatment plant effluent streams.

Several experts indicated that the pharmaceutical industry could also do more. As noted by expert \# 21, when asked if the pharmaceutical industry should assist municipal wastewater treatment plants with removing or managing wastewater that is contaminated with PhACs, the expert responded with: "Yes, this would conform with the principle of polluter pay, and would incent drug manufacturers to show interest in developing drug formulations that degrade more rapidly in conventional WWTP systems." Expert \# 13 provided the following response: "Ideally pharmaceutical companies would be required to submit information $\&$ data on the biodegradability of a pharmaceutical and its metabolites through various wastewater treatment processes as part of the drug approval process." Similarly, expert \# 12 stated "...the pharmaceutical industry needs to incorporate an awareness of the environmental implications and impacts of their products as part of their product development and data generation." It is interesting to note that this is similar to what Sweden already does (refer to section 2.3.3); doctors in Sweden are encouraged to consider each medication's cost-effectiveness and environmental impact when issuing prescriptions.

Expert \# 12 also stated that "... there is a disconnect between the reality of the wastewater industry (technology, availability of resources) and the apparent expectations of academia and the public (the cost to treat everything)" (e.g., academia and the public expect municipal wastewater treatment plants to want to remove all pollutants). Given the two noted barriers identified by experts (lack of political will, and high cost to take action to reduce PhACs using advanced wastewater treatment systems), this observation appears to be valid. The wastewater treatment industry, without more capital and supporting regulations, will be unwilling to install expensive wastewater treatment technologies to eliminate PhACs. The one academic who participated in this study, expert \# 4, explained 
that the world has a finite amount of financial resources available, hence society needs to prioritize what is causing the most damage - "we must tackle the large items first." In terms of PhACs, their priority ranking is not clear with respect to other pollutants. During the follow-up interview, we discussed how other contaminants have been shown to exhibit more harm to our natural environment. This expert's observations were made not to justify inaction, but rather to justify why academics and policymakers continue to study this problem.

\subsection{Comparing These Findings to Doerr-MacEwen and Haight's Results from 2006}

Doerr-MacEwen and Haight's 2006 work is drawn from Doerr-MacEwen's PhD thesis, completed in 2007, which provides further details on the information collected from study participants. These findings from 2006 act as baseline for this thesis. Now, ten years later and with more scientific knowledge available, it appears that no significant changes from the viewpoint of experts has occurred. In Doerr-MacEwen's thesis, she found 63\% "of the interviewees expressed positive opinions towards the [precautionary principle]" (p. 145), which is similar to this study's findings of $60 \%$ agreeing that the precautionary principle should in some way apply to this issue, although the sample size by for DoerrMacEwen's work was larger. Likewise, some of the top management strategies identified by experts in Doerr-MacEwen's thesis included advanced wastewater treatment, educating medical professions to minimize over-prescriptions, a PhAC return program, and a public education campaign; these findings from 2006 are very similar to the opinions expressed for this study in 2016. Ontario has since introduced a PhAC return program (O. Reg. 298/12, see section 2.3 for further details), which is likely why a PhAC return program was not mentioned by current study participants. Both this study and Doerr-MacEwen's thesis also revealed that cost and political will are significant barriers for this problem.

However, this study's literature review and consultation with expert stakeholders has revealed some new information. First, from the literature review, it was discovered that the British Columbia 
government in 2009 published a Water Quality Guideline for the pharmaceutically active 17 $\alpha-$ ethinylestradiol, which states:

For the protection of freshwater aquatic life, it is recommended that the 30-day average concentration of $17 \alpha$-ethinylestradiol (EE2) in water, based on 5 weekly samples, should not exceed $0.5 \mathrm{ng} \mathrm{L}^{-1}$ with no single value to exceed $0.75 \mathrm{ng} \mathrm{L}^{-1}$ (no more than $50 \%$ above the guideline value) (Nagpal \& Meays, 2009, p.17).

Although not legally binding, the Water Quality Guideline must be considered by British Columbia's Ministry of the Environment when making any decision that could affect water quality (Water Protection \& Sustainability Branch, 2015). This guideline did not exist in 2006 and was therefore not mentioned in Doerr-MacEwen's study. Yet, for this current study, no Ontario expert mentioned the British Columbia guideline as an action taken in another jurisdiction to manage PhACs in the environment. Second, Doerr-MacEwen's study makes no mention of the disappearance of chlorine in favour of UV disinfection, which expert \# 4 stated will lead to a greater release of PPCPs in the future and would have resulted from the addition of chlorinated wastewater effluents being added to the List of Toxic Substances in Schedule 1 of Canadian Environmental Protection Act in November of 1999 (Environment and Climate Change Canada, 2016).

Likewise, Doerr-MacEwen's thesis did not mention that several of Ontario's wastewater treatment plants do not require nitrification because they discharge to the Great Lakes which has a high assimilative capacity for nitrogen. Ontario's wastewater treatment plants employ biological processes that will remove some PhACs, even though that is not their primary purpose, and one of these biological processes is nitrification. Therefore, without using nitrification for some wastewater treatment plants that discharge into the Great Lakes, there is the possibility that higher rates of PhACs are being released into these important aquatic habitats. 


\subsection{Summary of Significant Findings Collected During this Consultation}

Overall, it appears that there was no real consensus among experts regarding level of risk that PhACs pose to the environment or to human health. All recognized some risk to the environment, but the level of risk varied depending on the expert providing the information.

Much of what was revealed by experts was found in the literature review. However, there were several important discoveries made during the expert consultation. First, UV disinfection is being favored over chlorine in wastewater treatment plants, which will lead to a greater release of PhACs in the future (response to questionnaire from expert \# 4). Second, several of Ontario's wastewater treatment plants do not require nitrification because they discharge to the Great Lakes and the Great Lakes have a high assimilative capacity for nitrogen, yet the nitrification process is one of wastewater treatment plant processes that naturally removes some PhACs (response to questionnaire from expert \# 13). Without collecting data from these specific wastewater treatment plants, it is impossible to know exactly how well Ontario facilities are removing PhACs if they are using UV disinfection instead of chlorine, or if they do not require nitrification. Given how important the Great Lakes are as an aquatic habitat, and that these experts identified these trends as a special concern, it would be worthwhile to collect site-specific data from these municipal plants to determine if higher levels of PhACs are being released from these facilities. 


\section{Conclusion}

This thesis asked: what is the perceived risk of pharmaceuticals to Ontario's aquatic environment, and what are the challenges and opportunities for government action to address this issue? One of the original goals of this work was to examine whether a purposefully selected group of experts believe PhACs are a concern, and if additional action should be taken in Ontario to manage this risk. This thesis also had several sub-objectives:

1) how potential point sources for PhACs are addressing pharmaceuticals in wastewater streams (e.g., hospitals, municipalities);

2) how governments currently understand and perceive the risk associated with pharmaceuticals;

3) whether existing legislation follows from that perceived risk;

4) in light of answers to 1 and 2, what actions have been taken or have been proposed to address pharmaceuticals and why; and

5) potential options available to the government, considering what other jurisdictions have done, and the cost and overall effectiveness of removing pharmaceutical products from streams.

To answer the first part of the main thesis question (what is the perceived risk of pharmaceuticals to Ontario's aquatic environment), the literature review indicated that PhACs are detected in waterways throughout the developed world including Ontario. These contaminants have been shown to pose some risk to the environment, but the exact nature of this risk is not fully understood. Specifically, effluent from wastewater treatment plants has been shown to negatively affect freshwater wildlife in multiple studies (e.g., Gross-Sorokin et al., 2005; Fent et al., 2006; Kidd et al., 2007; Gillis et al., 2014). However, in terms of risk characterization, it is extremely difficult to combine studies and extrapolate results from literature; different studies use different analytical methods to measure concentrations of contaminants (Kostich et al., 2014). This makes it challenging for experts to agree on the risk that PhACs pose to the environment, even though there is scientific evidence that PhACs can cause some harm to aquatic biota. Compounding this, biological systems 
involve many different interactions that make it challenging to prove causation and therefore difficult to determine the probability and severity of an adverse effect from PhACs (Kriebel et al., 2001).

The expert consultation performed for this thesis supports the findings from the literature review. Ontario experts are indeed aware that PhACs are present in Ontario's water cycle and pose some risk to the environment, but there was no consensus on the level of risk that these contaminants pose. Nor was there consensus on what actions can be taken to address this issue. There has been some work done in Ontario to characterize whether or not hospitals and long-term care facilities are point sources for PhACs. Based on a small sample size, long-term care homes and hospitals in Ontario have been shown to contribute a relatively large proportion of overall loading for antibiotic compounds in municipal wastewater treatment plants (see Table 7 in section 2.1.5.3) (Riaz ul Haq et al., 2012). These higher levels of antibiotics in hospital effluent are likely because a large amount of antibiotics are administered in hospitals, which was expected. Ontario's hospitals and long-term care homes ensure that PhACs are properly disposed of, instead of flushing unused PhACs into the water system, but no other actions are performed in these facilities to manage the amount of PhACs being discharged into the environment (e.g., "no mix" toilets to separate out urine for possible pre-treatment before entering municipal wastewater plants).

Ontario currently requires wastewater treatment plants to deliver secondary wastewater only, and PhACs are not one of the compounds targeted for removal (Ontario Ministry of the Environment and Energy, 1994; Lou et al., 2014). Yet Ontario's wastewater treatment plants employ biological processes that will naturally remove some PhACs, even though that is not their primary purpose. Experts generally agreed that it is difficult to justify spending additional capital to upgrade current wastewater treatment plants to include advanced technologies that can do an even better job of 
removing PhACs without clear scientific data showing that PhACs are pollutants that should be prioritized over other environmental hazards.

However, there were some notable Ontario-specific concerns raised. First, UV disinfection is being favored over chlorine in wastewater treatment plants, which will lead to a greater release of PhACs in the future (response to questionnaire from expert \# 4). Second, several of Ontario's wastewater treatment plants do not require nitrification because they discharge to the Great Lakes, which have a high assimilative capacity for nitrogen. Yet the nitrification process in wastewater treatment plants is one of places that naturally removes some PhACs (response to questionnaire from expert \# 13). Without collecting data from specific Ontario wastewater treatment plants, it is impossible to know exactly how well these facilities are naturally removing PhACs. It would be incorrect to assume their removal rates are comparable to values from the literature for the removal of PhACs from other conventional secondary wastewater plants. It could be worthwhile to collect site-specific data from these municipal wastewater treatment plants to determine if higher levels of PhACs are being released from these facilities.

Based on a jurisdictional review that examined Switzerland, Sweden, and British Columbia, it appears that there are some opportunities for government action. Both British Columbia and Sweden have implemented policies that recognize certain PhACs pose a risk to the environment, particularly ethinylestradiol (Nagpal \& Meays, 2009, Stockholms Läns Landsting, 2014).

British Columbia developed a Water Quality Guideline in 2009 for PhACs that must be considered by British Columbia's Ministry of the Environment when making any decision that could affect water quality. The guideline is as follows: "For the protection of freshwater aquatic life, it is recommended that the 30-day average concentration of $17 \alpha$-ethinylestradiol (EE2) in water, based on 5 weekly samples, should not exceed $0.5 \mathrm{ng}$ L- 1 with no single value to exceed $0.75 \mathrm{ng} \mathrm{L-1}$ (no more than 
50\% above the guideline value)." (Nagpal \& Meays, 2009, p.17). This author believes that Ontario could consider following British Columbia's approach. British Columbia has determined that a threshold for this particular PhAC is necessary to help protect freshwater aquatic life. Therefore, since Ontario is a province with an abundant supply of freshwater, Ontario could consider following British Columbia's lead and establish an acceptable maximum concentration for $17 \alpha$-ethinylestradiol in freshwater streams (after performing a cost-benefit analysis).

Sweden initiated the environmental hazard assessment, which classified PhACs according to their environmental risk and environmental hazard. Although this program is voluntary, the majority of pharmaceutical companies have chosen to participate in the program ( $\mathrm{CH} 2 \mathrm{M}$ Hill, 2011). Environmental risk is based on the ratio between predicted environmental concentration of the substance in natural water systems (PEC) and the highest concentration of the substance that does not have a harmful effect on the environment (PNEC). The only listed PhAC to receive a high risk assessment is ethinylestradiol, the same PhAC for which the British Columbia government has issued a Water Quality Guideline. This ranking system is available for medical doctors and patients, so both groups can consider the environmental impacts of medications. Similar to what Sweden has done, Ontario could consider educating doctors about the environmental effects of PhACs, and make this information available to patients.

While there may be other jurisdictions with policies to address PhACs in the environment, Switzerland, Sweden, and British Columbia were the only areas examined. These jurisdictions were chosen because they are either known for being environmentally proactive in their policies, or because they were highlighted in $\mathrm{CH} 2 \mathrm{M}$ Hill's jurisdictional analysis. A full discussion of this selection process was presented in section 2.3.1. Future work would benefit from an expanded and more comprehensive literature review because there could be other regions that are taking steps to address this issue. 
Before summarizing the significant findings from this work, it is important to step back and consider how and why this problem is a challenge for governments. Governments have limited resources available to deal with environmental concerns/stressors. Therefore, they must prioritize environmental topics and focus on those that warrant their attention. This prioritization can be influenced by the science (e.g., if a contaminant has been shown to pose a high level of risk to the environmental or human health) or by public demand (e.g., if public sentiment is very strong, then the government may act even without scientific certainty; the polarizing topic of hydraulic fracturing for natural gas is one example of this). Unfortunately for PhACs, the level of risk that trace contaminates pose to the environment is unknown, and PhACs are seen as a net benefit to society because they improve human health.

When asked if the precautionary principle applies to PhACs, expert \# 26 answered:

No. First of all, 'threats of serious or irreversible damage' have less application to current level of pharmaceutical contaminants. Secondly, safety of those affected by environmental degradation should be emphasized over 'cost-effective measures'. Indeed, some experts consulted during this study suggested that the precautionary principle could be used to justify governments taking no action at all. However, under the precautionary principle the choice to not take action is itself a policy decision, and therefore this policy decision should be scrutinized as carefully as the decision to take action.

\subsection{Summary of Significant Findings Collected During this Study}

The following list summarizes the most significant findings from this study, including information gathered during the literature review and information gathered from the expert consultation:

- PhACs have been detected in water throughout the developed world, yet no consensus has been reached regarding the level of risk that PhACs pose to the environment (Doerr-MacEwen and Haight, 2006). 
- Effluent from wastewater treatment plants has been shown to contain PhACs and negatively affect freshwater wildlife (Gross-Sorokin et al., 2005; Fent et al., 2006; Kidd et al., 2007; Gillis et al., 2014).

- Regulations dictate the level of wastewater treatment required for a certain region; there is no universal worldwide standard technology used to treat wastewater before it is released into the environment, however, Ontario requires secondary wastewater treatment in municipal wastewater plants (Ontario Ministry of the Environment and Energy, 1994; Lou et al., 2014).

- It is difficult to combine studies and extrapolate results from literature; different studies may use different analytical methods to measure concentrations of contaminants (Kostich et al., 2014).

- Measuring the level of risk for something depends on the probability and severity of an adverse effect to something of value, which in this case is the environment; however, biological systems involve many different interactions, which make it challenging to prove causation and therefore difficult to determine the probability and severity of an adverse effect (Kriebel et al., 2001).

- Both British Columbia and Sweden have implemented policies that recognize certain PhACs pose a risk to the environment, particularly ethinylestradiol (Nagpal \& Meays, 2009, Stockholms Läns Landsting, 2014).

- British Columbia developed a Water Quality Guideline in 2009 for PhACs that must be considered by British Columbia's Ministry of the Environment when making any decision that could affect water quality. The guideline is as follows: "For the protection of freshwater aquatic life, it is recommended that the 30-day average concentration of 17 $\alpha$-ethinylestradiol (EE2) in water, based on 5 weekly samples, should not exceed 0.5 ng L-1 with no single value to exceed 0.75 ng L-1 (no more than $50 \%$ above the guideline value)." (Nagpal \& Meays, 2009, p.17). 
- All Ontario wastewater treatment plants currently employ secondary wastewater treatment (response to questionnaire from expert \# 13).

- UV disinfection is being favored over chlorine in wastewater treatment plants, which will lead to a greater release of PPCPs in the future (response to questionnaire from expert \# 4).

- Several of Ontario's wastewater treatment plants do not require nitrification because they discharge to the Great Lakes which have a high assimilative capacity for nitrogen. However, the nitrification process in wastewater treatment plants is one of the areas within a conventional wastewater treatment plan that naturally removes some PhACs (response to questionnaire from expert \# 13).

\subsection{Future Considerations for Researchers and/or Decision-Makers}

Ideally, governments in Ontario and across Canada would work together to collect more

information on this topic and look for opportunities to ensure the environment is not harmed by trace

PhACs. Ontario experts consulted for this study believe that more information is needed before significant changes can be considered for Ontario's wastewater treatment plants, which is the primary source of these contaminants into the environment. Therefore, the following discussion summarizes actions that can be taken at various levels of government and by future researchers.

At the municipal level, if municipal governments want to show action because of local community or government desires, municipalities should consider passing by-laws that restrict PhACs from improper disposal through garbage and wastewater streams. As well, education campaigns were identified by several experts as one way to ultimately reduce some of the PhACs that end up in municipal wastewater streams. Education campaigns have already been used by some Ontario municipalities, as well as abroad, and are considered worthwhile to pursue. Therefore, municipal water utilities may wish to educate their customers on proper disposal of PhACs (e.g., the "I Don't Flush" 
campaign, which is performed in partnership with York Region, Region of Peel, and support from the Health Products Stewardship Association).

At the provincial level, Ontario's Drinking Water Surveillance Program regularly monitors provincial water streams for a variety of contaminants and results are published regularly through the government's Open Data platform. One year, for a special government report, this program was used to measure the amount of certain PhACs from across Ontario's water streams. Expanding the program to always include PhACs would benefit scientists, researchers, and policy-makers, since this would allow experts in the field to have a common baseline of information from which to work. Of note, the data collected under this program are made available to the public on a regular basis through a government website. As an added benefit, this monitoring system could allow one to track the effects of UVdisinfection replacing chlorine disinfection on PhAC concentrations.

In addition, Ontario's MOECC should consider setting a guidance level for $17 \alpha$-ethinylestradiol (EE2), perhaps in its Provincial Water Quality Objectives. The British Columbian government developed a Water Quality Guideline in 2009 for PhACs that must be considered by British Columbia's Ministry of the Environment when making any decision that could affect water quality. The guideline currently sets an ideal limit for one PhAC, and is written as follows: "For the protection of freshwater aquatic life, it is recommended that the 30-day average concentration of $17 \alpha$-ethinylestradiol (EE2) in water, based on 5 weekly samples, should not exceed $0.5 \mathrm{ng}$ L-1 with no single value to exceed $0.75 \mathrm{ng} \mathrm{L-1}$ (no more than 50\% above the guideline value)." (Nagpal \& Meays, 2009, p.17).

One further option for Ontario to consider would be to collect site-specific data from municipal wastewater treatment plants that favor UV disinfection over chlorine and/or that discharge to the Great Lakes and do not have a nitrification process. These concerns were raised by experts \# 4 and 13 , respectively, during the expert consultations. Without collecting data from these specific wastewater treatment plants, it is impossible to know exactly how much of a concern either of these . In addition, 
based on these data, the government could then perform a cost-benefit analysis on requiring nitrification processes for wastewater treatment plants that discharge to the Great Lakes.

The federal government could also continue to assess compounds as part of CEPA to determine if any PhACs should be considered "CEPA Toxic".

Outside of government action, researchers can also consider their role in guiding the government and the public in environmental decision-making. Specifically, they should consider how to communicate their research findings with the general population. In this particular case, once the environmental concerns are better understood, the public may be more willing to carefully dispose of PhACs and to ask governments to take some form of action. It may also be worthwhile for scientists to study how to prioritize PhACs relative to other contaminants of concern. This prioritization message can help decision-makers determine if it is worthwhile to take actions that can reduce PhACs entering the environment. Otherwise, in the absence of a precise method to determine the level of risk that PhACs pose, it is difficult for decision-makers, the public, and experts to agree on future action to manage PhACs. 


\section{Appendix A: Recruitment Materials}

\section{Recruitment Letter 1}

Dear [Insert Name]

I am Emily Hanna, a graduate student enrolled in the Environmental Applied Science and Management program at Ryerson University. I am currently working on my master's thesis, which explores issues and risks related to the release of prescription medical products into the environment. I have an undergraduate degree in Chemical Engineering from Queen's University and am currently working as a Senior Policy and Decision Analyst for an environmental office in Toronto.

As you are an expert in this field, I would very much like to invite you to participate in this study by way of a questionnaire that should take about 30 minutes to complete. I will email you a copy of the questionnaire and you will be able to complete it at your home or office at a time that is convenient for you. An attached consent form provides more details about the study, questionnaire, and data management process.

If you would like to participate, or if you have any questions, please let me know and I will be in touch to send you the questionnaire or provide you with further clarification.

I look forward to hearing from you at your earliest convenience.

Thank you,

Emily

Emily.Hanna@ryerson.ca 


\section{Recruitment Letter 2}

For participants to use to recruit fellow participants

Hello,

I was recently contacted by Emily Hanna, a graduate student enrolled in the Environmental Applied Science and Management program at Ryerson University. She is currently working on her master's thesis, which explores issues and risks related to the release of prescription medical products into the environment. She has an undergraduate degree in Chemical Engineering from Queen's University and is currently working as a Senior Policy and Decision Analyst for an environmental office in Toronto.

She has requested that I pass along her study details and contact information, as she is seeking the opportunity to have experts participate in her study. An attached consent form provides more details about the study, questionnaire, confidentiality and data management process; the questionnaire takes roughly 30 minutes to complete.

If you would like to participate in Emily's study, or if you have any questions, please contact her directly at Emily.Hanna@ryerson.ca.

Thank you. 


\section{Telephone Script}

Emily: Hello, my name is Emily Hanna, and I'm a graduate student enrolled in the Environmental Applied Science and Management program at Ryerson University. I am currently working on my master's thesis, which explores issues and risks related to the release of prescription medical products into the environment.

- Study participant responds. I will then follow with an explanation of why I am calling

Emily: I'm calling you because you are an expert in this area, and I would appreciate if you could participate in my study by way of a questionnaire. It should take about 30 minutes to complete. I can email you a consent form, which provides more details about the study, questionnaire, and data management process. The consent form also includes contact details for my supervisor. I can send you this information now if you wish?

- Study participant ideally agrees to receive additional information. Alternatively, if the contact is unwilling to participate, I will thank them for their time and say goodbye.

Emily: Thanks so much for your time today. So, just to review everything: I will send you an email with my recruitment letter to participate in the study as well as the consent form, both of which will provide you with further information on my project. If you would like to participate, or if you have any questions, please let me know! My email is Emily.Hanna@ryerson.com. You can also contact my supervisor, Dr. Christopher Gore, if you have any questions. His contact details are contained in the consent form. Thanks again. I look forward to hearing back from you after you've had a chance to review these materials. 


\section{Survey Questions for Thesis}

1) Please provide your name.

2) What is your affiliation? (e.g., university, government, industry, etc.)

3) What is your field of speciality? (e.g., toxicology, engineering, chemistry)

4) Where is your job located? (e.g., Guelph)

5) What is your job title and role in your organization?

6) How long have you been in this position? 
7) Since the 1970 s, scientists have been able to detect trace levels of pharmaceutical compounds throughout the water cycle. Analytical tools have improved since then and many of these compounds are now detected in different aquatic ecosystems.

a) Are you familiar with this issue? YES or NO

b) In your professional opinion, do trace pharmaceuticals in the natural environment and water cycle pose a risk for aquatic ecosystems, human health, or other groups? Please indicate the level of risk beside the group identified below:

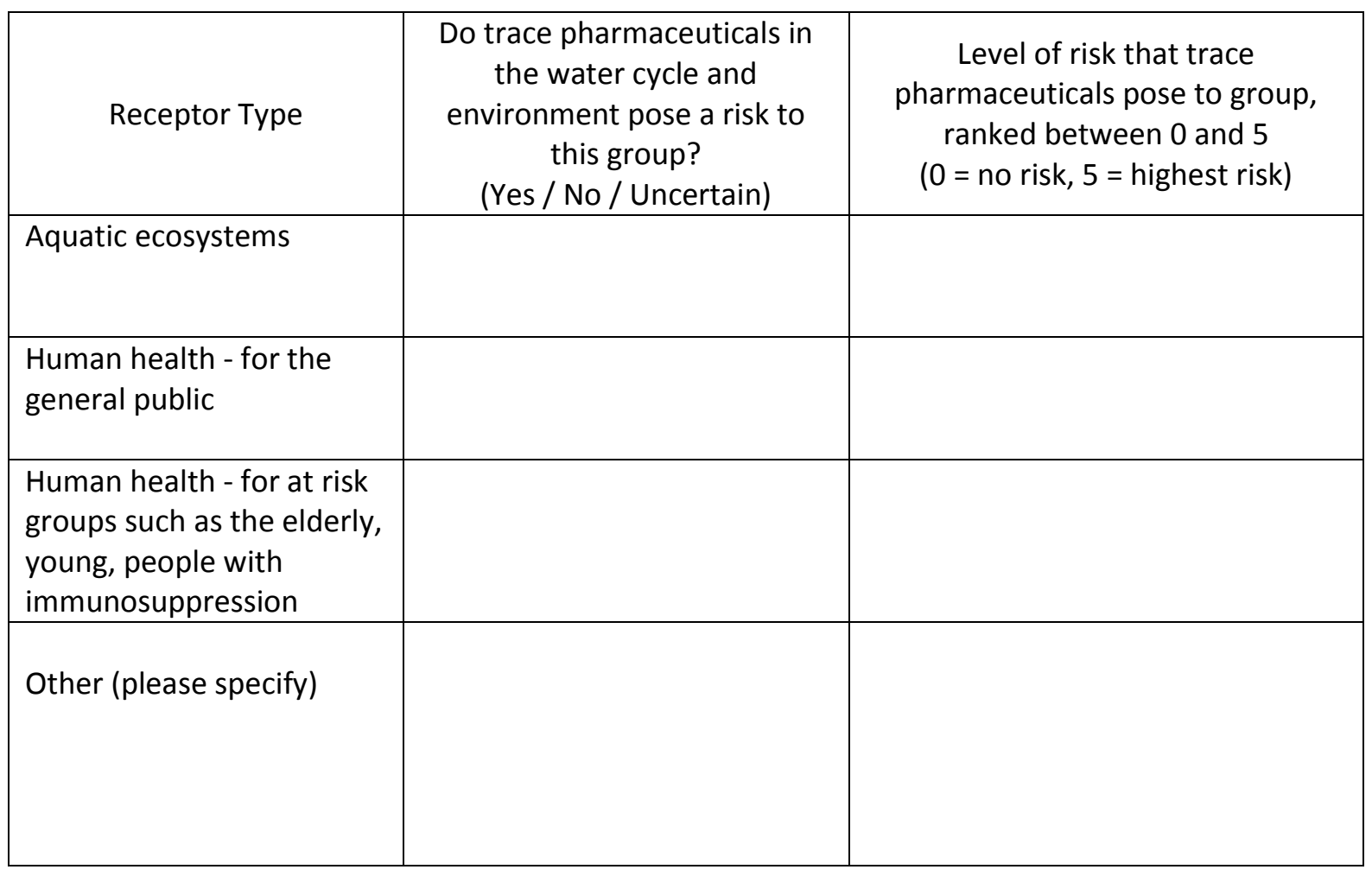


8) As per the 1992 Declaration of the Rio Conference on Environment and Development, the Precautionary Principle states that "where there are threats of serious or irreversible damage, lack of full scientific certainty shall not be used as a reason for postponing cost-effective measures to prevent environmental degradation." The Precautionary Principle is reaffirmed in the Canadian Environmental Protection Act, 1999. Do you think that the precautionary principle applies to pharmaceutical contaminants in the environment? Please explain.

9) Are you familiar with wastewater treatment processes in Ontario? YES or NO

a) Do you believe that Ontario's existing wastewater treatment plants adequately eliminate the majority of pharmaceutical products from wastewater, so that trace pharmaceutical products do not pose a serious or irreversible threat to the environment? Please elaborate.

- Yes - the majority of pharmaceuticals are eliminated in Ontario's existing wastewater treatment plants.

- Maybe

- Not sure

○ Unlikely

- No - the treatment is inadequate, the majority of pharmaceuticals are released into the environment in an unchanged state.

\section{Comment}

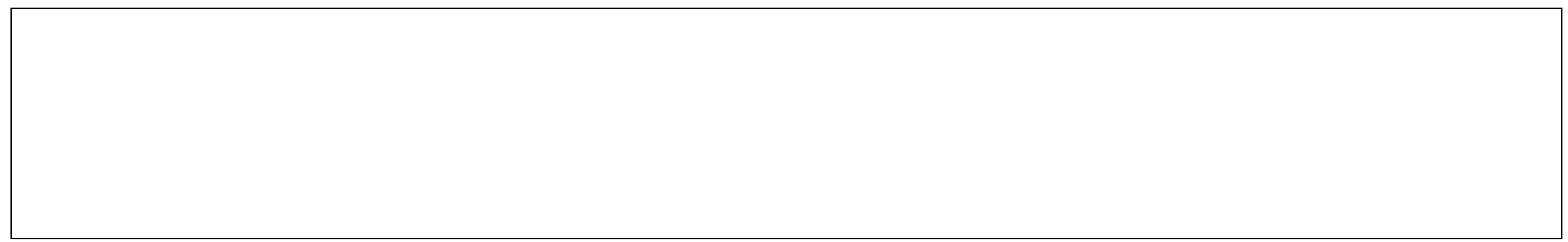

10) Are you aware of any current or proposed actions / programs / legislation, which apply in Ontario, that help manage the amount of pharmaceuticals being released into the environment? YES or NO

a) If YES, please populate the following table: 


\begin{tabular}{|l|l|l|l|}
\hline Action/Program/Legislation & \multicolumn{1}{|c|}{ Description } & $\begin{array}{c}\text { Do you think this is } \\
\text { effective? }\end{array}$ & \multicolumn{1}{|c|}{ Other Comments } \\
\hline $\begin{array}{l}\text { Example: } \\
\text { return program. }\end{array}$ & $\begin{array}{l}\text { In 2012, O. Reg. 298/12 was } \\
\text { passed. It requires a } \\
\text { pharmaceutical collection } \\
\text { system, operated by } \\
\text { producers, to run in Ontario. }\end{array}$ & Yes/No, because... & $\begin{array}{l}\text { Additional comments can be } \\
\text { made here. }\end{array}$ \\
\hline & & & \\
\hline & & & \\
\hline
\end{tabular}

b) Do you think that further actions / programs / legislation are needed in Ontario? Please explain. 
11) Are you aware of any actions / programs / legislation, used outside of Ontario, to reduce the amount of pharmaceuticals being released into the environment? YES or NO

If so, please populate the following table:

\begin{tabular}{|l|l|l|l|}
\hline \multicolumn{1}{|c|}{ Action/Program } & \multicolumn{1}{|c|}{ Description } & Location Used & $\begin{array}{c}\text { Do you think Ontario should } \\
\text { consider doing this? }\end{array}$ \\
\hline Example: & $\begin{array}{l}\text { Educate medical } \\
\text { professionals on the } \\
\text { environmental impacts of } \\
\text { pharmaceutical products. It } \\
\text { practitioners; } \\
\text { allows forcal substitution of } \\
\text { County Council's } \\
\text { Environmentally Classified } \\
\text { Pharmaceuticals } \\
\text { friendly drugs. }\end{array}$ & Sweden & Yes/No, because... \\
\hline & & & \\
\hline & & & \\
\hline & & & \\
\hline
\end{tabular}


12) Human pharmaceuticals enter our waterways through a variety of different routes, including municipal wastewater treatment plants. Concentrations for pharmaceuticals in the environment could be lowered by improving removal rates within these facilities.

a) Are you aware of any specific barriers to improve removal rates of pharmaceuticals within municipal wastewater treatment plants? YES or NO. Please explain.

b) Are you aware of any specific opportunities to improve removal rates of pharmaceuticals within municipal wastewater treatment plants? YES or NO. Please explain.

c) Do you think municipalities could do more to reduce the amount of pharmaceuticals that enter wastewater treatment plants? YES or NO. Please explain.

d) Do you think hospitals, retirement homes, and other institutions where pharmaceuticals are administered could do more to reduce the amount of pharmaceuticals that enter municipal wastewater treatment plants? YES or NO. And do you think reducing input from these sources would help overall loading of municipal wastewater treatment plants? YES or NO. Please explain.

e) Do you think that there is an information gap about this issue? YES or NO. Please explain. (e.g., Ontario needs to develop a coordinated water sampling and testing program, to develop a robust database of trace pharmaceutical products.)

f) Do you think the pharmaceutical industry should assist municipal wastewater treatment plants with removing or managing wastewater that is contaminated with trace pharmaceutical products? YES or NO. Please explain.

13) Please indicate any known technologies or processes that can remove/reduce pharmaceutical compounds from wastewater streams. 
a) Please indicate how important you think it is for the provincial government to take additional action to reduce the release of pharmaceuticals into the environment. Please elaborate.

○ very important

○ moderately important

○ neither important/unimportant

○ moderately unimportant

○ very unimportant

Comment:

b) Please indicate how important you think it is for the federal government to take additional action to reduce the release of pharmaceuticals into the environment. Please elaborate.

○ very important

○ moderately important

○ neither important/unimportant

○ moderately unimportant

o very unimportant 


\section{Comment:}

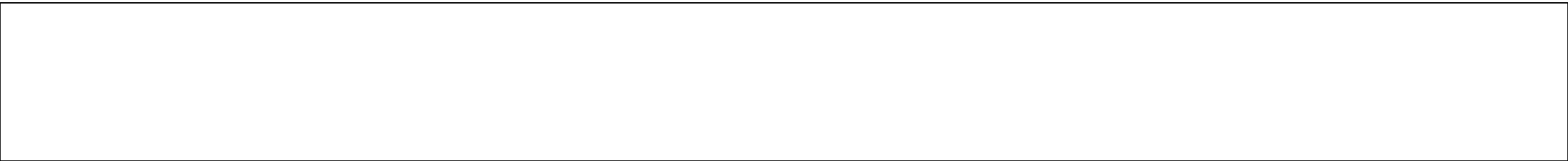

c) Please indicate how important you think it is for local municipal governments to take additional action to reduce the release of pharmaceuticals into the environment. Please elaborate.

○ very important

○ moderately important

○ neither important/unimportant

- moderately unimportant

o very unimportant

Comment:

15) Please provide any additional comments that you would like to make about pharmaceuticals in the environment. 


\section{Interview Guide for Follow-up Discussions}

1) Your response to question \# was interesting. Can you please explain more about this to me?

Further follow-up questions are listed below. Some may not be relevant:

a. Why do you think this is a significant issue?

b. Why do you feel this is a top concern?

c. Is there a certain specific problem that is causing this issue (e.g., insufficient funding, immature technology)

d. Are you aware of any studies that have been done on this topic?

e. Do you know if other jurisdictions have this concern?

f. Do you think there are any barriers, either at the provincial, federal, or municipal level, which could be removed to address your concern?

g. Are there any other associated concerns with this problem?

h. In an ideal world, what would be your solution?

i. What future work do you think should be done in this field/area?

2) I designed my questionnaire to be comprehensive; however, this is a big topic. Did you think that my questionnaire was thorough? Or, was there a gap in my questionnaire? Please explain. 


\section{References}

Acero, J.L, Benitez, F.J., Real F.J., Roldan G. 2010. Kinetics of aqueous chlorination of some pharmaceuticals and their eliminiation from water matrices. Water Research. 44 (14), pp. 4158 4170.

Arnold, K.E., Boxall, A.B.A., Brown, A.R., Cuthbert, R.J., Gaw, S., Hutchinson, T.H., Jobling, S., Madden, J.C., Metcalfe, C.D., Naidoo, V., Shore, R. F., Smits, J.E., Taggart, M.A., Thompson, H.M. (2013). Assessing the exposure risk and impacts of pharmaceuticals in the environment on individuals and ecosystems. Biology Letters 9, pp. 1-4

Atkinson, S.K., Marlatt, V.L., Kimpe, L.E., Lean, D. R. S., Trudeau, V. L., Blais, J. M. 2012. The occurrence of steroidal estrogens in south-eastern Ontario wastewater treatment plants. Science of the Total Environment 430, pp. 119-125.

Al-Ansari, Ahmed. 2012. Bioaccumulation of 17a-Ethinyl estradiol in Fish. PhD Thesis, University of Ottawa, Ottawa.

Baronti, C., Curini, R., D'Ascenzo, G., Di Corcia, A., Gentili, A., Samperi, R. (2000). Monitoring natural and syntheti estrogens at activated sludge sewage treatment plants and in receiving river water. Environmental Science and Technology. 34 (4), pp. 5059-5066.

Batt, A.L., Kostich, M.S., Lazorchak, J.M. (2008). Analysis of Ecologically Relevant Pharmaceuticals in Wastewater and Surface Water Using Selective Solid-Phase Extraction and UPLC-MS/MS.

Analytical Chemistry 80, pp. 5021-5030.

Becker, J. (2010) Minding the gap: research priorities to address pharmaceuticals in the environment. Environmental and Occupational Health Sciences, University of Illinois at Chicago School of Public Health. Accessed from:

http://www.sustainabilityroadmap.org/pims/pdfs/pim243_Minding_the_Gap.pdf

Bedner, M., MacCrehan, W.A. 2006. Transformation of acetaminophen by chlorination produces the toxicants 1,4-benzoquinone and N-acetyl-p-benzoquinone imine. Environmental Science and Technology 40 (2) pp. 516-522.

Bellona, C., Drewes, J.E., Oekler, G., Luna, J., Filteau, G., Amy, G. (2008). Comparing nanofiltration and reverse osmosis for drinking water augmentation. American Water Works Association. 100 (9), pp. $102-116$.

Benotti, M. J., Trenholm, R. A., Vanderford, B. J., Holady, J. C., Stanford, B. D., Snyder, S. A. (2009). Pharmaceutical and Endocrine Disrupting Compounds in U.S. Drinking Water. Environmental Science \& Technology, 43, pp. 597-603.

Byrd, D. M., Cothern, C. R. (2000). Introduction to Risk Analysis. Rockville, Maryland: Government Institutes. 
Cahill J. D., Furlong, E. T., Burkhard, M. R., Kolpin, D., Anderson, L. G. (2004). Determination of pharmaceutical compounds in surface-and ground-water samples by solid phase extraction and high performance liquid chromatography-electrospray ionization mass spectrometry. Journal of Chromatography. 1041, pp. 171-180.

Calisto, V., Esteves, C.I. (2012) Adsorption of the antiepileptic carbamazepine onto agricultural soils. Journal of Environmental Monitoring 14, pp. 1597-1603.

Callreus, T. (2005) The precautionary principle and pharmaceutical risk management. Drug Safety. 28 (6), pp. 465-471.

Canadian Council of Ministers of the Environment (CCME). Municipal Wastewater Effluent Development Committee. Municipal Wastewater Effluent in Canada. Retrieved September 20, 2015:

http://www.ccme.ca/files/Resources/municipal_wastewater_efflent/mwwe_general_background er_e.pdf

Canadian Standards Association. (1997). CAN/CSA-Q850-97 (reaffirmed 2002), Risk management: a guideline for decision-makers, A National Standard of Canada. Etobicoke, Ontario.

Carballa, M., Omil, F., Lema, J.M. (2007). Calculation Methods to Perform Mass Balances of Micropollutants in Sewage Treatment Plants. Application to Pharmaceutical and Personal Care Products (PPCPs). Environmental Science and Technology. 41, pp. 884-890.

Carlson, J.C., Stefan, M.I., Parnis, J.M., Metcalfe, C.D. 2015. Direct UV photolysis of selected pharmaceuticals, personal care products and endocrine disruptors in aqueous solution. Water Research. 84 (1), pp. 350-361.

Clara, M., Kreuzinger, N, Strenn, B., Gans, O., Kroiss, H. (2005). The solids retention time - a suitable design parameter to evaluate the capacity of wastewater treatment plants to remove micropollutants. Water Research 39 (1), pp. 97-106.

CH2M Hill (2011). Final Report: Literature Review and Jurisdictional Practices of Technologies to Reduce Non-Conventional Contaminants at Municipal Sewage Treatment Plants. Prepared for the Ontario Ministry of the Environment. PIBS 9715e.

Corcoran, J., Winter, M.J., Lange, A., Cumming, R., Owen, S.F., Tyler, C.R. (2015). Effects of the lipid regulating drug clofibric acid on PPAR $\alpha$-regulated gene transcript levels in common carp (Cyprinus carpio) at pharmacological and environmental exposure levels. Aquatic Toxicology, 161, pp. 127137.

Collier, R. (2012). Swallowing the pharmaceutical waters. Canadian Medical Association Journal, 184 (2), pp. 163-164.

Daughton, C. G., Ternes, T. A. (1999). Pharmaceuticals and Personal Care Products in the Environment: Agents of Subtle Change? Environmental Health Perspectives, 107 (6), 907-938 
Doerr-MacEwen, N. 2007. The Management of Human Pharmaceuticals in the Environment. PhD Thesis, University of Waterloo, Waterloo.

Doerr-MacEwen, N.A., Haight, M. (2006) Expert Stakeholders' Views in the Management of Human Pharmaceuticals in the Environment. Environmental Management 38, pp. 853-866.

Eckel, W., Ross, B., Isensee, R. K. (1993). Pentobarbital Found in Ground Water. Ground Water, 31 (5), pp. 801-804.

Environment and Climate Change Canada (2016). Chlorinated wastewater effluents. Retrieved January 24, 2016 from: https://www.ec.gc.ca/toxiques-toxics/Default.asp?lang=En\&n=98E80cC6$0 \& x m l=9554670 A-95 C 2-481 D-8 F 85-864134780734$

Environment and Climate Change Canada (2016). Chemicals Management Plan Progress Report Issue 5, Fall 2015. Retrieved February 13, 2016 from: http://www.ec.gc.ca/eseees/default.asp?lang=En\&n=B6D66F41-1

Environment Canada, June 24, 2013 (2013). ARCHIVED - Environmental Assessment Regulations. Retrieved on July 20, 2015 from: http://www.hc-sc.gc.ca/ewhsemt/contaminants/person/impact/reg/index-eng.php

Environment Canada, June 24, 2013 (2013b). ARCHIVED - More Information about the Environmental Assessment Regulations. Retrieved on July 20, 2015 from: http://www.hc-sc.gc.ca/ewhsemt/contaminants/person/impact/reg/faq-eng.php

Environment Canada, 2013 (2013c). Archived - Wastewater Management. Retrieved September 27, 2015: https://www.ec.gc.ca/eu-ww/default.asp?lang=En\&n=0FB32EFD-1.

Environmental Commissioner of Ontario, 2003/2004 Annual Report: Choosing Our Legacy (Toronto, ON: Queen's Printer for Ontario; 2004). Available from: http://eco.on.ca/wpcontent/uploads/2015/03/2003-04-AR.pdf

Environmental Commissioner of Ontario, 2012/2013 Annual Report: Serving the Public (Toronto, ON: Queen's Printer for Ontario; 2013). Available from: http://eco.on.ca/wpcontent/uploads/2015/03/2012-13-AR.pdf

Esplugas, S., Bila, D. M., Krause, L.G.T., Dezotti, M. 2007. Ozonation and advanced oxidation technologies to remove endocrine disrupting chemicals (EDCs) and pharmaceuticals and personal care products (PPCPS) in water effluents. Journal of Hazardous Materials. 149 (3), pp. 631-342.

Estrada-Arriaga, E.B., Mijaylova, P.N. (2011). Influence of operational parameters (sludge retention time and hydraulic residence time) on the removal of estrogens by membrane bioreactor. Environmental Science and Pollution Research 18 (7), pp. 1121-1128.

Fent, K., Weston, A.A., Caminada, D. (2006). Review: Ecotoxicology of human pharmaceuticals. Aquatic Toxicology 76, pp. 122-159. 
Fram, M., Belitz, K. (2011) Occurrence and concentrations of pharmaceutical compounds in groundwater used for public drinking-water supply in California. Science of the Total Environment 409, pp. 3409 $-3417$.

Gauthier, H., Yargeau, V., Cooper, D., Biodegradation of pharmaceuticals by Rhodococcus rhodochorous and Aspergillus niger by co-metabolism. Science of the Total Environment, 2010.408 (7), pp. 1701-1706.

Gillis, P. L., Gagne, F., McInnis, R., Hooey, T. M., Choy, E. S., Andre, C., Hoque, M. E., Metcalfe, C. D. (2014). The impact of municipal wastewater effluent on field-deployed freshwater mussels in the Grand River (Ontario, Canada). Environmental Toxicology and Chemistry 33 (1), pp. 137-143.

Green, R.WE., Taggart, M.A., Senacha, K.R., Raghavan, B., Pain, D.J., Jhala, Y. Cuthbert, R. (2007). Rate of decline of the oriental white-backed vulture population in India estimated from a survey of diclofenac residues in carcasses of Ungulates. PLoS ONE 2(8), e686. doi:10.1371/journal.pone. 0000686

Gross-Sorokin, M. Y., Roast, S. D., Brighty, G. C. (2006). Assessment of Feminization of Male Fish in English Rivers by the Environment Agency of England and Wales. Environment Health Perspectives 114 (1), pp. 147 - 151.

Heberer, T. (2014). An Insight into the Discovery of the Contamination of the Environment and Drinking Water by Pharmaceuticals. In W.E. Goldstein (Ed.) Pharmaceutical Accumulation in the Environment: Prevention, Control, Health Effects, and Economic Impact. Boca Raton, Florida: CRC Press Taylor \& Francis Group

Herberer, T. 2002 Occurrence, fate, and removal of pharmaceutical residues in the aquatic environment: a review of recent research data. Toxicology Letters 131 (1/2), 5-17.

Holm, J. V., Rugge, K., Bjerg, P., Christensen, T. H. (1995). Occurrence and Distribution of Pharmaceutical Organic Compounds in the Groundwater Downgradient of a Landfill (Grindsted, Denmark). Environmental Science \& Technology, 25(5), pp. 1415-1420.

Holt, L.M., Laurson, A.E., McCarthy, L.D., Bostan, I.V., Spongberg, A.L. (2010). Effects of land application of municipal biosolids on nitrogen-fixing bacteria in agricultural soil. Biology and Fertility of Soils 46 (4), pp. 407-413.

Ignasiak, M., Duncanson, S. MacMillan, S. 2014. Draft regulations released for deposits of deleterious substances under the Fisheries Act. Osler Resources for Canadian Legislation and Regulation. Retrieved August 15, 2015 from: https://www.osler.com/en/resources/regulations/2014/draftregulations-released-for-deposits-of-deleter

Ignasiak, M., Duncanson, S., 2014. Draft Regulations Released for Deposits of Deleterious Substances under the Fisheries Act. Osler law firm. 
https://www.osler.com/en/resources/regulations/2014/draft-regulations-released-for-depositsof-deleter, February 20, 2014.

Jones, O.A.H., Voulvoulis N., Lester J.N., Human Pharmaceuticals in Wastewater Treatment Processes. Critical Reviews in Environmental Science and Technology, 2005. 35 (4) p. 401-427.

Khan, W., Nicell, J. (2015). Human health relevance of pharmaceutically active compounds in drinking water. The American Association of Pharmaceutical Scientists Journal 17 (3), pp. 558-585.

Kidd K. A., Blanchfield, P. J., Mills, K. H., Palace, V. P., Evans, R. E., Lazorchak, J. M., Flick, R. R. (2007). Collapse of a fish population after exposure to a synthetic estrogen. Proceedings of the National Academy of Sciences, 104 (21), pp. 8897-8901.

Kim, S., Aga, D.S., Potential Ecological and Human Health Impacts of Antibiotics and Antibiotic-Resistant Bacteria from Wastewater Treatment Plants. Journal of Toxicology and Environmental Health, Part B, 2007. 10(8), pp. 559-573.

Kim, S., Eichhorn, P., Jensen, J.N., Weber, A. S., Aga, D.S. 2005. Removal of antibiotics in wastewater: effect of hydraulic and solid retention times on the face of tetracycline in the activated sludge process. Environmental Science and Technology, 39, pp. 5816-5823.

Kingsmore, L. 2013. The management of post-consumer pharmaceutical waste: a comparison between British Columbia and Ontario programs. MASc Thesis, Ryerson University, Toronto.

Kostich, M.S., Batt, A.L., Lazorchak , J.M. (2014). Concentrations of prioritized pharmaceuticals in effluents from 50 large wastewater treatment plants in the US and implications for risk estimation. Environmental Pollution 184, pp. 354-359.

Kleywegt, S., Smyth, S-A., Parrott, J., Schaefer, K., Lagacé, E., Payne, M., Topp, E., Beck, A., McLaughlin, A. and K. Ostapyk (eds). 2007. Pharmaceuticals and Personal Care Products in the Canadian Environment: Research and Policy Directions. NWRI Scientific Assessment Report Series No.8. 53

Kriebel, D., Tickner, J., Epstein, P., Lemons, J., Levins, R., Loechler, E.L., Quinn, M., Rudel, R., Schettler, R., Stoto, M. (2001). The precautionary principle in environmental science. Environmental Health Perspectives. 109 (9), pp. 871- 876.

Kummerer, K., Drugs in the environment: emission of drugs, diagnostic aids, and disinfectants into wastewater by hospitals in relation to other sources - a review. Chemosphere, 2001. 45, pp. 957969.

Lou, Y., Guo, W., Ngo, H.H., Nghiem, L.D., Hai, F.L, Zhang, J., Liang, S., Wang, X.C. (2014). A review on the occurrence of micropollutants in the aquatic environment and their fate and removal during wastewater treatment. Science of The Total Environment. 434-474 (1), pp. 619-641. 
Luo, Y., Guo, W., Ngo, H.H., Nghiem, L.D., Hai, F. I., Zhang, J., Liang, S., Wang, X.C. (2014). A review on the occurrence of micropollutants in the aquatic environment and their fate and removal during wastewater treatment. Science of The Total Environment, 473-474, pp. 619-641.

Mahmoudi, H., Renn, O., Vanclay, F., Hoffmann, V., Karami, E. (2013). A framework for combining social impact assessment and risk assessment. Environmental Impact Assessment Review. 43, pp. 1-8.

Margot, J., Kienle, C., Magnet, A., Weil, M., Rossi, L., Felippe de Alencastro, L., Abegglen, C., Thonney, D., Chevre, N., Sharer, M., Barry, D.A. (2013). Treatment of micropollutants in municipal wastewater: Ozone or powdered activated carbon? Science of the Total Environment. 461-462,pp. 480-498.

Martin-Diaz, L., Franzellitti, S., Buratti, S., Valbonesi, P., Capuzzo, A., Fabbri, E. (2009). Effects of environmental concentrations of the antiepileptic drug carbamazepine on biomarkers and CAMPmediated cell signaling in the mussels Mytilus galloprovincialis. Aquatic Toxicology 94, pp. 177-185

Maszkowski, J., Stolte, S., Kumirska, J., Lukaszewicz, P., Mioduszewska, K., Puckowski, A., Caban, M., Wagil, M., Stepnowski, P., Bialk-Bielinska, A. (2014a). Beta-blockers in the environment: Part 1. Mobility and hydrolysis study. Science of the Total Environment. 493, pp. 1112-1121.

Maszkowski, J., Stolte, S., Kumirska, J., Lukaszewicz, P., Mioduszewska, K., Puckowski, A., Caban, M., Wagil, M., Stepnowski, P., Bialk-Bielinska, A. (2014b). Beta-blockers in the environment: Part 2. Ecotoxicity study. Science of the Total Environment. 493, pp. 1122-1126.

Metcalfe, C.D., Miao, X., Koenig, B.G., Struger, J. (2003). Distribution of acidic and neutral drugs in surface waters near sewage treatment plants in the lower great lakes, Canada. Environmental Toxicology and Chemistry, 22 (12), pp. 2881-2889.

Mohajerani, M., Mehrvar, M., Ein-Mozaffari, F (2009). An Overview of the Integration of Advanced Oxidation Technologies and Other Processes for Water and Wastewater Treatment. International Journal of Engineering, 2 (3), pp. 120-147.

Mrozik, W., Stefanska, J. (2014). Adsorption and biodegradation of antidiabetic pharmaceuticals in soils. Chemosphere, 95, pp.281-288.

Nagpal, N, Meays, C. (2009). Water Quality Guidelines for Pharmaceutically-active-Compounds (PhACs): $17 \alpha$-ethinylestradiol (EE2) - Technical Appendix. Ministry of the Environment, Province of British Columbia, Science and Information Branch, Water Stewardship Division. http://www.env.gov.bc.ca/wat/wq/BCguidelines/PhACs-EE2/PhACs-EE2-tech.pdf

O'Connor, D.R. 2002, Report of the Walkerton Inquiry: Part 2 - A Strategy for Safe Drinking Waters. The Walkerton Inquiry, Toronto.

Ontario Ministry of the Environment, 1998. Policy Proposal Notice: Proposed 1998 model sewer use bylaw. EBR Registry Number: PA8E0029, Retrieved September 1, 2015: 
http://www.ebr.gov.on.ca/ERS-WEB-

External/displaynoticecontent.do?noticeld $=0 D g 4 M Q==\&$ statusld $=O D g 4 M Q==\&$ language $=e n$

Ontario Ministry of the Environment, 2008. Design Guidelines for Sewage Works. ISBN 978-1-4249-8438-

1. Retrieved August 23, 2015: http://www.urecon.com/learning/pdfs/Sewage_Works.pdf

Ontario Ministry of the Environment, 2010. Survey of the occurrence of pharmaceuticals and other emerging contaminants in untreated source and finished drinking water in Ontario. Retrieved September 1, 2015 from: http://www.ontario.ca/document/full-survey-survey-occurrencepharmaceuticals-and-other-emerging-contaminants-untreated-source-and

Ontario Ministry of the Environment and Climate Change, 2015. Drinking Water Surveillance Program. Ontario Government's Open Data website. Retrieved September 1, 2015: https://www.ontario.ca/data/drinking-water-surveillance-program

Ontario Ministry of the Environment and Energy, 1994. Program Development Branch. Levels of Treatment for Municipal and Private Sewage Treatment Works Discharging to Surface Waters. Retrieved September 1, 2015: http://booksnow1.scholarsportal.info/ebooks/oca10/7/std01079342.ome/std01079342.pdf

Ontario Ministry of the Environment and Energy, 1994. Program Development Branch. Guideline F-5: Levels of Treatment for Municipal and Private Sewage Treatment Words Discharging to Surface Waters. Retrieved September 24, 2015: https://archive.org/stream/std01079342.ome/std01079342\#page/n0/mode/2up

Pauwels, B., Verstraete W., The treatment of hospital wastewater: an appraisal, Journal of Water Health, 2006. 4(4), pp. 405-416

Pate-Cornell, M.S. (1996). Uncertainties in risk analysis: Six levels of treatment. Reliability Engineering and System Safety 54, pp. 95-111.

Pérez, S., Eichhorn, P., and Aga, D. S. (2005). Evaluating the biodegradability of sulfamethazine, sulfamethoxazole, sulfathiazole, and trimethoprim at different stages of sewage treatment. Environmental Toxicology and Chemistry. 24, pp. 1361-1367.

Plumlee, M.H., Stanford, B.D., Debroux, J., Hopkinds, D.C., Snyder, S.A. 2014. Costs of Advanced Treatment in Water Reclamation. Ozone: Science \& Engineering, 36, pp. 485-495.

Postigo, C., Richardon, S. (2014). Transformation of pharmaceuticals during oxidation/disinfection processes in drinking water treatment. Journal of Hazardous Materials, 279, pp. 461-475

The Presidential/Congressional Commission on Risk Assessment and Risk Management. (1997). Framework for environmental health risk management: final report, volume 1. Retrieved September 15, 2015: http://oaspub.epa.gov/eims/eimscomm.getfile?p_download_id=36372 
Riaz ul Haq, M., Metcalfe, C., Li, H., Parker, W. (2012) Discharge of pharmaceuticals into municipal sewers from hospitals and long-term care facilities. Water Quality Research Journal of Canada. 47 (2), pp. 141-152.

Richardson, M.L., Bowron, J.M. (1985). The face of pharmaceutical chemicals in the aquatic environment. The Journal of Pharmacy and Pharmacology, 37, pp. 1-12.

Routledge, E.J, Sheahan, E., Desbrow C., Brighty, G.C., Waldock, M., Sumpter, J.P. (1998). Identification of Estrogenic Chemicals in STW Effluent. 2. In Vivo Responses in Trout and Roach. Environmental Science and Technology, 32, pp. 1559-1565.

Sabourin, L., Duenk, P., Bonte-Gelok, S., Payne, M., Lapen, D.R., Topp, E. (2012). Uptake of pharmaceuticals, hormones, and parabens into vegetables grown in soil fertilized with municipal biosolids. Science of The Total Environment 431, pp. 233-236

Smith, D., Fischbacher, M. (2009). The changing nature of risk and risk management: The challenge of borders uncertainty and resilience. Risk Management. 11 (1), pp. 1-12.

Snyder, S., Lue-Hing, C., Cotruvo, J., Drewes, J.E., Eaton, A., Pleus, R.C., Schlenk, D. (2010). Pharmaceuticals in the Water Environment, National Association of Clean Water Agencies (NACWA) Report.

Snyder, S.A., Adham, S., Redding, A.M., Cannon, F.S., DeCarolis, J., Oppenheimer, J., Wert, E.C. Yoon, Y. 2007. Role of membranes and activated carbon in the removal of endocrine disruptors and pharmaceuticals. Desalination. 202 (1-3), pp. 156-181.

Spellman, F. (2014). Personal Care Products and Pharmaceuticals in Wastewater and the Environment. DEStech Publications, 2014, Lancaster, Pennsylvania.

Stockholms Läns Landsting. (2014.) Environmentally Classified Pharmaceuticals [Brochure]. Stockholm: N.P. https://noharm-europe.org/sites/default/files/documentsfiles/2633/Environmental\%20classified\%20pharmaceuticals\%202014-2015\%20booklet.pdf

Suarez, S., Carballa, M., Omil, F., Lema, J.M. (2008). How are pharmaceutical and personal care products (PPCPS) removed from urban wastewaters? Reviews in Environmental Science and Bio/Technology. 7, pp. 125-138.

Sumpter, J.P. (2009). Protecting aquatic organisms from chemicals: the harsh realities. Philosophical Transactions of the Royal Society. 367, pp. 3877-3894.

Tauxe-Wuersch, A., De Alencastro, L.F., Grandjean, D., Tarradellas, J., 2005. Occurrence of several acidic drugs in sewage treatment plants in Switzerland and risk assessment. Water Research 39, pp. 1761-1772

Ternes, T. A. (1998). Occurrence of drugs in German sewage treatment plants and rivers. Water Research. 32 (11), pp. 3245-3260. 
Ternes, T.A., Joss A., Siegrist H. (2004). Scrutinizing pharmaceuticals and personal care products in wastewater treatment. Environmental Science and Technology 38, pp. 393-398.

Ternes, T.A., Stumpf, M., Mueller, J., Kaberer, K., Wilken, R.D., Servos, M. (1999). Behavior and occurrence of estrogens in municipal sewage treatment plants - 1. Investigations in Germany, Canada and Brazil. Science of the Total -Environment. 225 (1-2), p. 81-90.

Tickner, J.A., Geiser, K. (2004). The precautionary principle stimulus for solutions - and alternatives-based environmental policy. Environmental Impact Assessment Review 24, pp. 801-824.

Topp, E., Monteiro, S., Beck, A., Coelho, B.B., Boxall, A. B.A., Duenk, P.W., Kleywegt, S., Lapen, D. R., Payne, M., Sabourin, L., Li, H., Metcalfe, C.D. (2008). Runoff of pharmaceuticals and personal care products following application of biosolids to an agricultural field. Science of The Environment. 396 (1), pp. 52-59.

Underwood, J.C., Harvey, R.W., Metge, D.W., Repert, D.A., Baumgartner, L.K., Smith, R.L., Roane, T.M., and Barber, L.B. (2011) Effects of the antimicrobial sulfamethoxazole on groundwater bacterial enrichment. Environmental Science and Technology, 45 (7), pp. 3096-3101.

United Nations General Assembly. (1992). Report of the United Nations Conference on Environment and Development (No. A/CONF.151/26 Vol. I). Rio de Janeiro.

U.S. Environmental Protection Agency (U.S. EPA), Primer for Municipal Wastewater Treatment Systems, (EPA Publication No. 832-R-04-001). 2004.

U.S. Food and Drug Administration, 2015 (US FDA, 2015). Medicines recommended for disposal by flushing listed by medicine and active ingredient. Available from:

http://www.fda.gov/downloads/Drugs/ResourcesForYou/Consumers/BuyingUsingMedicineSafely /EnsuringSafeUseofMedicine/SafeDisposalofMedicines/UCM337803.pdf

Verlicchi, P., Aukidy, M. A., Jelic, A., Petrovic, M., Barcelo, D. (2014). Comparison of measured and predicted concentrations of selected pharmaceuticals in wastewater and surface water: A case study of catchment area in the Po Valley (Italy). Science of The Total Environment. 470-471, pp. 544-584

Water Protection \& Sustainability Branch (2015). British Columbia Approved Water Quality Guidelines: Aquatic Life, Wildlife\& Agriculture - Summary Report. Ministry of the Environment. http://www2.gov.bc.ca/assets/gov/environment/air-landwater/water/waterquality/waterqualityguidesobjs/approved-wat-qualguides/approved_wqg_summary_dec_17_2015.pdf

Westman, W. E. (1972). Some Basic Issues in Water Pollution Control Legislation: Contrasts between technologial and ecologial perspectives on the regulation of effluents underlie current debates in water pollution legislation. American Scientist, 60 (6), pp. 767-773. 
World Health Organization (WHO), Pharmaceuticals in Drinking-Water. France. 2012 WHO/HSE/WSH/11.05.

Zwiener, C. (2007). Occurrence and analysis of pharmaceuticals and their transformation products in drinking water treatment. Analytical and Bioanalytical Chemistry. 387 (4), pp. 1159-1162. 